\title{
FREDRIK HALLMER
}

MEDICATION-RELATED

OSTEONECROSIS OF THE JAW

Occurence, Risk Factors, Pathogenesis \& Treatment
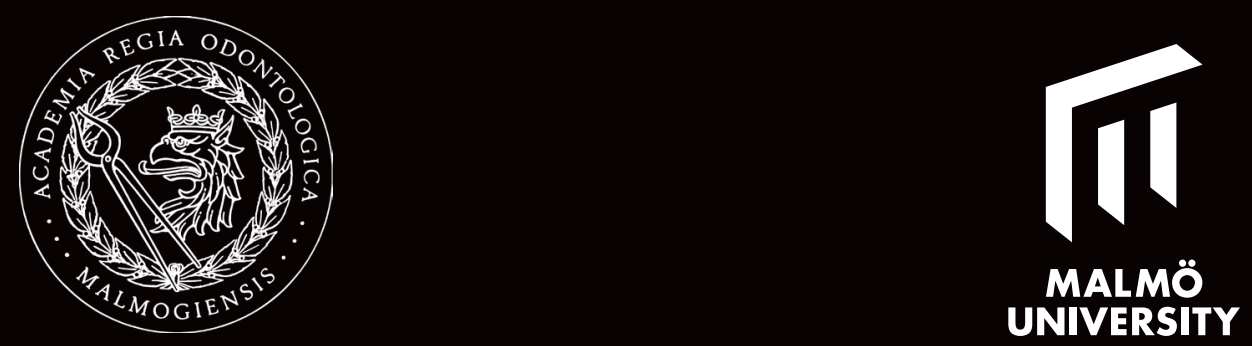

MEDICATION-RELATED OSTEONECROSIS OF THE JAW 
ISBN 978-91-7104-983-4 (print)

ISSN 978-91-7104-984-1 (pdf)

Holmbergs, Malmö 2019 


\section{FREDRIK HALLMER}

\section{MEDICATION-RELATED OSTEONECROSIS OF THE JAW}

Occurence, Risk Factors, Pathogenesis \& Treatment

Department of Oral and Maxillofacial Surgery and Department of Oral Diagnostics Faculty of Odontology Malmö University, 2019 
Publikationen finns även elektroniskt, se muep.mau.se 
To Catrin and Hedvig, to my mother and father 



\section{TABLE OF CONTENTS}

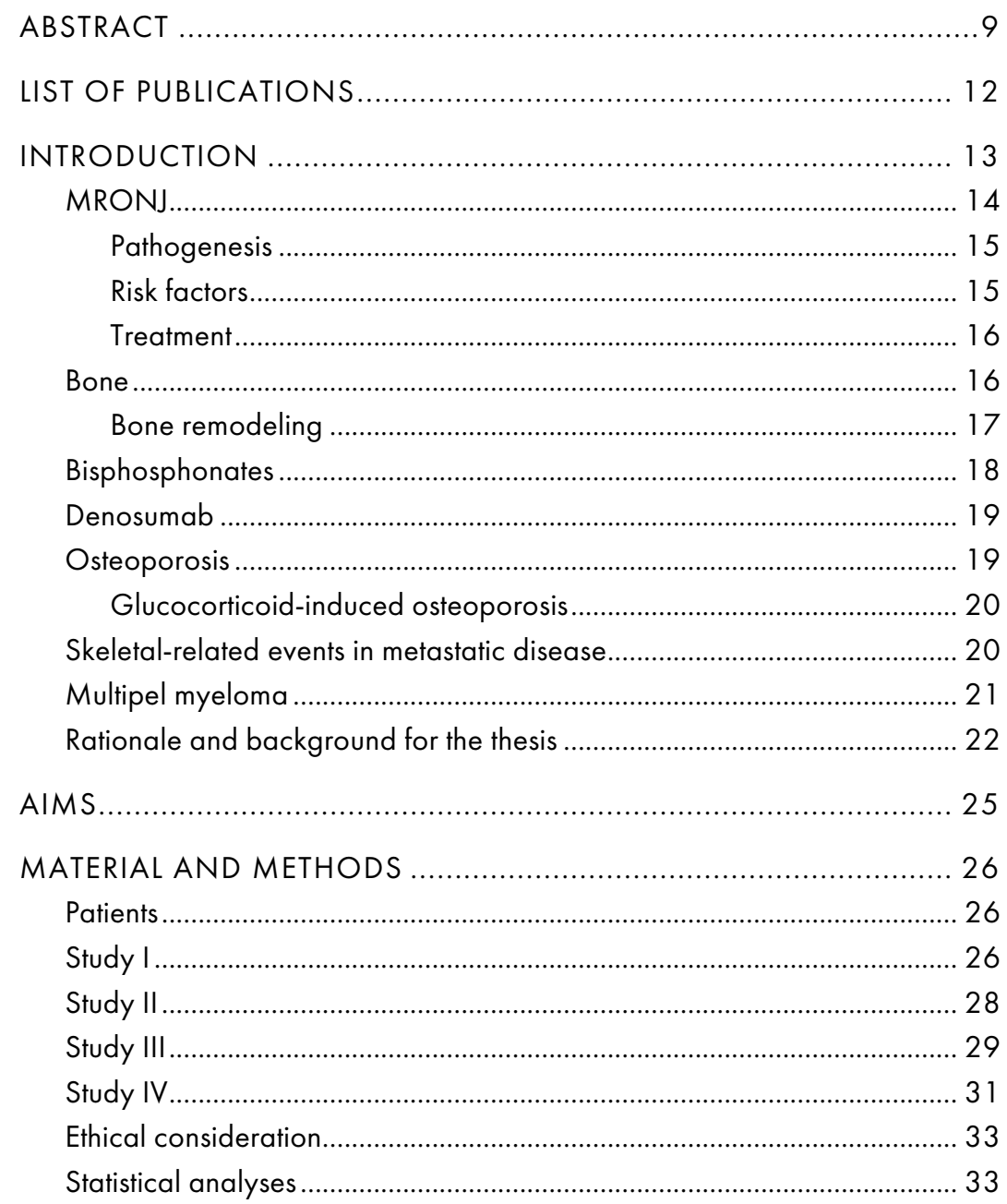




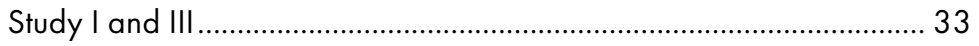

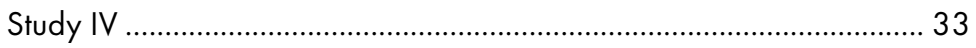

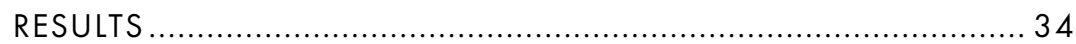

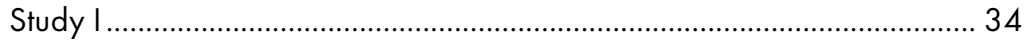

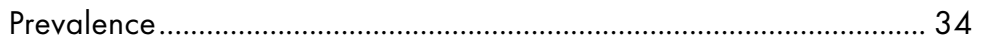

Underlying disease and type of bisphosphonates............................... 34

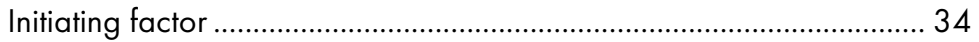

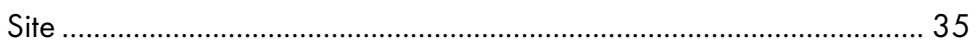

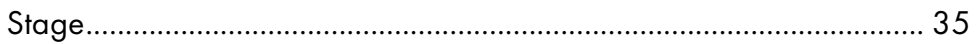

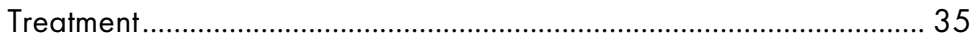

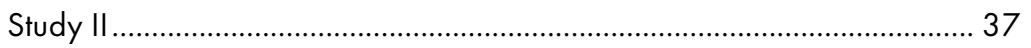

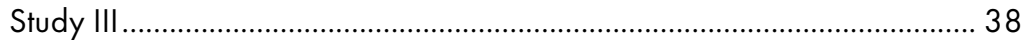

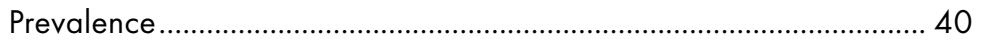

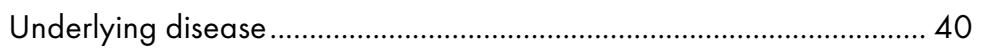

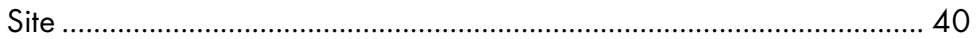

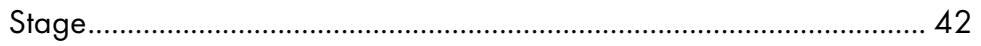

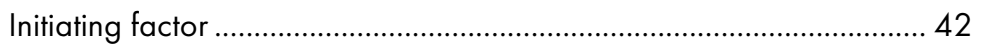

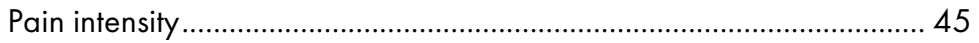

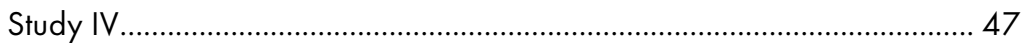

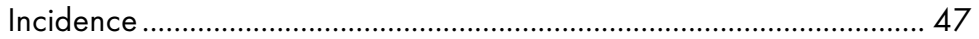

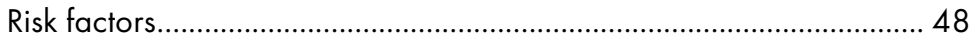

DISCUSSION ................................................................... 51

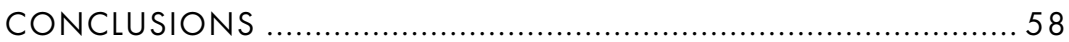

FUTURE RESEARCH ..................................................... 59

POPULÄRVETENSKAPLIG SAMMANFATTNING ...................... 61

ACKNOWLEDGEMENTS ................................................... 63

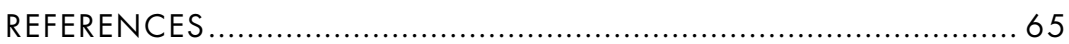

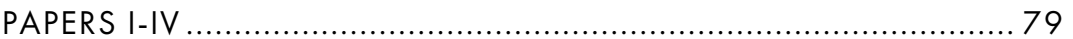




\section{ABSTRACT}

The antiresorptive drugs bisphosphonates and denosumab are widely used to preserve bone strength by inhibiting osteoclast mediated bone resorption. High dose intravenous bisphosphonates and high dose denosumab are mainly used to treat skeletal related events in patients with metastatic bone disease such as metastatic breast cancer and metastatic prostate cancer or in patients with multiple myeloma. In patients with osteoporosis, oral bisphosphonates are mostly used. Medication-related osteonecrosis of the jaw (MRONJ) is a serious side effect associated both with bisphosphonates and denosumab treatment. The first report on MRONJ was published in 2003. At first, the condition was believed to be a new disease, but it was later proved to be the same disease, which existed more than 100 years ago in match factory workers, and phosphate miners, in whom the disease was recognized as phossy jaw.

The overall aim of this thesis was to study the occurrence, risk factors, pathogenesis and treatment of MRONJ.

Study I describes prevalence, trigger factors and treatment outcomes of MRONJ retrospectively between the years 2003-2010 in Region Skåne. During this time, 55 patients had been diagnosed with MRONJ. Of these patients, 31 patients with a malignant disease were treated with high dose intravenous bisphosphonates and 24 patients with osteoporosis were treated with oral bisphosphonates. The prevalence of MRONJ was estimated to be $0.024 \%$ for patient on oral bisphosphonates and $2.8 \%$ for patients on high 
dose intravenous bisphosphonates. Tooth extraction was the most common trigger factor. After treatment of MRONJ, healing occurred more frequently in patients with osteoporosis treated with oral bisphosphonates than in patients with a malignant disease treated with high dose intravenous bisphosphonates.

Study II investigated the association between microflora and MRONJ by using $16 S r R N A$ pyrosequencing technique for the detection of bacteria in necrotic bone lesions. Included were 18 consecutive patients with MRONJ, ten with osteoporosis and eight with metastatic disease. Bone biopsies were retrieved with two separate $3 \mathrm{~mm}$ sterile trepan burrs from the centre of the necrotic bone and from visible healthy bone. The necrotic bone lesions contained mainly anaerobic bacteria, representative for periodontal microflora, suggesting that a periodontal infection in combination with antiresorptive treatment could initiate the osteonecrosis.

Study III is a prospective cohort study where the prevalence and initiating factors of MRONJ and the outcome of surgical therapy were analysed. All new cases of MRONJ between 2012 and 2015 in Region Skåne were included. Fifty-five patients with MRONJ were identified. The prevalence of MRONJ for patients on oral bisphosphonates was $0.043 \%$, on high dose intravenous bisphosphonates $1.03 \%$ and on high dose denosumab $3.64 \%$. Periodontal disease preceded development of MRONJ in 41 patients. Fifty patients were treated surgically and followed up for at least 2 months. Lesions progressed to remission or healing in $80.0 \%$ of patients treated with sequestrectomy and in $92.5 \%$ of patients treated with block resection.

In study IV, the aim was to prospectively determine the incidence and define risk factors for MRONJ in patients with metastatic breast cancer treated with zoledronic acid and/or denosumab. Breast cancer patients diagnosed between 2012 and 2015 in the region of Skåne with one or several bone metastases and treated with zoledronic acid or denosumab were included. Systemic risk factors (age, zoledronic acid or denosumab use, treatment time, chemo- 
therapy or corticosteroid use, diabetes and smoking habits) were recorded. Sixteen patients of $242(6.6 \%)$ developed MRONJ during the 77 months study period (from 1st of January 2012 to 31st of May 2018). The incidence of MRONJ in patients treated with high dose zoledronic acid was $4.1 \%$, and for patients with high dose denosumab $13.6 \%$. The risk of developing MRONJ in patients on denosumab was significantly higher compared to patients treated with zoledronic acid. Corticosteroid use was associated with a significant decreased risk of MRONJ and diabetes was associated with a significantly increased risk of MRONJ. Chemotherapy or smoking was not associated with a significant increased risk of MRONJ.

In conclusion, the incidence of MRONJ is more than three times higher in breast cancer patients treated with denosumab compared to breast cancer patients treated with zoledronic acid. The prevalence in patients with osteoporosis on oral bisphosphonates is low, $<0.05 \%$. Corticosteroid use decreases the risk of developing MRONJ whilst diabetes increases the risk. The most common local risk factor is a periodontal disease. Periodontal bacteria play a central role in the pathogenesis and development of MRONJ. The treatment outcome of MRONJ demonstrates healing in most patients treated surgically. 


\section{LIST OF PUBLICATIONS}

This thesis is based on the following articles, referred to in the text by their Roman numerals. The articles are appended at the end of the thesis.

I. Osteonecrosis of the jaw in patients treated with oral and intravenous bisphosphonates: experience in Sweden. Hallmer F, Bjørnland T, Nicklasson A, Becktor JP, Andersson G. Oral Surg Oral Med Oral Pathol Oral Radiol. 2014 Aug;118(2):202-8.

II. Bacterial diversity in medication-related osteonecrosis of the jaw. Hallmer F, Bjørnland T, Andersson G, Becktor JP, Kristoffersen AK, Enersen M. Oral Surg Oral Med Oral Pathol Oral Radiol. 2017 Apr;123(4):436-444.

III. Prevalence, initiating factor, and treatment outcome of medication-related osteonecrosis of the jaw-a 4-year prospective study. Hallmer F, Andersson G, Götrick B, Warfvinge G, Anderud J, Bjørnland T. Oral Surg Oral Med Oral Pathol Oral Radiol. 2018 Dec;126(6):477-485.

IV. Incidence of and risk factors for medication-related osteonecrosis in women with breast cancer with bone metastasis: a cohort study. Hallmer F, Bjarnadottir O, Malmström P, Götrick B, Andersson G. Manuscript. 


\section{INTRODUCTION}

Medication-related osteonecrosis of the jaw (MRONJ) is a serious side effect associated with both bisphosphonates and denosumab treatment (Ruggiero et al., 2014) . In 2003 and 2004, oral and maxillofacial surgeons began to report cases of non-healing of exposed necrotic bone in the maxillofacial region in patients treated with bisphosphonates (Marx, 2003; Ruggiero et al. 2004). At first, the condition was believed to be a new disease, but it actually proved to be a disease that had existed more than 100 years ago in match factory workers and phosphate miners in whom the disease was known as phossy jaw (Marx, 2008; Miles, 1972; Myers \& McGlothlin, 1996). The "strike anywhere" match was invented in the 1860 s, after white phosphorus was added to the sulfur-based matchstick coating to trigger a more volatile flame. The phosphorus-based vats released toxic fumes into the factory air and "dippers and handlers" were exposed to the fumes. Many match factory workers developed inflammation and sclerosis of the bones and of the periosteum of the face, due to chronic phosphorus poisoning, later resulting in a suppurative process and osteonecrosis. The osteonecrosis most often started in the alveolar process of the jawbone and was most common in the mandible. Preventive methods were addressed including excluding workers with dental caries from the match factories, offering them tooth extraction and after that at least two weeks' exclusion from work to minimise the risk of developing phossy jaw (Ward, 1928). It has been estimated that phossy jaw developed in a significant percentage of workers, usually within 3 to 5 years of exposure (Pollock et al., 2015). In the 
United States, a law was passed 1914 prohibiting the importation and exportation of white phosphorus matches. It seemed, then, that phossy jaw was a thing of the past (Ward, 1928).

In the mid-1990s, the new potent phosphorous containing drugs zoledronic acid and pamidronic acid was introduced to enhance the quality of life by reducing the frequency of morbid skeletalrelated events caused by osteolytic metastases in the most common cancer form in women, breast cancer, and the second most common in men, prostate cancer (Body, 1997; DeSantis et al., 2014; Ferlay et al., 2015; Gilbert et al., 2003; Lundqvist et al., 2016). Bone metastases can cause substantial morbidity and mortality in metastatic cancer. The metastases can cause pain and might cause fractures and spinal cord compression (Saylor \& Smith, 2010).

Surprisingly, when introducing a new phosphorous drug, no one took in an account the knowledge of phossy jaw and that this could cause osteonecrosis of the jaw as seen in match factory workers 100 years ago.

\section{MRONJ}

MRONJ is defined by the American Association of Oral and Maxillofacial Surgeons (AAOMS) as "exposed necrotic bone or bone that can be probed through an intraoral or extraoral fistula in the maxillofacial region after current or previous treatment with antiresorptive agents. It must have persisted for longer than eight weeks with no history of radiation therapy to the jaws or obvious metastatic disease of the jaws" (Ruggiero et al., 2014).

MRONJ is staged from 0-3 according to the recommendations of the AAOMS 2014 (Ruggiero et al., 2014). Stage 0 is defined as no clinical evidence of necrotic bone but non-specific clinical findings, radiographic changes and symptoms; Stage 1 as exposed necrotic bone or fistulas that could be probed to bone without pain or signs of infection (asymptomatic); Stage 2 as exposed necrotic bone or fistulas that could be probed to bone with pain or signs of infection (symptomatic) and Stage 3 as exposed necrotic bone or fistulas that could be probed to bone with pain or signs of infection and one or 
more of the following: pathological fracture, oral-cutaneous fistula, involvement of the maxillary sinus or necrosis extending to the inferior border of the ramus of the mandible.

\section{Pathogenesis}

The pathogenesis of MRONJ has not yet been fully elucidated. One hypothesis is that MRONJ is a result of bisphosphonateinduced suppression of the remodeling of the bone in the jaws (Allen \& Burr, 2009). The hypothesis is based on studies showing that the jaw has a high remodeling rate, that bisphosphonates suppress remodeling and that remodeling is considerably higher in the jaw compared with other skeletal sites (Russell et al., 2008; Russell et al., 2007). An animal study showed the mandible remodeling rates, specifically within the alveolar region, to be more than ten times higher than those within the long bones (Allen \& Burr, 2008). However, the question of how the suppression of remodeling results in necrotic bone is not answered by this hypothesis.

Another theory is that MRONJ is caused by a dental infection. In an animal study, ligature-periodontal inflammation was induced in rats treated with zoledronic acid. Osteonecrosis was observed associated with periodontitis in the group of rats treated with zoledronic acid, suggesting that periodontal disease and zoledronic acid therapy are sufficient for MRONJ development (Aghaloo et al., 2011).

\section{Risk factors}

Risk factors reported for the development of MRONJ include general risk factors such as corticosteroid treatment, chemotherapy, diabetes and smoking (Khan et al., 2016; Marx et al., 2005; Otto et al., 2012) as well as local risk factors such as anatomic locations predisposed to trauma (Rasmusson \& Abtahi, 2014). The trigger factor in a majority of cases is tooth extraction (Otto et al., 2012). 


\section{Treatment}

Treatment choice for MRONJ is still controversial and recommendations from AAOMS suggest antibacterial mouth rinses, symptomatic treatment with antibiotics in the early stages and, in more severe cases, superficial debridement for long term palliation of infection and pain (Ruggiero et al., 2014). Conservative treatment include procedures such as minor local debridement with elimination of sharp bone edges, local hygiene of the area of exposed bone, the use of topical antibacterial agents, and systemic antibiotics for infection and pain control. In a study long-term antibiotics resulted in complete or partial healing in $18 \%$ of the patients (Lazarovici et al., 2009). Similar findings were obtained in studies where conservative treatment showed poor treatment outcome with a high recurrence rate of MRONJ (Magopoulos et al., 2007; Zervas et al., 2006).

Surgical interventions have previously been reported to be capable of exacerbating bone exposure and a conservative approach was recommended, (Ruggiero et al., 2006; Van den Wyngaert et al., 2009). More recent reports suggest a more radical treatment strategy with surgical removal of the necrotic bone and primary closure in combination with antibiotic treatment and in severe cases segmental resection. (Bedogni et al., 2011; Pautke et al., 2011; Pichardo \& van Merkesteyn, 2016; Stockmann et al., 2014; Williamson, 2010).

\section{Bone}

Bone consists of extracellular matrix (crystallised mineral salts), collagen fibers and bone cells. Bone tissue consists of four different types of bone cells (osteoblasts, osteoclasts, osteocytes and osteogenic cells) (Tortora, 2011). Osteogenic cells are bone stem cells from the mesenchyme turning into osteoblasts. The osteoblast is a bone cell with mesenchymal origin from osteoprogenitor cells. Osteoblasts synthesise collagen and the proteins osteocalcin and osteopontin into the organic matrix of the bone, the osteoid (VanPutte, 2014). Osteoblasts also deposit hydroxyapatite salts mineralising the organic matrix to a dense tissue (Tortora, 2011). Osteocytes 
are mature osteoblasts located in lacunae trapped inside the bone tissue and responsible for maintaining the metabolism of bone tissue. The osteoclast is a multinucleated cell with a hematopoietic origin in precursor cells from self-fusion mononuclear monocytes/macrophages. Osteoclasts are responsible for bone resorption (Boyle et al., 2003).

\section{Bone remodeling}

Through remodeling of the bone matrix the bone is continuously renewed. The remodeling cycle starts with resorption of collagen and minerals by the osteoclasts at the surface of the bone and osteoblasts then deposits new mineral and collagen fibers to rebuild the bone tissue (Boyle et al., 2003).

To start the remodeling cycle, osteoclasts must be recruited. Osteoblasts produce a transmembrane protein, RANKL (Receptor Activator of Nuclear factor Kappa B-Ligand) that binds to a receptor on the surface of the osteoclast precursor cells, RANK (Receptor Activator of Nuclear factor Kappa B). The pre-osteoclasts fuse together to form large multinuclear cells and are thereby activated and differentiated into mature osteoclasts (Boyle et al., 2003). Resorption is initiated when the osteoclasts attaches to the bone surface with developed ruffled border. The osteoclasts then release protons $(\mathrm{H}+)$ to lower the $\mathrm{pH}$ on the bone surface and thereby start a breakdown of minerals such as hydroxyapatite crystals. Enzymes are also released that decompose the bone matrix such as the protein collagen. During the resorption the cytokines insulinlike growth factor 1 (IGF-1) and transforming growth factor (TGF), embedded in the bone, are released and activate osteoblasts to initiate new bone formation. The osteoblasts can also downregulate the osteoclast activation by secreting osteoprotegerin (OPG) which binds to RANKL and thereby prevents the ligand from binding to RANK. Thus, RANKL and OPG both affect the degree of activated osteoclasts by up and down regulation and thereby balance and control the amount of bone resorption (Boyle et al., 2003). 


\section{Bisphosphonates}

Bisphosphonates are drugs that inhibit bone resorption, bone metabolism and bone remodeling through inhibition of osteoclasts (Allen \& Burr, 2009, 2011; Russell et al., 2008). Bisphosphonates have high affinity for hydroxyapatite crystals of the bone (Drake et al., 2008) and they bind preferentially to bones which have high turnover rates. They are liberated again only when the bone in which they are deposited is resorbed (Lin, 1996). Due to an irreversible binding to the hydroxyapatite crystals in bone mineral, bisphosphonates have a half-life of approximately eleven years (Lasseter et al., 2005). The true mechanism of action of bisphosphonates is still unknown. One theory is that bisphosphonates are absorbed by the osteoclasts during bone remodeling, causing apoptosis of the osteoclast and decreasing osteoclast progenitor development and recruitment (Drake et al., 2008; Hughes et al., 1995). Another theory is that bisphosphonates interfere with and inhibit proteins on osteoclasts' cell surface, necessary for the attachment of the osteoclast to the bone surface (Drake et al., 2008).

Bisphosphonates can be divided into two groups, non-nitrogencontaining and nitrogen-containing. The presence of a nitrogen group increases the bisphosphonates antiresorptive potency by ten times (Drake et al., 2008). It is mainly nitrogen-containing bisphosphonates that have been associated with the development of MRONJ. The explanation for this is probably that the nitrogencontaining side chains increase the potency and perhaps toxicity (Otto et al., 2010, 2012).

In general, when orally administered the bisphosphonates alendronic acid and pamidronic acid are poorly absorbed from the gastrointestinal tract as a result of their poor lipophilicity which prevents transcellular transport across epithelial barriers. This means a low bioavailability of 0.3-0.8\%. (Daley-Yates et al., 1991; Gertz et al., 1995). 
Intravenously administered bisphosphonates on the other hand lead to a rapid uptake in bone tissue. To date, all bisphosphonates studied show no evidence of metabolism. Renal excretion is the only route of elimination (Lin, 1996).

\section{Denosumab}

Denosumab is an IgG2 monoclonal antibody with an affinity and specificity for RANK ligand (RANKL) that inhibits RANKL from activating its receptor, RANK, on the surface of osteoclasts and their precursors. Prevention of RANKL-RANK interaction inhibits osteoclast formation, function and survival, thereby decreasing bone resorption (Cummings et al., 2009).

Denosumab is administered subcutaneously. The mean half-life of denosumab is 26 days (Chen et al., 2018). After cessation of denosumab treatment normal osteoclast function can be expected after approximately 12 months (Iranikhah et al., 2018; McClung et al., 2017).

\section{Osteoporosis}

Osteoporosis is a systemic skeletal disease characterised by low bone mass leading to increased fracture risk and reduced bone strength. Osteoporotic fractures predominantly occur at major skeletal site such as vertebrae, proximal femur, distal forearm, or scapulae (Awasthi et al., 2018).

The main treatment goal of osteoporosis is prevention of osteoporotic fracture, by achieving maximal bone mineral density with adequate calcium and vitamin $\mathrm{D}$ intake, a balanced diet, and weight bearing exercise (Nguyen, 2017). Estrogen therapy can also be an important therapy for osteoporosis (Awasthi et al., 2018). Both bisphosphonates and denosumab are effective in reducing the incidence of clinical vertebral fractures, as well as other clinical fractures in patients suffering from osteoporosis (Black \& Rosen, 2016). Alendronic acid has been shown to increase bone mineral density and reduce clinical fractures with $14 \%$ in women with osteoporosis (Cummings et al., 1998). 
In patients with osteoporosis, oral bisphosphonates (alendronic acid, ibandronic acid or risedronic acid) are mostly used. In some patients that do not tolerate oral bisphosphonates, zoledronic acid ( 5 $\mathrm{mg}$ ) can be used as an annual infusion or denosumab $(60 \mathrm{mg})$ as subcutanous injection twice a year (Cummings et al., 2009; Jacques et al., 2012).

\section{Glucocorticoid-induced osteoporosis}

Glucocorticoids play an important role in the treatment of many inflammatory conditions, for example rheumatoid arteritis (Buckley et al., 2017). However, glucocorticoid use causes a decline in bone mass during treatment with bone loss and/or fractures as a result (Lane \& Lukert, 1998; Saag et al., 1994).

\section{Skeletal-related events in metastatic disease}

The molecular mechanisms by which tumour cells metastasise to bone are likely to involve invasion, cell adhesion to bone, and the release of soluble mediators from tumor cells that stimulate osteoclast-mediated bone resorption. As both bisphosphonates and denosumab are powerful inhibitors of osteoclast activity, they are used in the treatment of patients with osteolytic metastases (Boissier et al., 2000). Pain is the most frequent consequence of bone metastases for patients with advanced cancer and can significantly increase the emotional and physical burden of the metastatic disease (Body et al., 1998; Janjan et al., 1998).

Intravenous bisphosphonates or denosumab are used to reduce skeletal-related events such as painful pathologic fractures as well as to treat hypercalcemia associated with bone metastases in patients with metastatic breast cancer or prostate cancer (Saylor \& Smith, 2010; Stopeck et al., 2010). In a study by Berenson et al, zoledronic acid at doses of 2 and $4 \mathrm{mg}$ and pamidronic acid at a dose of $90 \mathrm{mg}$ each significantly reduced the need for radiation therapy to bone in patients with metastatic breast cancer or multiple myeloma, in contrast with $0.4 \mathrm{mg}$ zoledronic acid, which did not. Skeletal-related events of any kind also occurred less frequent- 
ly in patients treated with 2 or $4 \mathrm{mg}$ zoledronic acid or pamidronic acid than with $0.4 \mathrm{mg}$ zoledronic acid (Berenson et al., 2001).

Denosumab have been shown to be superior to bisphosphonates when it comes to preventing skeletal-related events among patients with breast cancer and bone metastases (Stopeck et al., 2010). The greater effect of denosumab over bisphosphonate in preventing the worsening of pain may be explained by its greater ability to inhibit osteoclast formation and function, thereby suppressing cancerinduced bone destruction (Cleeland et al., 2013).

\section{Multipel myeloma}

Multiple myeloma is a haematological malignancy. The pathogenesis of multiple myeloma is characterised by the clonal proliferation of plasma cells in the bone marrow. In more than $80 \%$ of patients with multiple myeloma, a myeloma bone disease develops as a result of multiple myeloma plasma cells-mediated activation of osteoclast activity and suppression of osteoblast activity. Multiple myeloma spread to the skeleton is characterised by the formation of osteolytic lesions, which increase the risk of skeletal-related events such as pathologic fracture, spinal cord compression and hypercalcaemia (Lee et al., 2017). Bisphosphonates prevent, reduce and delay multiple myeloma-related skeletal-related events. Intravenous pamidronic acid and zoledronic acic and oral clodronate are used in the management of multiple myeloma (Engelhardt et al., 2014). The European Myeloma Network recommends the use of bisphosphonates in multiple myeloma patients suffering from lytic bone disease or severe osteoporosis since they are an essential component for reducing skeletal morbidity (Engelhardt et al., 2014). In a recent Cochrane review on bisphosphonates in multiple myeloma, the results showed that there was moderate-quality evidence of a reduction in mortality from $41 \%$ to $31 \%$ (Mhaskar et al., 2017). 


\section{Rationale and background for the thesis}

As MRONJ is a severe side effect of antiresorptive treatment with bisphosphonates and denosumab, there is a need to examine the incidence, pathogenesis and risk factors for the disease and to evaluate methods to prevent and treat the condition.

It is estimated that the bisphosphonates pamidronic acid and zoledronatic acid, mainly used in oncologic treatments, had been used in about 2.5 million patients worldwide up til 2003 (Tarassoff \& Csermak, 2003). In 2010, when this study started, about 700 publications, mostly case reports and review articles, were available on MRONJ. There were only a few studies on incidence and these reported incidences between $0.01 \%$ and $18.6 \%$ (Madrid et al., 2010; Mavrokokki et al., 2007; Ulmner et al., 2014). In Sweden, the low incidence $(0.09 \%)$ is based on a survey sent to oral and maxillofacial surgery clinics estimating the incidence on MRONJ in patients on oral bisphosphonates (Ulmner et al., 2014). The high incidence number $(18.6 \%)$ is the cumulative incidence in patients on intravenous bisphosphonates (Madrid et al., 2010). As the incidence varies widely, it seems crucial to determine the true incidence of MRONJ. A study describing the frequency and clinical characteristics with a large number of patients diagnosed with MRONJ was reported from Australia (Mavrokokki et al., 2007). In 2004-2005 a postal survey was sent to oral and maxillofacial surgeons, to other dental specialists and to Commonwealth of Australia Adverse Drug Reaction Committee. MRONJ was found in $0.01-0.04 \%$ of osteoporotic patients mainly on weekly oral alendronate. If extractions were carried out the calculated frequency was $0.09-0.34 \%$. In patients with bone malignancies, treated mainly with intravenous zoledronic acid or pamidronic acid, the corresponding figures were $0.88-1.15 \%$ and $6.67-9.1 \%$. The authors concluded that their retrospective study with multiple assumptions and without independent assessments of cases showed the need for prospective clinical trials (Mavrokokki et al., 2007).

A systematic review (Migliorati et al., 2010) examined the prevalence of MRONJ prevention and treatment protocols and quality 
of life issues in the cancer population. The literature search identified hundreds of publications but only 28 articles fulfilled the inclusion criteria, and 22 were used for prevalence analysis (Abu-Id et al., 2008; Badros et al., 2006; Boonyapakorn et al., 2008; Cartsos et al., 2008; Chiandussi et al., 2006; Dimopoulos et al., 2006; Durie et al., 2005; Estilo et al., 2008; Farrugia et al., 2006; Hoff et al., 2008; Khamaisi et al., 2007; Magopoulos et al., 2007; Marx, 2003; Mavrokokki et al., 2007; Pozzi et al., 2007; Ruggiero et al., 2004; Wessel et al., 2008; Wilkinson et al., 2007; Zavras \& Zhu, 2006). There were no randomised clinical trials available and no meta-analysis. The overall weighted prevalence of MRONJ included a sample of 39124 patients with a mean weighted prevalence of $6.1 \%$. The weighted prevalence was $13.3 \%$ for studies with documented follow-up with a sample size of 927 individuals. In studies with undocumented follow-up the weighted prevalence was $0.7 \%$ in a sample of 8829 chart reviews and in epidemiological studies, evaluating a total of 29368 individual records, the weighted prevalence was $1.2 \%$. The authors conclude that high-quality studies are needed to accurately characterise the prevalence of MRONJ and to determine effective treatment protocols. They suggest that future investigations should include 1) a clear statement of the total number of individuals in the study and whether patients were drawn from a single pool or were referred from outside of the centre, 2) obtain a progressive pain score on all patients (VAS or similar) 3) state the duration, total dose and range of bisphosphonate therapy 4) include information on all other possible aggravating factors such as: smoking, diabetes and use of glucocorticoids 5) stage the MRONJ lesions according to AAOMS staging system or other comparable system 6) specifically and clearly define endpoints and outcomes.

The European Medicines Agency (EMEAS) concluded in September 2009, based on the latest evaluation of their scientific committee, the Agency's Committee for Medicinal Products for Human Use (CHMP), that there is an increased risk of osteonecrosis of the jaw in patients taking bisphosphonates. The Committee also concluded that further data are needed to determine precise measures 
that could minimise the risk of MRONJ including looking at how intravenous bisphosphonates should be given such as dose, frequency of administration, duration of treatment and looking into the risk of osteonecrosis of the jaw in patients taking oral bisphosphonates for long periods. The CHMP noted that other possible risk factors for developing osteonecrosis of the jaw should be considered such as gender, genetic factors, smoking and other treatments or diseases, as well as the type of cancer and how long the patient has had it. In 2015, the European Medicines Agency (EMEAS) completed a periodic review of Aclasta (zoledronic acid), that concluded the risk of osteonecrosis of the jaw to be very low, included a number of measures to minimise the risk and an update to the product information and an introduction of a patient reminder card. EMEAS is planning similar measures for other intravenous bisphosphonates and denosumab, used for osteoporosis or for preventing bone complications of cancers, as these are also associated with a risk of osteonecrosis of the jaw.

Treatment principles, which are known from osteonecrosis of other causes, include antibiotic treatment and surgical removal of necrotic bone (O’Dell \& Sinha, 2011). Up to 2011, most reports dealing with MRONJ reflect the fact that treatment in accordance with these principles is not very successful. Different antibiotic regimes generally have little effect on MRONJ (Magopoulos et al., 2007; Zervas et al., 2006). MRONJ cases are lengthy and the outcome of surgery with sequestrectomy is either disappointing or at best unknown.

Some authors discourage surgical intervention as the effect is sparsely documented and surgery can aggravate MRONJ (Zarychanski et al., 2006). However, a technique published in 2011, with fluorescence-guided bone resection in Stage 2 and 3 MRONJ lesions in patients with intravenous bisphosphonate treatment for metastatic bone disease has shown promising results. Surgical intervention with mucosal closure showed no signs of wound dehiscence in $85 \%(17 / 20)$ of cases at the site of the previous osteonecrosis (Pautke et al., 2011). 


\section{AIMS}

The overall aim of this thesis was to study the occurrence, risk factors, pathogenesis and treatment of MRONJ.

Specific aims were:

- To study the prevalence, location and initiating factors for MRONJ in patients with osteoporosis or malignant disease.

- To study the association between the oral microbiota and MRONJ by using $16 S r R N A$ pyrosequencing technique.

- To evaluate treatment outcomes for MRONJ in patients with osteoporosis or malignant disease.

- To analyse the treatment outcome of MRONJ after sequestrectomy versus block resection.

- To study the incidence and systemic risk factors of MRONJ in patients with metastatic breast cancer treated with zoledronic acid or denosumab. 


\section{MATERIAL AND METHODS}

\section{Patients}

The studies were carried out in Region Skåne, one of 21 administrative regions in Sweden. Region Skåne is the third largest region with 1.2-1.3 million inhabitants (www.skatteverket.se). Four departments of oncology were responsible for treatment of breast cancer and four departments of oral and maxillofacial surgery were responsible for the treatment of MRONJ. The departments were located at the hospitals in Malmö, Kristianstad, Helsingborg, and Lund.

\section{Study I}

Patients diagnosed with maxillofacial pathology in the period 2003-2010 were identified in the Melior database at the four departments of oral and maxillofacial surgery. Patient records were searched for the ICD 10 WHO inflammatory conditions of the jaw (K10.2), unspecified disease of jaws (K10.9), unspecified osteomyelitis (M86.9), osteonecrosis due to drugs (M87.1), and other osteonecrosis (M87.8) and 341 patients were identified. Fifty-five of these had been diagnosed with MRONJ and were included in Study I. 
Data were collected and analysed on:

- Prevalence

- Underlying disease (osteoporosis or malignant disease)

- Type of bisphosphonate (oral or intravenous)

- Initiating factor

- Site

- Stage

- Treatment and treatment outcomes

The outcome variable was healing defined as complete mucosal coverage without any exposed bone and without any sign of infection. 


\section{Study II}

Twenty-two consecutive patients from the ongoing prospective study (Study III) were recruited between June 2013 and February 2015 , in relation to the surgical treatment of the necrosis at the Department of Oral and Maxillofacial Surgery in Lund. Four patients were excluded due to current antibiotic treatment or antibiotic treatment within three months prior to the study. Two separate bone biopsies were collected from each patient in relation to the surgical treatment of the necrosis to study the association between microflora and MRONJ by using culture-independent molecular techniques for the detection of bacteria in necrotic bone lesions. After removal of the superficial layers exposed to the oral milieu with a round burr under irrigation with saline, the first sample was retrieved from the centre of the necrotic bone lesion. The second sample was then retrieved from a region of visually healthy bone adjacent to the necrotic bone as an intraoperative control sample to analyse if the oral microflora exists in the bone tissue outside the macroscopic necrotic bone. Each biopsy was immediately placed in cryotubes with DNA/RNA stabilising solution (RNA Later). In two healthy patients, bone biopsies were collected in relation to planned surgical extraction of impacted third molars without any signs of local odontogenic infection.

$16 \operatorname{SrRNA}$ gene fragments from bacterial DNA were amplified with polymerase chain reaction. DNA extractions of clinical samples were performed using the MasterPure DNA isolation kit from Epicentre (MCD85201, Epicentre Biotechnologies, WI). 16S rRNA gene fragments from bacterial DNA were amplified with PCR using universal eubacterial primers, forward primer 334f (5'CCAGACTCCTACGGGAGGCAGC-3'), and reverse primer 939r (5'- CTTGTGCGGGCCCCCGTCAATTC-3') (Baker, Smith, \& Cowan, 2003; Wang \& Qian, 2009) targeting the V3-V5 hypervariable region. 


\section{Study III}

All new patients diagnosed with MRONJ from 1st of January 2012 until 31st of December 2015 were included in Study III. The patients were followed up prospectively until 31st of December 2016.

Data were collected in case report form and analysed on:

- Prevalence

- Gender

- Underlying disease (osteoporosis or malignant disease)

- Type of antiresorptive drug

- Dosage and treatment time until necrosis occurred

- Initiating factor

- Site

- Stage

- Treatment and treatment outcomes

Previous intraoral x-rays were retrieved in order to analyse the diagnosis initiating MRONJ. A horizontal visual analogue scale (VAS) from 0 to 10 before and after treatment was used to record pain intensity, where zero indicated "no pain" and ten indicated "pain cannot be worse".

Data on the use of bisphosphonates and denosumab were obtained from statistics on prescriptions (www.socialstyrelsen.se), and statistics on drugs delivered to the health care sector in the region.

Patients were classified into two groups according to surgical treatment, sequestrectomy or block resection. Patients without progressive bone disease with ongoing bone destruction but with a well-defined sequestrum were treated with sequestrectomy including a local mucosal flap, removal of the sequestrum and debridement of the necrotic bone. Patients with progressive bone disease 
with ongoing bone destruction, observed on radiograph or ongoing pain and infection, were treated with block resection including a surgical removal of the necrotic bone and primary closure. Surgical marginal block resection included thorough surgical debridement with saucerisation of the bone until the vital bleeding bone margins were reached.

The outcome variable was healing after 2 months after treatment with complete disappearance of exposed bone and the absence of infection in the jaw affected by MRONJ.

Fifty-five patients with MRONJ were recruited. Forty-three were women (mean age 73.1 years) and 12 were men (mean age 63.6 years). Fifty patients were included in the study and followed up for periods of $2-46$ months (mean $=15.9$ months). Five patients were excluded either because the patients had died or due to progression of their diseases making it impossible for them to attend a follow-up visit after 2 months and for evaluate of treatment outcome. 


\section{Study IV}

Women above 17 years of age with histologically or cytologically confirmed breast cancer and radiographic evidence of one or several bone metastases were eligible for study entry.

Patients receiving zoledronic acid or denosumab during the study period were identified in the treatment registries and the medical records at the four participating hospitals.

Exclusion criteria were prior exposure to oral or intravenous bisphosphonates and/or denosumab for treatment of advanced cancer, prior treatment with oral bisphosphonates or denosumab for other bone loss conditions (e.g. osteoporosis), history evidence of MRONJ or osteomyelitis of the jaw as well as radiation therapy to the head and neck region.

To ensure a certain exposure to the antiresorptive medication, we included patients who received at least 3 infusions of zoledronic acid or 3 injections of denosumab. Patients were enrolled from January $1^{\text {st }} 2012$ and to December $31^{\text {st }} 2015$ and followed until May $31^{\text {st }} 2018$. Treatment consisted of $4 \mathrm{mg}$ of zoledronic acid administered i.v. during 15 minutes every 4 to 6 weeks or $120 \mathrm{mg}$ denosumab (Xgeva®, Amgen Inc., Thousand Oaks, California, USA) subcutaneous every 4 weeks.

Data collected from patient medical records included age, bisphosphonate or denosumab use, treatment time, chemotherapy or corticosteroid use, diabetes and smoking habits.

The cohort included 263 patients. Of these 21 patients were excluded, 15 with only one infusion with zoledronic acid, 3 with only one treatment with denosumab and 3 treated with oral bisphosphonates due to osteoporosis prior to the study. Thus the studied cohort consisted of $242(92.0 \%)$ patients. Mean age was 64.0 years (range 31-90). 
All patients diagnosed with MRONJ between $1^{\text {st }}$ of January 2012 and $31^{\text {st }}$ of May 2018 were analysed in the study.

Data collected from patient medical records included and were analysed on:

- Incidence

- Age

- Zoledronic acid or denosumab use and treatment time

- Chemotherapy

- Corticosteroid treatment

- Diabetes

- Smoking 


\section{Ethical consideration}

The Regional Ethics Committee at Lund, Sweden approved the four studies: Dnr 2011/274 (Study I, II, III and IV), Dnr 2012/760 (Study II and III) and Dnr 2018/344 (Study IV). The studies were conducted in compliance with the Helsinki Declaration, and each patient in the prospective studies signed a detailed informed consent form.

\section{Statistical analyses}

Study I and III

SPSS for Windows software (Version 14;0 SPSS, Chicago, IL, USA) was used for data management and statistical analysis. Students' ttest was used for continuous variables. Between group comparisons before and after treatment were tested with chi-square. A significance level of $5 \%$ was used in all tests.

\section{Study IV}

The relation between MRONJ and different background variables (treatment time, corticosteroid treatment, chemotherapy, diabetes mellitus and smoking) were investigated by odds-ratios (OR) with $95 \%$ confidence intervals. The OR was tested by chi-square tests using a significance level of $5 \%$. Time to MRONJ were analysed using the Kaplan-Meier method. All calculations were done in SPSS version 25 (IBM Corp. Released 2017. IBM SPSS Statistics for Windows, Version 25.0. Armonk, NY: IBM Corp.). 


\section{RESULTS}

\section{Study I}

Prevalence

Between 2003 and 2010, 55 patients with MRONJ were identified. The prevalence of MRONJ in patients on oral bisphosphonates was estimated to be $0.024 \%$ and the prevalence in patients on intravenous bisphosphonates was estimated to be $2.8 \%$.

Underlying disease and type of bisphosphonates

The most common reason for antiresorptive treatment was osteoporosis $(\mathrm{n}=24 ; 44 \%)$, followed by multiple myeloma $(\mathrm{n}=15 ; 27 \%)$, breast cancer $(n=11 ; 20 \%)$ and prostate cancer $(n=5 ; 9 \%)$. All patients with osteoporosis were treated with oral bisphosphonates and all patients with a malignant disease were treated with intravenous bisphosphonates $(\mathrm{n}=31 ; 56 \%)$. More women with osteoporosis were diagnosed with MRONJ than women with cancer $(\mathrm{p}=0.025)$. The osteoporotic patients were older than the patients with a malignant disease $(\mathrm{p}=0.008)$.

Initiating factor

The most common initiating factor was tooth extraction $(\mathrm{n}=36$; $66 \%$ ), follow by cases referred to as unknown (spontaneous) $(\mathrm{n}=12 ; 22 \%)$, dental implant surgery $(\mathrm{n}=4 ; 7 \%)$ and local trauma $(\mathrm{n}=3 ; 5 \%)$. 
Site

The most common site was the mandible $(n=43 ; 78 \%)$. Within the mandible, 35 lesions were localised in the posterior part of the mandible, 6 cases in the anterior mandible, one in the anterior and right posterior mandible and one case involved the whole mandible. Twelve cases were localised in the maxilla $(22 \%) ; 8$ in the posterior part, two in the anterior part and two patients had lesions involving the whole maxilla.

\section{Stage}

The most common was Stage $2(\mathrm{n}=31 ; 56 \%)$, followed by Stage 1 $(\mathrm{n}=14 ; 26 \%)$, and Stage $3(\mathrm{n}=10 ; 18 \%)$.

\section{Treatment}

The patients were treated with antibiotics or surgery or a combination of medical and surgical treatment. Antibiotic treatment was carried out with phenoxymethylpenicillin, metronidazole or clindamycin per os. Patients were treated with antibiotics for ongoing infection. Surgical treatment in stage 1 and 2 cases included a local resection with superficial debridement and/or removal of sequester (sequestrectomy). Stage 3 cases were treated with a local resection including removal of sequester and resection of necrotic bone after elevating a mucoperiosteal flap and primary closure obtained.

All patients with osteoporosis except two were treated with antibiotics. Twenty were treated with a local resection of the necrotic lesion. Healing occurred in most patients with osteoporosis $(n=19$; $79 \%$ ) and all of these were treated with local resection of the necrotic lesion in combination with antibiotics, except one patient who received no antibiotics. In five patients, no healing was noticed; one of these was treated with local resection.

In patients with cancer, most patients were treated with antibiotics $(\mathrm{n}=28 ; 90 \%)$. Local resection of the necrotic lesion was undertaken in 27 cases and all of these received antibiotics as well. Three patients were treated with local resection alone. Healing was noticed 
in eight patients $(26 \%)$ with a malignant disease, five with underlying disease breast cancer and three with multiple myeloma.

A significantly better treatment outcome, with complete healing of the mucosa, was identified in the osteoporosis group treated with oral bisphosphonates than in cancer patients treated with intravenous bisphosphonates, $(p=0.00009)$. All successful cases were treated with a combination of surgical therapy and systemic antibiotics, except one case treated with antibiotics alone, and one case treated with local resection only. 


\section{Study II}

Altogether 18 patients with MRONJ (14 females, 4 males), with a mean age of 71.9 years (range 41-91 years) were included in the study. The most common underlying disease was osteoporosis $(\mathrm{n}=10 ; 56 \%)$, followed by breast cancer $(\mathrm{n}=4 ; 22 \%)$, prostate cancer $(\mathrm{n}=3 ; 17 \%)$ and multiple myeloma $(\mathrm{n}=1 ; 6 \%)$. The most common antiresorptive treatments were oral bisphosphonates $(n=8$; $44 \%)$, followed by subcutaneously administered denosumab $(n=6$; $33 \%$ ), a combination of oral and intravenous bisphosphonates or denosumab $(\mathrm{n}=3 ; 17 \%)$ and intravenous bisphosphonate $(\mathrm{n}=1$; $6 \%)$

The necrotic bone samples from the 18 patients were all strongly positive for $16 S r R N A$ PCR. Visually healthy bone samples in seven patients were negative for $16 S r R N A$ PCR. In 11 of the patients, the visually healthy bone was also detected as positive where six PCR products were strong and five weak.

Eight dominating taxa groups were identified at genus level. In both necrotic and visual healthy bone samples there were: Porphyromonas, Lactobacillus, Tannerella, Prevotella, Actinomyces, Treponema, Streptococcus and Fusobacterium. In some patients, the periopathogenic bacteria dominate and in other, the Lactobacillus or Prevotella dominate.

When comparing necrotic samples from the patients with osteoporosis, treated with bisphosphonate, a higher level of periopathogenic bacteria was detected in this group than in the group treated with denosumab (XGEVA).

Analyses of the bone samples from the two healthy controls were negative for $16 S r R N A$ by PCR. 


\section{Study III}

Patient characteristics of the 55 consecutive patients are presented in Table I.

\begin{tabular}{|c|c|c|c|c|c|c|c|c|}
\hline $\begin{array}{l}\text { Patient } \\
\text { number }\end{array}$ & Gender & Age & Disease & $\begin{array}{l}\text { Antiresoptive } \\
\text { Treatment }\end{array}$ & Trigger factor & Stage & $\begin{array}{c}\text { Surgical } \\
\text { treatment }\end{array}$ & $\begin{array}{c}\text { Outcome } \\
\text { after } 2 \\
\text { months }\end{array}$ \\
\hline 1 & $M$ & 65 & Myeloma & Pamidronic acid & Spontaneous & 1 & Sequestrectomy & Healed \\
\hline 2 & $\mathrm{~F}$ & 89 & Osteoporosis & Risedronic acid & $\begin{array}{c}\text { Tooth } \\
\text { extraction }\end{array}$ & 2 & Sequestrectomy & Excluded \\
\hline 3 & $F$ & 71 & Myeloma & Zoledronic acid & $\begin{array}{c}\text { Tooth } \\
\text { extraction }\end{array}$ & 2 & Sequestrectomy & Healed \\
\hline 4 & $M$ & 65 & $\begin{array}{l}\text { Prostate } \\
\text { cancer }\end{array}$ & $\begin{array}{l}\text { Zoledronic acid } \\
+ \text { denosumab }\end{array}$ & $\begin{array}{c}\text { Tooth } \\
\text { extraction }\end{array}$ & 3 & Sequestrectomy & Excluded \\
\hline 5 & $\mathrm{~F}$ & 79 & Osteoporosis & Alendronic acid & $\begin{array}{l}\text { Tooth } \\
\text { extraction }\end{array}$ & 2 & Block resection & Failed \\
\hline 6 & $\mathrm{~F}$ & 42 & Breast cancer & Zoledronic acid & $\begin{array}{c}\text { Marginal } \\
\text { periodontitis }\end{array}$ & 1 & Block resection & Healed \\
\hline 7 & $\mathrm{~F}$ & 51 & $\begin{array}{l}\text { Giant cell } \\
\text { tumor }\end{array}$ & Denosumab & $\begin{array}{l}\text { Tooth } \\
\text { extraction }\end{array}$ & 2 & Block resection & Healed \\
\hline 8 & $\mathrm{~F}$ & 71 & Breast cancer & Zoledronic acid & $\begin{array}{c}\text { Marginal } \\
\text { periodontitis }\end{array}$ & 3 & Block resection & Remission \\
\hline 9 & $\mathrm{~F}$ & 70 & Lung cancer & Ibandronic acid & $\begin{array}{c}\text { Tooth } \\
\text { extraction }\end{array}$ & 2 & Block resection & Healed \\
\hline 10 & $M$ & 73 & Myeloma & $\begin{array}{c}\text { Zoledronic acid } \\
+ \text { ibandronic } \\
\text { acid }\end{array}$ & $\begin{array}{l}\text { Tooth } \\
\text { extraction }\end{array}$ & 2 & Block resection & Remission \\
\hline 11 & M & 65 & Myeloma & Pamidronic acid & $\begin{array}{c}\text { Tooth } \\
\text { extraction }\end{array}$ & 2 & Sequestrectomy & Healed \\
\hline 12 & $\mathrm{~F}$ & 86 & $\begin{array}{l}\text { Osteoporosis } \\
\text { (RA) }\end{array}$ & Alendronic acid & $\begin{array}{c}\text { Tooth } \\
\text { extraction }\end{array}$ & 2 & Block resection & Remission \\
\hline 13 & $\mathrm{~F}$ & 68 & Osteoporosis & Alendronic acid & $\begin{array}{l}\text { Tooth } \\
\text { extraction }\end{array}$ & 2 & Block resection & Healed \\
\hline 14 & $\mathrm{~F}$ & 66 & Breast cancer & Zoledronic acid & $\begin{array}{c}\text { Tooth } \\
\text { extraction }\end{array}$ & 2 & Sequestrectomy & Failed \\
\hline 15 & $\mathrm{~F}$ & 76 & Breast cancer & $\begin{array}{l}\text { Zoledronic acid } \\
+ \text { denosumab }\end{array}$ & $\begin{array}{c}\text { Marginal } \\
\text { periodontitis }\end{array}$ & 2 & Block resection & Remission \\
\hline 16 & $\mathrm{~F}$ & 72 & Osteoporosis & Alendronic acid & $\begin{array}{c}\text { Tooth } \\
\text { extraction }\end{array}$ & 2 & Block resection & Healed \\
\hline 17 & $F$ & 91 & Osteoporosis & Alendronic acid & $\begin{array}{l}\text { Tooth } \\
\text { extraction }\end{array}$ & 2 & Block resection & Healed \\
\hline 18 & $M$ & 68 & $\begin{array}{l}\text { Prostate } \\
\text { cancer }\end{array}$ & Denosumab & $\begin{array}{c}\text { Marginal } \\
\text { periodontitis }\end{array}$ & 2 & Block resection & Remission \\
\hline 19 & $M$ & 65 & $\begin{array}{l}\text { Prostate } \\
\text { cancer }\end{array}$ & Denosumab & $\begin{array}{c}\text { Marginal } \\
\text { periodontitis }\end{array}$ & 2 & Sequestrectomy & Remission \\
\hline 20 & $\mathrm{~F}$ & 68 & Osteoporosis & Alendronic acid & $\begin{array}{c}\text { Tooth } \\
\text { extraction }\end{array}$ & 2 & Block resection & Healed \\
\hline 21 & $\mathrm{~F}$ & 86 & Osteoporosis & $\begin{array}{l}\text { Risedronic acid } \\
+ \text { denosumab }\end{array}$ & $\begin{array}{l}\text { Tooth } \\
\text { extraction }\end{array}$ & 2 & Block resection & Healed \\
\hline 22 & M & 66 & $\begin{array}{c}\text { Prostate } \\
\text { cancer }\end{array}$ & Denosumab & $\begin{array}{c}\text { Tooth } \\
\text { extraction }\end{array}$ & 2 & Block resection & Excluded \\
\hline 23 & $\mathrm{~F}$ & 82 & Breast cancer & Denosumab & $\begin{array}{c}\text { Tooth } \\
\text { extraction }\end{array}$ & 2 & Sequestrectomy & Remission \\
\hline 24 & $\mathrm{~F}$ & 84 & Osteoporosis & Alendronic acid & $\begin{array}{c}\text { Tooth } \\
\text { extraction }\end{array}$ & 2 & Block resection & Healed \\
\hline 25 & $F$ & 70 & $\begin{array}{l}\text { Osteoporosis } \\
\text { (RA) }\end{array}$ & Alendronic acid & $\begin{array}{c}\text { Tooth } \\
\text { extraction }\end{array}$ & 2 & Block resection & Healed \\
\hline 26 & $\mathrm{~F}$ & 66 & Breast cancer & Denosumab & $\begin{array}{c}\text { Marginal } \\
\text { periodontitis }\end{array}$ & 2 & Block resection & Healed \\
\hline 27 & $\mathrm{~F}$ & 41 & Breast cancer & Denosumab & $\begin{array}{l}\text { Apical } \\
\text { periodontitis }\end{array}$ & 2 & Block resection & Healed \\
\hline
\end{tabular}




\begin{tabular}{|c|c|c|c|c|c|c|c|c|}
\hline 28 & $\mathrm{~F}$ & 78 & Osteoporosis & $\begin{array}{c}\text { Alendronic acid } \\
+ \text { Zoledronic } \\
\text { acid }\end{array}$ & $\begin{array}{c}\text { Tooth } \\
\text { extraction }\end{array}$ & 2 & Block resection & Healed \\
\hline 29 & M & 66 & Myeloma & Pamidronate & $\begin{array}{c}\text { Tooth } \\
\text { extraction }\end{array}$ & 2 & Block resection & Healed \\
\hline 30 & $\mathrm{~F}$ & 76 & Osteoporosis & Alendronic acid & $\begin{array}{c}\text { Tooth } \\
\text { extraction }\end{array}$ & 2 & Block resection & Healed \\
\hline 31 & $F$ & 65 & Breast cancer & Denosumab & $\begin{array}{c}\text { Marginal } \\
\text { periodontitis }\end{array}$ & 1 & Block resection & Healed \\
\hline 32 & $\mathrm{~F}$ & 82 & Osteoporosis & Alendronic acid & $\begin{array}{c}\text { Marginal } \\
\text { periodontitis }\end{array}$ & 3 & Block resection & Healed \\
\hline 33 & M & 70 & $\begin{array}{l}\text { Prostate } \\
\text { cancer }\end{array}$ & Denosumab & $\begin{array}{l}\text { Tooth } \\
\text { extraction }\end{array}$ & 2 & Block resection & Failed \\
\hline 34 & $\mathrm{~F}$ & 69 & Breast cancer & Bondronate & Spontaneous & 1 & No treatment & Excluded \\
\hline 35 & $\mathrm{~F}$ & 71 & Osteoporosis & Alendronic acid & $\begin{array}{c}\text { Tooth } \\
\text { extraction }\end{array}$ & 2 & Block resection & Healed \\
\hline 36 & $\mathrm{~F}$ & 70 & $\begin{array}{l}\text { Osteoporosis } \\
\text { (RA) }\end{array}$ & Alendronic acid & $\begin{array}{c}\text { Marginal } \\
\text { periodontitis }\end{array}$ & 2 & Block resection & Healed \\
\hline 37 & M & 71 & $\begin{array}{l}\text { Osteoporosis } \\
\text { (RA) }\end{array}$ & Denosumab & $\begin{array}{l}\text { Tooth } \\
\text { extraction }\end{array}$ & 1 & No treatment & Excluded \\
\hline 38 & $\mathrm{~F}$ & 83 & Osteoporosis & Alendronic acid & $\begin{array}{c}\text { Tooth } \\
\text { extraction }\end{array}$ & 1 & Block resection & Healed \\
\hline 39 & $F$ & 64 & Breast cancer & Ibandronic acid & $\begin{array}{l}\text { Tooth } \\
\text { extraction }\end{array}$ & 1 & Block resection & Healed \\
\hline 40 & $\mathrm{~F}$ & 75 & Osteoporosis & $\begin{array}{l}\text { Alendronic acid } \\
+ \text { denosumab }\end{array}$ & $\begin{array}{c}\text { Tooth } \\
\text { extraction }\end{array}$ & 1 & Block resection & Healed \\
\hline 41 & $\mathrm{~F}$ & 82 & Osteoporosis & $\begin{array}{l}\text { Alendronic acid } \\
+ \text { denosumab }\end{array}$ & $\begin{array}{c}\text { Tooth } \\
\text { extraction }\end{array}$ & 3 & Sequestrectomy & Healed \\
\hline 42 & $\mathrm{~F}$ & 63 & Breast cancer & Denosumab & $\begin{array}{c}\text { Tooth } \\
\text { extraction }\end{array}$ & 1 & Block resection & Healed \\
\hline 43 & $\mathrm{~F}$ & 79 & Osteoporosis & Alendronic acid & $\begin{array}{c}\text { Tooth } \\
\text { extraction }\end{array}$ & 2 & Block resection & Healed \\
\hline 44 & $\mathrm{~F}$ & 63 & $\begin{array}{l}\text { Osteoporosis } \\
\text { (RA) }\end{array}$ & $\begin{array}{l}\text { Alendronic acid } \\
+ \text { zoledronic } \\
\text { acid }\end{array}$ & $\begin{array}{c}\text { Tooth } \\
\text { extraction }\end{array}$ & 2 & Sequestrectomy & Healed \\
\hline 45 & $F$ & 84 & Osteoporosis & Alendronic acid & $\begin{array}{c}\text { Tooth } \\
\text { extraction }\end{array}$ & 3 & Sequestrectomy & Failed \\
\hline 46 & $\mathrm{~F}$ & 70 & Osteoporosis & Alendronic acid & $\begin{array}{c}\text { Tooth } \\
\text { extraction }\end{array}$ & 2 & Block resection & Healed \\
\hline 47 & $\mathrm{~F}$ & 80 & $\begin{array}{c}\text { Osteoporosis } \\
\text { (RA) }\end{array}$ & Alendronic acid & $\begin{array}{c}\text { Tooth } \\
\text { extraction }\end{array}$ & 3 & Block resection & Remission \\
\hline 48 & $F$ & 74 & Osteoporosis & Alendronic acid & Spontaneous & 2 & Block resection & Healed \\
\hline 49 & $\mathrm{~F}$ & 87 & Osteoporosis & Alendronic acid & $\begin{array}{c}\text { Tooth } \\
\text { extraction }\end{array}$ & 2 & Block resection & Healed \\
\hline 50 & $\mathrm{~F}$ & 70 & Osteoporosis & $\begin{array}{l}\text { Alendronic acid } \\
+ \text { denosumab }\end{array}$ & $\begin{array}{c}\text { Tooth } \\
\text { extraction }\end{array}$ & 2 & Block resection & Healed \\
\hline 51 & M & 68 & $\begin{array}{c}\text { Prostate } \\
\text { cancer }\end{array}$ & Denosumab & $\begin{array}{c}\text { Apical } \\
\text { periodontitis }\end{array}$ & 2 & Block resection & Healed \\
\hline 52 & $\mathrm{~F}$ & 75 & Osteoporosis & Alendronic acid & $\begin{array}{l}\text { Denture } \\
\text { trauma }\end{array}$ & 2 & Block resection & Healed \\
\hline 53 & $\mathrm{~F}$ & 77 & Osteoporosis & $\begin{array}{l}\text { Alendronic acid } \\
+ \text { denosumab }\end{array}$ & $\begin{array}{l}\text { Tooth } \\
\text { extraction }\end{array}$ & 3 & Block resection & Healed \\
\hline 54 & $M$ & 81 & $\begin{array}{l}\text { Osteoporosis } \\
\text { (RA) }\end{array}$ & Alendronic acid & $\begin{array}{l}\text { Tooth } \\
\text { extraction }\end{array}$ & 3 & Sequestrectomy & Remission \\
\hline 55 & $\mathrm{~F}$ & 76 & $\begin{array}{l}\text { Osteoporosis } \\
\text { (RA) }\end{array}$ & $\begin{array}{c}\text { Risedronic acid } \\
\text { + zoledronic } \\
\text { acid }\end{array}$ & $\begin{array}{c}\text { Marginal } \\
\text { periodontitis }\end{array}$ & 3 & Block resection & Failed \\
\hline
\end{tabular}

Table I. Characteristics of 55 consecutive patients with MRONJ treated with oral or intravenous bisphosphonate or subcutaneously administered denosumab. ( $R A=$ Rheumatoid arthritis). 


\section{Prevalence}

The estimated number of patients on oral bisphosphonates (alendronic acid and risedronic acid) for treatment of osteoporosis, during the period 2012-2015 was around 50000 in Region Skåne. The prevalence of MRONJ for patients on oral bisphosphonates was estimated to be $0.043 \%$.

We estimated that around 700 patients were on intravenous bisphosphonates (zoledronic acid and pamidronic acid) due to metastatic diseases, during the period 2012-2015 in Region Skåne. The prevalence of MRONJ in patients on intravenous bisphosphonates was estimated to be $1.03 \%$.

The estimated numbers of patients on high dose denosumab, due to metastatic diseases during the period 2012-2015 in Region Skåne were around 1700 . The prevalence of MRONJ in patients on denosumab was estimated to be $3.64 \%$.

\section{Underlying disease}

The most common reason for antiresorptive treatment was osteoporosis $(\mathrm{n}=31 ; 56 \%)$, followed by breast cancer $(\mathrm{n}=11 ; 20 \%)$, prostate cancer $(\mathrm{n}=6 ; 11 \%)$, multiple myeloma $(\mathrm{n}=5 ; 9 \%)$, lung carcinoma $(n=1 ; 2 \%)$ and giant cell carcinoma $(n=1 ; 2 \%)$.

There were no significant differences $(\mathrm{p}=0.176)$ in healing in relation to the underlying disease.

\section{Site}

Most lesions were located in the mandible $(\mathrm{n}=41 ; 75 \%)$ with 32 in the posterior part (segment 4 or 6) (one of the cases shown in Fig. 1 ), five in the anterior part and four cases were located in more than one segment of the mandible.

Fourteen lesions were located in the maxilla $(n=14 ; 25 \%), 11$ in the posterior part, two in the anterior part (one of the cases shown in Fig. 2) and one involved more than one segment of the maxilla. 
There was no significant difference $(\mathrm{p}=0.156)$ in healing in relation to the site of the necrosis.

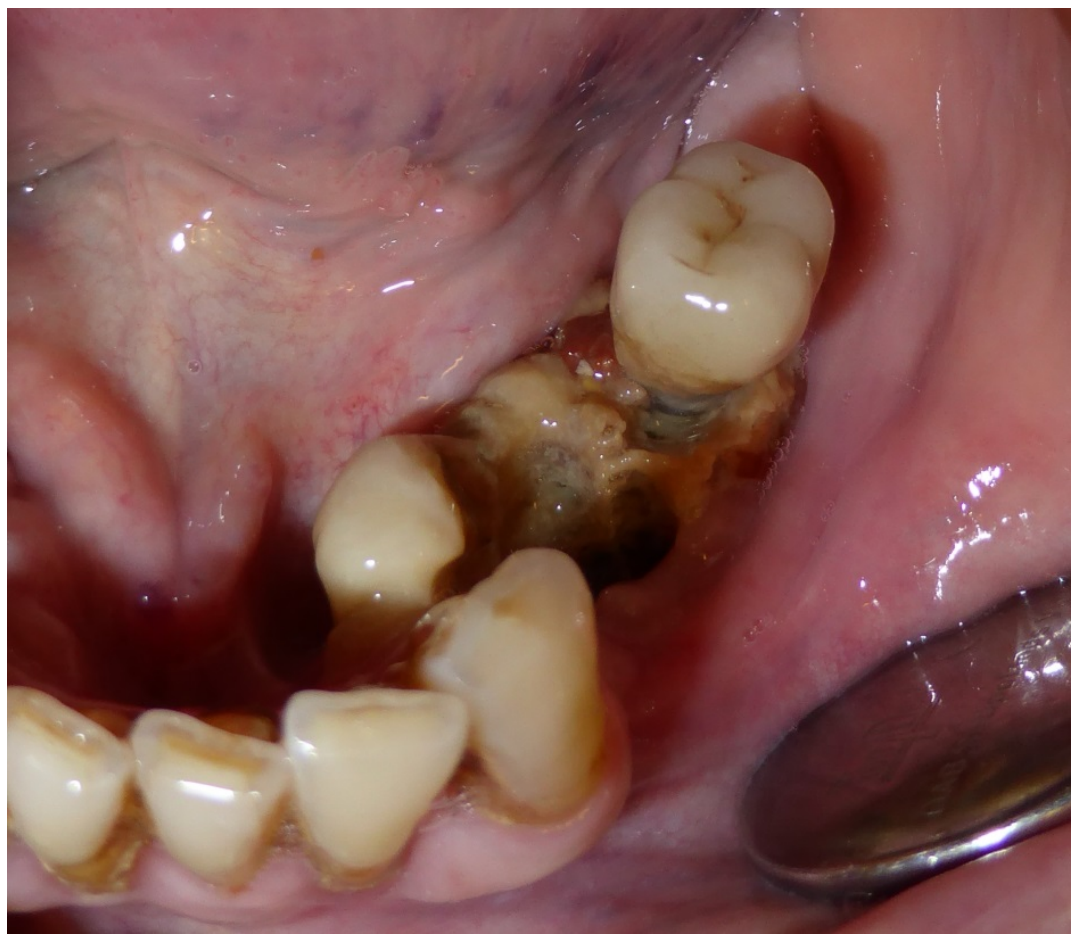

Figure 1. Exposed necrotic bone involving the tori in the mandible in patient $n r 22$. 


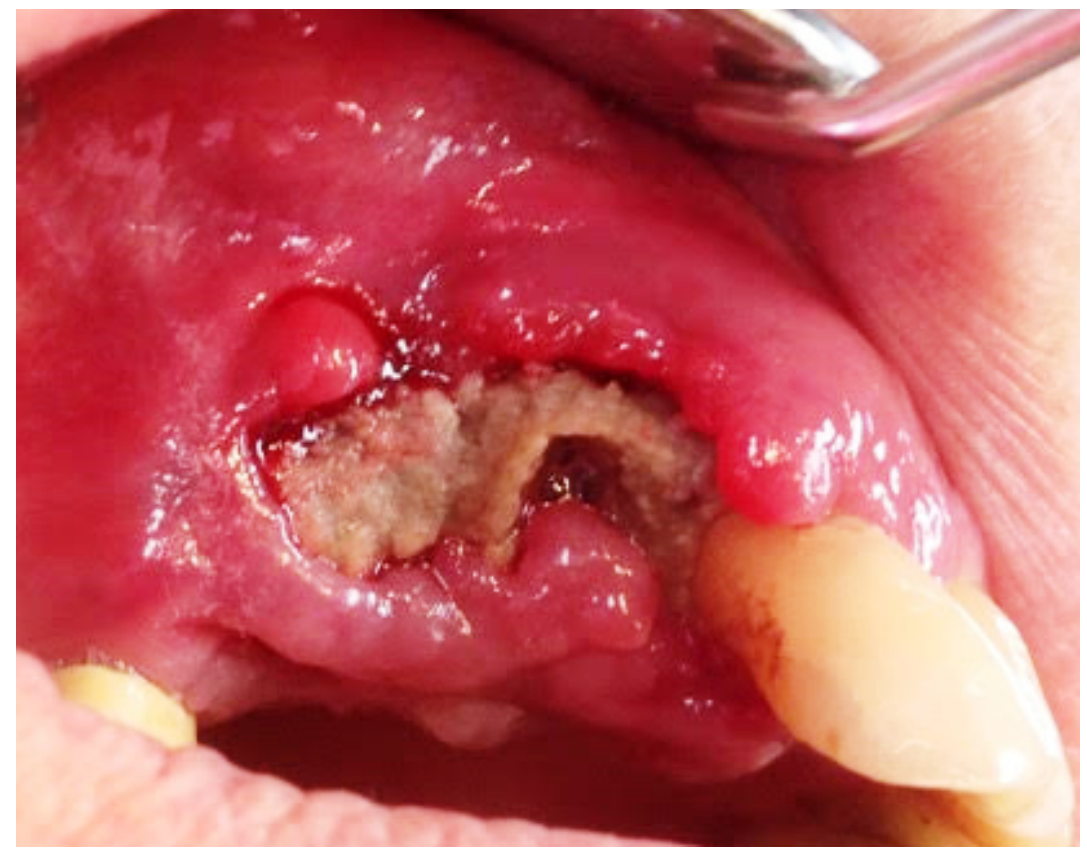

Figure 2. Exposed necrotic bone in the anterior part of the maxilla in patient $n r 23$.

\section{Stage}

Ten patients were classified as Stage 1, 36 patients were classified as Stage 2, and nine patients as Stage 3.

There was no significant difference $(\mathrm{p}=0.067)$ in healing in relation to the stage of the necrosis.

\section{Initiating factor}

The most common initiating factor for development of MRONJ was tooth extraction $(n=39 ; 71 \%)$ followed by marginal periodontitis $(\mathrm{n}=10 ; 18 \%$ ) (one of the cases is shown in Fig. 3), spontaneously (unknown) ( $\mathrm{n}=3 ; 5 \%)$; apical periodontitis $(\mathrm{n}=2 ; 4 \%)$ and as a result of denture trauma $(n=1 ; 2 \%)$. 
There was no significant difference $(\mathrm{p}=0.394)$ in healing in relation to initiating factor.

In 32 out of 39 cases where the initiating factor was tooth extraction it was possible to retrieve intraoral radiographs taken before the extraction from the patient's general dental practitioner. The radiographs were analysed by a specialist in Oral and Maxillofacial Radiology. Twenty-nine (91\%) of the 32 tooth extractions were of teeth with either severe marginal periodontitis (15 patients) or apical periodontitis ( 3 patients) or both diagnoses on the same tooth (11 patients). Together with 10 patients with MRONJ caused by marginal periodontitis and 2 due to apical periodontitis alone as an initiating factor, local periodontal destruction including marginal bone loss adjacent to root surfaces preceded development of MRONJ in a total of 41 patients. 


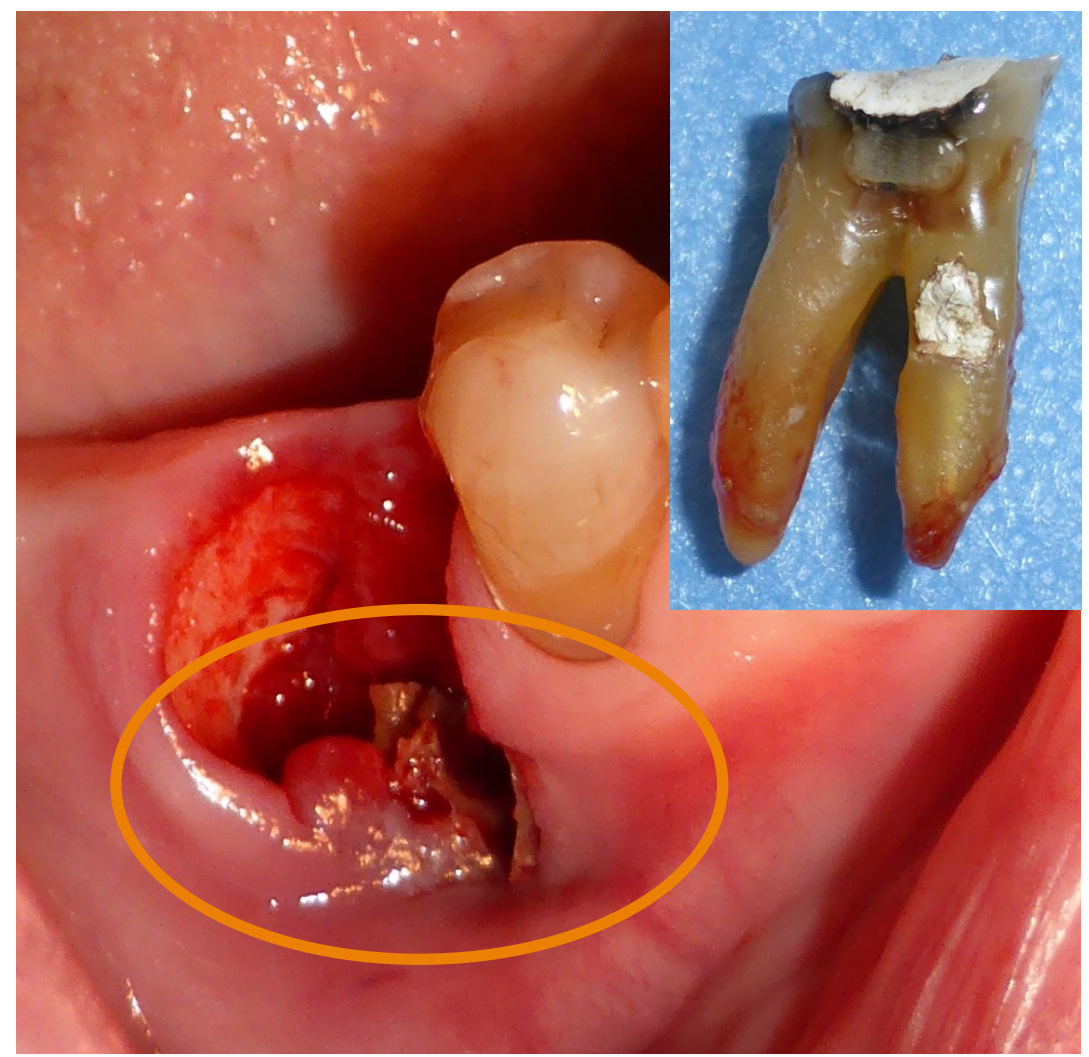

Figure 3. Marginal periodontitis as the initiating factor demonstrating exposed necrotic bone with an established MRONJ lesion at the time of the extraction. 
Surgical treatment

Ten patients were treated with sequestrectomy. Five lesions $(50 \%)$ healed. Three went into remission (two patients with stage 2 and one with stage 3$)$. The overall improvement rate was $8 / 10$ (80.0\%). Mean follow-up time was 13.3 months (range 5-29 months). After healing, no adverse events were recorded. Forty patients were treated with block resection (one of the cases shown in Fig. 4). Thirty-one lesions healed $(77.5 \%)$. Six cases went in remission (four patients with stage 2 and two with stage 3). The overall improvement rate was $37 / 40(92.5 \%)$. Mean follow-up time was 16.7 months (range 2-46 months). After healing, no adverse events were recorded.

There was no significant difference $(\mathrm{p}=0.118)$ in healing in patients treated surgically with block resection or sequestrectomy.

There was no significant difference $(\mathrm{p}=0.094)$ in healing rate between men or women.

Pain intensity

Mean VAS for 10 patients treated with sequestrectomy before treatment was 3.9 and after treatment, 1.0. Mean VAS for 40 patients treated with block resection before treatment was 3.8 and after treatment, 0.2. Mean VAS for six patients in remission before treatment was 3.7 and after treatment, 0.0. 


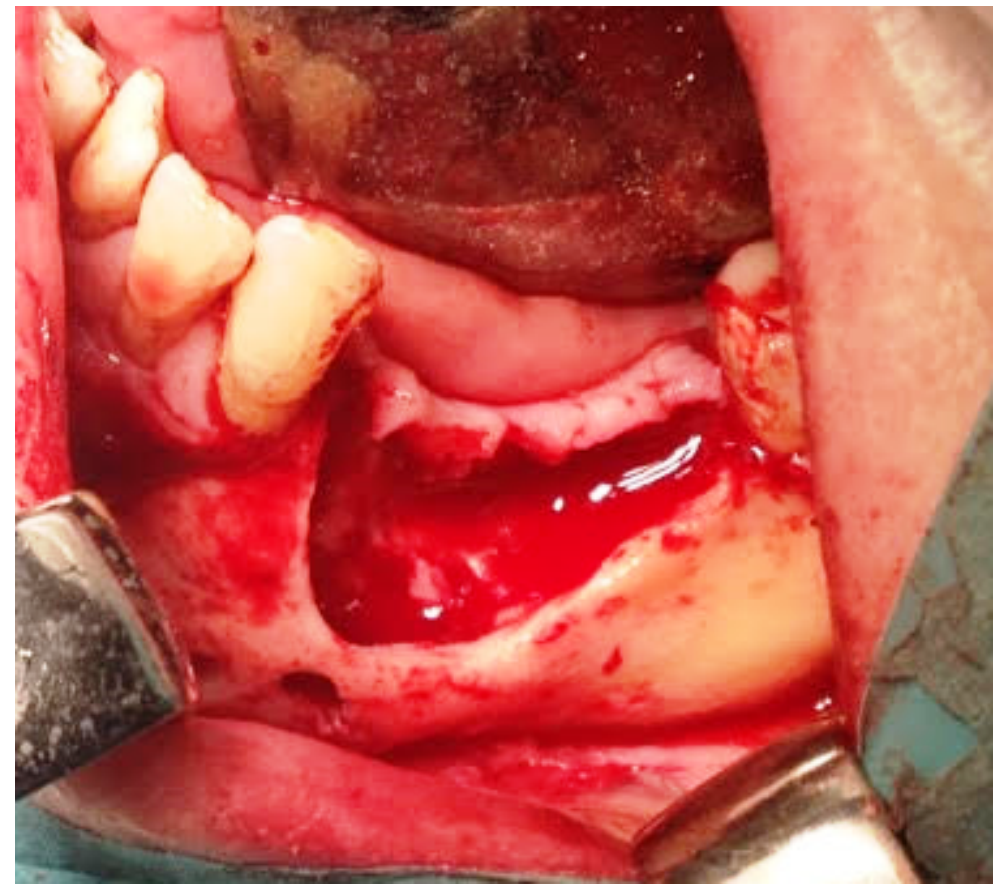

Figure 4. Block resection including smoothening of sharp edges after removal of all necrotic bone. 


\section{Study IV}

Incidence

Sixteen of 242 patients $(6.6 \%)$ developed MRONJ during the study period. Their mean age was 64.6 years (range 41-84). The incidence of MRONJ in patients treated with zoledronic acid was $4.1 \%$, and for patients treated with denosumab it was $13.6 \%$. For patients initially treated with zoledronic acid which subsequently switched to denosumab the incidence was $8.3 \%$ (Table II). The risk of developing MRONJ in patients on denosumab was significantly higher compared with those on zoledronic acid (OR 3.7; 95\% CI 1.3-10.6, $\mathrm{p}=0.011)$. The cumulative incidence of MRONJ is presented in Fig. 5.

\begin{tabular}{lcccc}
\hline \multicolumn{5}{l}{ Table II. Zoledronic acid (Z), Denosumab (D) } \\
\hline $\begin{array}{l}\text { Antiresorptive } \\
\text { Treatment }\end{array}$ & No MRONJ & MRONJ & Total & Incidence \\
Z & 164 & 7 & 171 & $4,1 \%$ \\
D & 51 & 8 & 59 & $13,6 \%$ \\
Z+D & 11 & 1 & 12 & $8,3 \%$ \\
Total & 226 & 16 & 242 & $6,6 \%$ \\
& & & & \\
& & & & \\
\hline
\end{tabular}

Table II. Incidence of MRONJ in women with disseminated breast cancer according to anitresorptive treatment. 


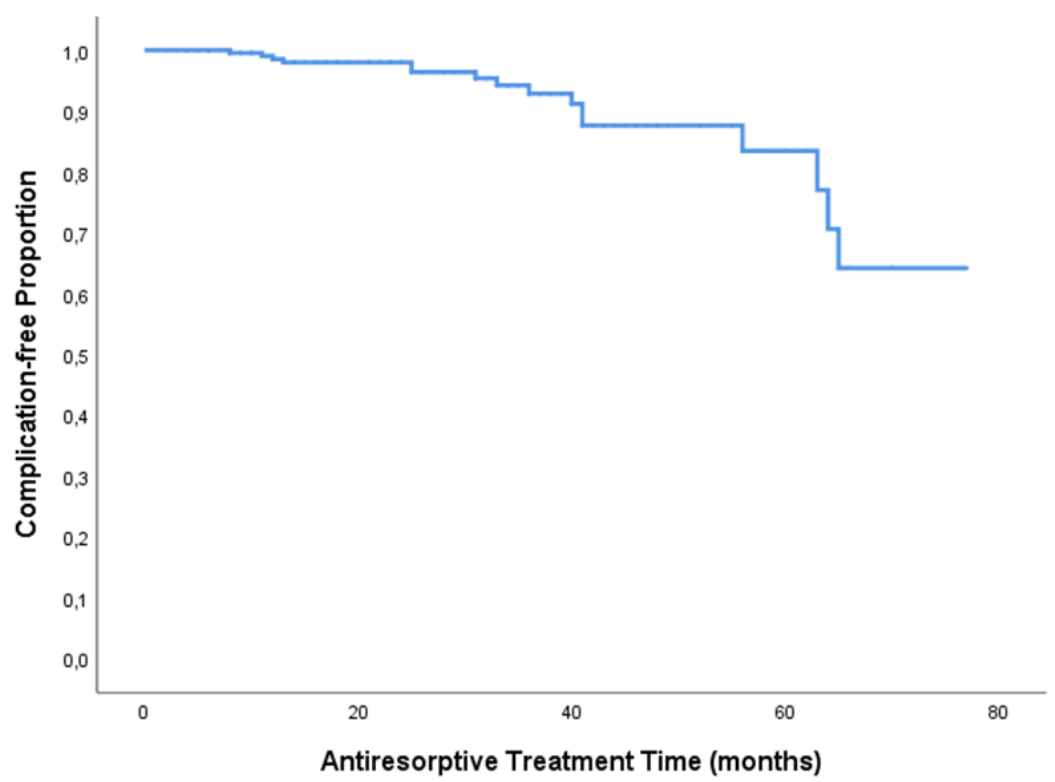

Figure 5. Cumulative incidence of MRONJ in patients on zoledronic acid and/or denosumab with metastatic breast cancer.

\section{Risk factors}

Mean antiresorptive treatment time for all patients was 27.5 months. For patients developing MRONJ the mean treatment time was 35.3 months (range 8-70) and in patients not developing MRONJ 27.0 months (range 2-77). The mean treatment time for zoledronic acid was $26.1 \pm 17.0$ months, $25.4 \pm 16.7$ months for patients not developing MRONJ and 40.9 \pm 18.8 months with MRONJ. The mean treatment time for denosumab was $30.8 \pm 17.5$ months, $31.3 \pm 17.5$ months for patients without development of MRONJ and $27.8 \pm 18.5$ months with MRONJ.

Corticosteroid treatment was administered to 163 of the 242 patients. Of these 163 , six were diagnosed with MRONJ compared to 10 of the 79 not receiving corticosteroids. Corticosteroid use was associated with a significantly decreased risk of MRONJ (OR 0.3 ; 95\% CI 0.1-0.8, $\mathrm{p}=0.008$ ) (Table III). The mean treatment 
time of antiresorptive treatment was $25.1 \pm 17.0$ months with corticosteroid treatment and $31.9 \pm 16.4$ months without corticosteroid treatment.

Chemotherapy was administered to 145 of the 242 patients. Of the 145 patients treated with chemotherapy, 12 were diagnosed with MRONJ compared to four of the 97 not receiving chemotherapy. Chemotherapy was not associated with a significantly increased risk of MRONJ (OR 2.1; 95\% CI 0.7-6.7, p=0.2) (Table III). The mean treatment time of antiresorptive treatment was $26.1 \pm 16.9$ months with chemotherapy and $29.6 \pm 17.6$ months without chemotherapy.

Fourteen of the 242 patients had diabetes mellitus. Of these 14, 3 patients had MRONJ. Diabetes was associated with a significantly increased risk of MRONJ (OR 4.5; 95\% CI 1.1-18.1, p=0.02) (Table III). The mean treatment time of antiresorptive treatment was $20.5 \pm 17.7$ months with diabetes and $28.0 \pm 17.2$ months without diabetes.

Twenty-seven of the 242 patients were regular smokers, 4 out of 16 in the group with MRONJ. Smoking was not associated with a statistically increased risk of MRONJ (OR 2.9; 95\% CI 0.9-9.9, $\mathrm{p}=0.07$ ) (Table III). The mean treatment time of antiresorptive treatment was $30.7 \pm 18.8$ months in smokers and $27.1 \pm 17.1$ months in non-smokers. 
Table III

\begin{tabular}{lrrrrrrr}
\hline Corticosteroids & No MRONJ & MRONJ & Total & $(\%)$ & OR & $95 \% \mathbf{C l}$ & $\boldsymbol{p}$ \\
No treatment & 69 & 10 & 79 & $12,7 \%$ & & & \\
Treatment & 157 & 6 & 163 & $3,7 \%$ & 0.3 & $0.1-0.8$ & 0.008
\end{tabular}

\section{Chemotherapy}

$\begin{array}{lrrrrrrr}\text { No treatment } & 93 & 4 & 97 & 4,1 \% & & & \\ \text { Treatment } & 133 & 12 & 145 & 8,3 \% & 2.1 & 0.7-6.7 & 0.2\end{array}$

$\begin{array}{lrrrrrrr}\text { Diabetes } & & & & & & \\ \text { No } & 215 & 13 & 228 & 5,7 \% & & & \\ \text { Yes } & 11 & 3 & 14 & 21,4 \% & 4.5 & 1.1-18.1 & 0.02\end{array}$

\begin{tabular}{lrrrrrrr|} 
Smoking & & & & & & & \\
\hline No & 203 & 12 & 215 & $5,6 \%$ & & & \\
\hline Yes & 23 & 4 & 27 & $14,8 \%$ & 2.9 & $0.9-9.9$ & 0.07 \\
\hline
\end{tabular}

Table III. Risk factors of MRONJ in women with disseminated breast cancer according to corticosteroid treatment, chemotherapy, diabetes or smoking. 


\section{DISCUSSION}

In Sweden, population registers and cancer registers covering the whole population are available. This makes Sweden particularly suitable for studies with a cohort covering a well-defined region such as Region Skåne. By tradition, Swedes have been positive to participation in clinical and epidemiological studies and no patients refused to participate in our studies. The health care system in Sweden consists of 21 administrative regions. Region Skåne in the south is the third largest, with a population base of approximately 1.3 million people. Four Oral and Maxillofacial Surgery clinics in Skåne (Malmö, Lund, Helsingborg and Kristianstad) are responsible for the treatment of patients with MRONJ. During the entire study period, the author of this thesis was the responsible oral and maxillofacial surgeon for diagnostics, recruitment and treatment of all patients with MRONJ in Skåne.

In study I, III and IV, the incidence, prevalence, initiating factors, risk factors, treatment and treatment outcome of MRONJ in Region Skåne was investigated. In addition, the pathogenesis of MRONJ was investigated (study II).

The prevalence of MRONJ in Region Skåne was studied both retrospectively (study I) and prospectively (study III) and the relatively low prevalence numbers are in accordance with a study from Australia (Mavrokokki et al., 2007). However, other studies show a higher prevalence (Kuhl et al., 2012). The low prevalence numbers in our studies might be explained by a generally good oral health in Sweden with a decreasing number of individuals with marginal 
bone loss and periodontitis since the general dental insurance was introduced in 1973 (Norderyd et al., 2015).

The advantage of a prospective study is that the possibility to include all cases increases. The somewhat higher prevalence of MRONJ in the prospective study supports this hypothesis. Another advantage of a prospective study is that information on systemic risk factors such as medication with chemotherapy or comorbidities such as diabetes and smoking habits can be recorded with greater precision.

It has been speculated that as osteonecrosis caused by bisphosphonates and denosumab almost exclusively appears in the jaws, the process is initiated by an odontogenic infection (Otto et al., 2010). Study II was the first study published on human, showing the connection between oral microbial and the development of MRONJ. In an experimental study from 2011 periodontal disease was induced in rats treated with zoledronic acid. As the bone was exposed to an environment toxic to bone cells, for example the periodontal bacteria from a periodontal disease or oral microbial colonising the extraction socket after tooth extraction, it was hypothesised to result in development of MRONJ (Aghaloo et al., 2011).

All samples in study II taken and analysed from the necrotic bone lesions contained mainly anaerobic bacteria, representative of periodontal microflora. Furthermore, it was shown in study III that a periodontal disease preceded tooth extraction in most cases where later MRONJ developed. These findings support the hypothesis that a periodontal infection in combination with antiresorptive treatment initiates the osteonecrosis (Otto et al., 2010, 2017; Panya et al., 2017) and not the tooth extraction itself. In edentulous jaws, dentures have been reported to cause MRONJ, suggesting that a local trauma ruptures the mucosa and exposes the jawbone to oral bacteria (Khan et al., 2016). It cannot be fully determined if the infection is in fact a primary or secondary event in the pathophysiology of MRONJ, however the role of odontogenic infection seems central. The most likely hypothesis is that the 
MRONJ lesion is initiated by a periodontal disease and starts as an osteomyelitis (Rasmusson \& Abtahi, 2014) starting with a periosteal bone formation, which at a later stage turns necrotic. This hypothesis is further supported by findings were the osteonecrosis was already established at the time of tooth extraction due to a periodontal disease as seen in several cases in study III.

Risk factors for development of MRONJ can be divided into local and systemic risk factors. Local risk factors are often defined as factors that trigger the osteonecrosis such as tooth extraction or periodontal disease (Saad et al., 2012; Vahtsevanos et al., 2009) as well as predisposed anatomical locations where the risk of developing has been reported to be higher in the mandible than in the maxilla (Marx et al., 2005). This is similar to dry socket where the extraction socket after third molar removal in the mandible is predisposed compared to other teeth (Tarakji et al., 2015). These risk factors are in accordance with the findings in study I and study III were tooth extraction was the most common factor triggering MRONJ and local periodontal destruction including marginal bone loss adjacent to root surfaces preceded development of MRONJ in most cases in study III. In both study I and III, 3/4 of the lesions were located in the mandible.

Chemotherapy, corticosteroid treatment, and smoking habits have all been reported as systemic risk factors for MRONJ (Khan et al., 2016; Marx et al., 2005; Otto et al., 2012). Diabetes mellitus have also been correlated with the development of MRONJ (Jarnbring et al., 2015). This is in accordance with our findings in study IV were diabetes was associated with a significantly increased risk of MRONJ. In the study by Jarnbring et al there was no correlation with simultaneous treatment with corticosteroids, or chemotherapy in patients on intravenous bisphosphonates due to multiple myeloma. In our study of patients treated with intravenous bisphosphonates and/or denosumab due to metastatic breast cancer (study IV), the risk for MRONJ in patients on chemotherapy was not significantly increased. However, corticosteroid use was associated with a significantly decreased risk of MRONJ. This is in 
contrast to findings by Saad et al (Saad et al., 2012). Our findings might be explained by a positive anti-inflammatory effect of corticosteroids reducing periodontitis (Chatzopoulos et al., 2018) which in most cases is a strong local risk factor for triggering MRONJ as shown in study I and III. In addition, MRONJ often starts as an osteomyelitis (Rasmusson \& Abtahi, 2014) with periosteal bone formation as seen in stage 0 lesions, probably caused by the inflammatory response to an oral infection such as marginal or apical periodontitis, and might thus be prevented by corticosteroid treatment.

In a study (Kyrgidis et al., 2008), smoking was reported as a risk factor for MRONJ in cancer patients, however not statistically significant. The authors concluded that smoking does not seem to be an independent risk factor. Thumbigere-Math et al showed in a retrospective study that smoking significantly increased the risk of developing MRONJ in cancer patients (Thumbigere-Math et al., 2012). In our study, there was no significant increase in risk. This might be explained by a low number of smoking patients in study IV.

The most important risk factor might be the finding in study IV when comparing what type of antiresorptive drug used and treatment time until development of MRONJ. For zoledronic acid the incidence of MRONJ was $4.1 \%$ and for denosumab $13.6 \%$, resulting in a more than three times as high a risk of MRONJ in patients treated with denosumab compared with zoledronic acid. Patients on denosumab also developed MRONJ already after 28 months while in patients on zoledronic acid the mean time was 41 months. Plausible reasons for the higher incidence and earlier onset of MRONJ in patients treated with denosumab can be differing mechanisms of the medication and effects on the patient. It has been demonstrated that skeletal-related events were delayed longer and reduction in bone turnover was increased with denosumab compared to zoledronic acid (Stopeck et al., 2010). In a study comparing denosumab and zoledronic acid in several cancer types, both bone turnover markers were significantly lower and hy- 
pocalcemia was more common in the denosumab group, which can suggest stronger effect on bone metabolism (Lipton et al., 2012).

According to the latest position paper by the AAOMS published in 2014, conservative treatment, including superficial debridement and systemic antibiotics, is recommended in Stage 1 and 2 lesions while surgical therapy with removal of the bone lesion is only recommended in Stage 3 cases (Ruggiero et al., 2014). In study I, sequestrectomy (local resection) of MRONJ in osteoporotic patients showed healing in a majority of cases regardless of stage $(79.2 \%)$. The most likely explanation for the higher success rate recorded in osteoporotic patients is that they were treated with oral bisphosphonates. In the study group with cancer patients, all patients were treated with intravenous bisphosphonates zoledronic acid, ibandronic acid and pamidronic acid. Intravenous bisphosphonates have higher binding affinity and potency to bone, probably resulting in greater remodelling suppression compared with oral bisphosphonates like alendronatic acid, used in treatment of osteoporosis (Allen \& Burr, 2009). The differences in potency between oral and intravenous bisphosphonates probably explain the differences in treatment outcome between patients with osteoporosis and patients with cancer in this study. The treatment protocol in study I was mainly based on the recommendations from AAOMS position paper 2007 ("American Association of Oral and Maxillofacial Surgeons position paper on bisphosphonate-related osteonecrosis of the jaws.," 2007) and an earlier publication promoting a conservative approach (Ruggiero et al., 2006). This probably explains the low success rate in treatment outcome in cancer patients $(25.8 \%)$. All successful cases in study I were treated with a combination of sequestrectomy (local resection) and systemic antibiotics, except one case treated with antibiotics alone, and one case treated with local resection only.

In study III, 50 patients were eligible for surgical treatment and possible to evaluate healing at a minimum of two months after surgery. In 10 patients, treated with sequestrectomy (local resection) healing occurred in $5(50 \%)$ and in 40 patients treated with 
block resection, 31 patients healed $(77.5 \%)$. Our success rate for patients treated with block surgery is in accordance with other studies (Aljohani et al., 2018; Pichardo \& van Merkesteyn, 2016; Stockmann et al., 2014; Williamson, 2010). The results are further strengthened by Favia et al who in a recent publication concluded that MRONJ occurring both in neoplastic and non- neoplastic patients benefits more from a surgical treatment approach, whenever deemed possible, as non- surgical treatments do not seem to allow complete healing of the lesions (Favia et al., 2018). In study III, surgical treatment of MRONJ in osteoporotic patients showed healing in a majority of cases, 23 of $29(79.3 \%)$, similar to study I but in contrast to cancer patients where 13 of 21 (61.9\%) healed in study III compared to only $25.8 \%$ in study I. In study II, a migration of bacteria from the macroscopic necrotic bone into the visual healthy bone was seen. A more radical approach undertaken with block resection in study III with removal of more bone adjacent to the obvious necrotic lesion probably added to the more successful treatment outcome. Even higher success rates might have been obtained in study III if a drug holiday (6-12 months) had been advocated before the surgical treatment in patients on denosumab, (Damm \& Jones, 2013) and (Ohga et al., 2018).

When obtaining success rates in surgical treatment of MRONJ lesions in both cancer patients and osteoporotic patients as high as those in study III and similar studies (Aljohani et al., 2018; Pichardo \& van Merkesteyn, 2016; Stockmann et al., 2014; Williamson, 2010), much depends on the surgeon's skill and expertise (Ristow et al., 2015). A major challenge of surgical treatment is to distinguish the demarcation between viable and necrotic bone so that a minimum amount of bone is removed. This is important both to facilitate healing and to maximise the chances of dental or prosthetic rehabilitation (Ristow et al., 2015).

In most publications, the treatment goal for MRONJ healing is defined as no signs of exposed necrotic bone after treatment and complete mucosal coverage (Otto et al., 2016). In study III, $72 \%$ of the lesions healed completely. However, for the patients, especially 
those with metastatic disease, palliation as a treatment goal is probably sufficient. In our study, another six $(11 \%)$ patients went into remission without subjective symptoms (VAS=0) but with some remaining exposed bone, after block resection in combination with oral antibiotics. These patients were not willing to undergo additional surgery, suggesting that they had been successfully treated and now being classified as stage 1 instead of stage 2 or 3 as they had been before treatment.

The incidence and prevalence for MRONJ in patients on bisphosphonates seems reasonable compared with other studies. However, a new striking finding not previously reported is the more than 3 times higher risk of MRONJ in patients treated with denosumab compared with zoledronic acid.

The results in study II and III suggest that if teeth with severe periodontal disease are treated and oral health is optimised before antiresorptive treatment commences, this might prevent the development of MRONJ in most cases. Furthermore, the results suggest that the same prophylactic dental decision protocol used for patients intended to receive radiation of the jaws due to head and neck cancer (Bruins et al., 1999) could be considered in patients scheduled for bisphosphonates or denosumab treatment. Teeth with severe periodontal disease should be removed before antiresorptive treatment.

In the patients who developed MRONJ, surgical intervention seems to be the most beneficial treatment strategy provided it is performed by an oral and maxillofacial surgeon experienced at handling MRONJ. The treatment should be a combination treatment with a multidisciplinary approach and the patient's dentist, primary care physician or oncologist should be involved in the treatment process. 


\section{CONCLUSIONS}

- The prevalence of MRONJ in patients with osteoporosis on oral bisphosphonates is $<0.05 \%$, in patients with a malignant disease on intravenous bisphosphonates $<3.0 \%$ and on high dose denosumab $<4.0 \%$.

- In most cases a periodontal disease initiates the development of MRONJ.

- The most common location for MRONJ was the posterior part of the mandible.

- The necrotic bone lesions contain mainly anaerobic bacteria, representative of periodontal microflora.

- Block resection shows a higher success rate compared to sequestrectomy and demonstrates healing in both patients with osteoporosis and with malignant disease.

- Diabetes increases the risk for MRONJ.

- Corticosteroid treatment decreases the risk of MRONJ.

- The incidence of MRONJ in patients with metastatic breast cancer treated with zoledronic acid was $4.1 \%$ and denosumab $13.6 \%$. 


\section{FUTURE RESEARCH}

As cases of MRONJ recently have been reported to be associated with new antiangiogenic drugs, such as the tyrosine kinase inhibitors suntinib and everolimus or the monoclonal antibody bevacizumab, in the treatment of cancer forms such as renal cell carcinoma, lung cancer, breast cancer and glioblastoma multiforma, there is a need for further studies to determine risk factors and incidence of MRONJ (Abel Mahedi Mohamed el al., 2018; Yamamoto et al., 2017).

Furthermore, there are reports of cases of osteonecrosis of the jaw caused by a self-produced drug called "Krokodil" in former heroin abusers (Poghosyan et al., 2014). These cases resemble the cases of phossy jaws seen over 100 years ago in match factories caused by white phosphorus (Marx, 2008; Miles, 1972). Ironically, the drug contains red phosphorus from matchboxes. The red phosphorus is mixed with codeine containing analgesics and other easily acquired chemical components used for synthesis of this drug. The drug is used intravenously. Today, most reports are from former USSR countries (Hakobyan \& Poghosyan, 2017; Poghosyan et al., 2014) but the risk of this drug spreading to other countries highlights the demand for more research and awareness of the risk of osteonecrosis of the jaw caused by "Krokodil".

Finally, in recent case reports (Otto et al., 2018) and (Hallmer et al., 2018), the beneficial effects of denosumab in the treatment of a rare condition, Diffuse sclerosing osteomyelitis of the mandible, 
has been highlighted. Denosumab in a single treatment resulted in remarkable pain relief. Further studies, with a control group and long-time follow up is needed. 


\section{POPULÄRVETENSKAPLIG SAMMANFATTNING}

Bisfosfonater och denosumab är benresorptionshämmande läkemedel. De används för att hämma den bennedbrytning som ökar risken för frakturer hos patienter med osteoporos eller skelettmetastaserande cancer.

En allvarlig komplikation vid behandling med benresorptionshämmande läkemedel är en särskild typ av käkbensnekros, Medication-Related Osteonecrosis of the Jaws (MRONJ). Inga andra ben i kroppen utvecklar nekros i samband med behandling med dessa preparat. MRONJ är ett smärtfullt tillstånd som karakteriseras av blottlagt och ofta infekterat käkben. Dessa käkbensnekroser påminner om de fall av "fosforkäke" som sågs hos tändsticksarbetare för ca 100 år orsakade av vit fosfor.

Avhandlingens syfte var att undersöka orsaken till MRONJ, hur vanligt tillståndet är, vilka riskfaktorer som finns, om all benresorptionshämmande läkemedel medför lika stor risk samt vilken behandling som ger bäst resultat.

Delarbete I var en retrospektiv studie som omfattade de patienter som diagnostiserats och behandlats för MRONJ under 2003-2010 vid de käkkirurgiska klinikerna i Skåne. Tillståndet var vanligast $\mathrm{i}$ underkäken och hade i de flest fall uppkommit i samband med tanduttagning.

Den typ av bisfosfonater som gavs intravenöst för att förebygga fraktur till följd av cancermetastas i skelettet orsakade högre andel 
MRONJ (2,8\%) än de bisfosfonater som gavs i tablettform till patienter med osteoporos $(0,024 \%)$.

Efter behandling av MRONJ var fullständig utläkning vanligare hos patienter med bisfosfonater i tablettform än hos patienter som behandlats med bisfosfonater intravenöst.

I delarbete II togs bakterieprov från käkbenet hos patienter med MRONJ. I bennekroserna påträffades anaeroba bakterier av samma typ som de som brukar förekomma vid tandlossningssjukdom. Detta tyder på att bakterier från tandköttsfickan kan utgöra en initierande faktor vid uppkomsten av MRONJ. Delarbete II är den första publikationen som visade sambandet mellan den orala mikrofloran och MRONJ.

Delarbete III var en prospektivt studie där alla nydiagnostiserade patienter med MRONJ i Skåne under 2012-2015 inkluderades. Studien visade att MRONJ i flesta fall orsakades av tandlossningssjukdom. Hos patienter som behandlades med benresorptionshämmande läkemedel pga skelettmetastaserande cancer var MRONJ vanligast hos patienter med högdos denosumab (3,64\%), följt av patienter som fick bisfosfonater i högdos intravenöst $(1,03 \%)$. Hos patienter som behandlats med bisfosfonater i låg dos i tablettform pga osteoporos var MRONJ ovanligt $(0,043 \%)$. Behandling av MRONJ visade ökad chans för läkning hos patienter behandlade kirurgiskt med lådresektion.

Delarbete IV var en prospektiv studie som omfattade alla patienter med skelettmetastaserande bröstcancer i Skåne som behandlats med benresorptionshämmande läkemedel under åren 2012-2015. MRONJ var vanligare vid behandling med denosumab i hög dos $(13,6 \%)$ än vid behandling med bisfosfonater intravenöst i hög dos $(4,1 \%)$. Diabetes ökade risken för MRONJ och behandling med kortison minskade risken. 


\section{ACKNOWLEDGEMENTS}

Many persons have contributed and inspired this thesis along the way. I would like to express my warmest thanks to my family, friends and colleagues, especially;

Bengt Götrick, my supervisor. Thank you for all the help in writing and our valuable discussions in finalising this thesis.

Gunilla Andersson, my co-supervisor. I cannot thank you enough for all the invaluable help throughout the years in this process of becoming a researcher. You have inspired, guided and encouraged me, during the work of this thesis.

Tore Bjørnland, my co-supervisor, for all scientific input, help in writing and for always being available for discussions and for the hospitably when visiting Oslo.

Per Malmström, Olöf Bjarnadottir, Morten Enersen, Anne Karin Kristoffersen, Jonas Anderud, Gunnar Warfvinge, Jonas Becktor and Anders Nicklasson, my co-authors. Many thanks for all the help in analysing, writing and preparing the manuscripts.

All the staff at the Departments of Oral and Maxillofacial Surgery and the Departments of Oncology in Region Skåne.

Per-Erik Isberg, for all the help with statistics. 
Mikael Korduner, for encouraging me in this project, now the skrank is reached.

Martin Lindström, for technical support.

Christina Stenervik, for excellent secretarial assistance.

Cecilia Hallström, for revision of the English text.

David Reinedahl, for valuable discussions.

Finally, I would like to thank my family, Catrin and Hedvig and my mother and father for all the support. 


\section{REFERENCES}

Abel Mahedi Mohamed, H., Nielsen, C. E. N., \& Schiodt, M. (2018). Medication related osteonecrosis of the jaws associated with targeted therapy as monotherapy and in combination with antiresorptives. A report of 7 cases from the Copenhagen Cohort. Oral Surgery, Oral Medicine, Oral Pathology and Oral Radiology, 125(2), 157-163. http://doi.org/10.1016/j.oooo.2017.10.010

Abu-Id, M. H., Warnke, P. H., Gottschalk, J., Springer, I., Wiltfang, J., Acil, Y., ... Kreusch, T. (2008). "Bis-phossy jaws" - high and low risk factors for bisphosphonate-induced osteonecrosis of the jaw. Journal of CranioMaxillo-Facial Surgery : Official Publication of the European Association for Cranio-Maxillo-Facial Surgery, 36(2), 95-103. http://doi.org/10.1016/j.jcms.2007.06.008

Aghaloo, T. L., Kang, B., Sung, E. C., Shoff, M., Ronconi, M., Gotcher, J. E., ... Tetradis, S. (2011). Periodontal disease and bisphosphonates induce osteonecrosis of the jaws in the rat. Journal of Bone and Mineral Research : The Official Journal of the American Society for Bone and Mineral Research, 26(8), 1871-1882. http://doi.org/10.1002/jbmr.379

Aljohani, S., Troeltzsch, M., Hafner, S., Kaeppler, G., Mast, G., \& Otto, S. (2018). Surgical treatment of medication-related osteonecrosis of the upper jaw: Case series. Oral Diseases. http://doi.org/10.1111/odi.12992

Allen, M. R., \& Burr, D. B. (2008). Mandible matrix necrosis in beagle dogs after 3 years of daily oral bisphosphonate treatment. Journal of Oral and Maxillofacial Surgery : Official Journal of the American Association of Oral and Maxillofacial Surgeons, 66(5), 987-994. http://doi.org/10.1016/j.joms.2008.01.038 
Allen, M. R., \& Burr, D. B. (2009). The pathogenesis of bisphosphonaterelated osteonecrosis of the jaw: so many hypotheses, so few data. Journal of Oral and Maxillofacial Surgery : Official Journal of the American Association of Oral and Maxillofacial Surgeons, 67(5 Suppl), 61-70. http://doi.org/10.1016/j.joms.2009.01.007

Allen, M. R., \& Burr, D. B. (2011). Bisphosphonate effects on bone turnover, microdamage, and mechanical properties: what we think we know and what we know that we don't know. Bone, 49(1), 56-65. http://doi.org/10.1016/j.bone.2010.10.159

American Association of Oral and Maxillofacial Surgeons position paper on bisphosphonate-related osteonecrosis of the jaws. (2007). Journal of Oral and Maxillofacial Surgery : Official Journal of the American Association of Oral and Maxillofacial Surgeons, 65(3), 369-376. http://doi.org/10.1016/j.joms.2006.11.003

Awasthi, H., Mani, D., Singh, D., \& Gupta, A. (2018). The underlying pathophysiology and therapeutic approaches for osteoporosis. Medicinal Research Reviews, 38(6), 2024-2057. http://doi.org/10.1002/med.21504

Badros, A., Weikel, D., Salama, A., Goloubeva, O., Schneider, A., Rapoport, A., ... Meiller, T. (2006). Osteonecrosis of the jaw in multiple myeloma patients: clinical features and risk factors. Journal of Clinical Oncology : Official Journal of the American Society of Clinical Oncology, 24(6), 945-952. http://doi.org/10.1200/JCO.2005.04.2465

Baker, G. C., Smith, J. J., \& Cowan, D. A. (2003). Review and re-analysis of domain-specific $16 \mathrm{~S}$ primers. Journal of Microbiological Methods, 55(3), 541-555. http://doi.org/10.1016/j.mimet.2003.08.009

Bedogni, A., Saia, G., Bettini, G., Tronchet, A., Totola, A., Bedogni, G., ... Blandamura, S. (2011). Long-term outcomes of surgical resection of the jaws in cancer patients with bisphosphonate-related osteonecrosis. Oral Oncology, 47(5), 420-424. http://doi.org/10.1016/j.oraloncology.2011.02.024

Berenson, J. R., Rosen, L. S., Howell, A., Porter, L., Coleman, R. E., Morley, W., ... Seaman, J. J. (2001). Zoledronic acid reduces skeletal-related events in patients with osteolytic metastases. Cancer, 91(7), 1191-1200.

Black, D. M., \& Rosen, C. J. (2016). Clinical Practice. Postmenopausal Osteoporosis. The New England Journal of Medicine, 374(3), 254-262. http://doi.org/10.1056/NEJMcp1513724

Body, J. J. (1997). Clinical research update: zoledronate. Cancer, 80(8 Suppl), 1699-1701. 
Body, J. J., Bartl, R., Burckhardt, P., Delmas, P. D., Diel, I. J., Fleisch, H., ... Rubens, R. D. (1998). Current use of bisphosphonates in oncology. International Bone and Cancer Study Group. Journal of Clinical Oncology : Official Journal of the American Society of Clinical Oncology, 16(12), 38903899. http://doi.org/10.1200/JCO.1998.16.12.3890

Boissier, S., Ferreras, M., Peyruchaud, O., Magnetto, S., Ebetino, F. H., Colombel, M., ... Clezardin, P. (2000). Bisphosphonates inhibit breast and prostate carcinoma cell invasion, an early event in the formation of bone metastases. Cancer Research, 60(11), 2949-2954.

Boonyapakorn, T., Schirmer, I., Reichart, P. A., Sturm, I., \& Massenkeil, G. (2008). Bisphosphonate-induced osteonecrosis of the jaws: prospective study of 80 patients with multiple myeloma and other malignancies. Oral Oncology, 44(9), 857-869. http://doi.org/10.1016/j.oraloncology.2007.11.012

Boyle, W. J., Simonet, W. S., \& Lacey, D. L. (2003). Osteoclast differentiation and activation. Nature, 423(6937), 337-342. http://doi.org/10.1038/nature01658

Bruins, H. H., Jolly, D. E., \& Koole, R. (1999). Preradiation dental extraction decisions in patients with head and neck cancer. Oral Surgery, Oral Medicine, Oral Pathology, Oral Radiology, and Endodontics, 88(4), 406-12. Retrieved from http://www.ncbi.nlm.nih.gov/pubmed/10519746

Buckley, L., Guyatt, G., Fink, H. A., Cannon, M., Grossman, J., Hansen, K. E., ... McAlindon, T. (2017). 2017 American College of Rheumatology Guideline for the Prevention and Treatment of Glucocorticoid-Induced Osteoporosis. Arthritis \& Rheumatology (Hoboken, N.J.), 69(8), 1521-1537. http://doi.org/10.1002/art.40137

Cartsos, V. M., Zhu, S., \& Zavras, A. I. (2008). Bisphosphonate use and the risk of adverse jaw outcomes: a medical claims study of 714,217 people. Journal of the American Dental Association (1939), 139(1), 23-30.

Chatzopoulos, G. S., Cisneros, A., Sanchez, M., \& Wolff, L. F. (2018). Systemic medical conditions and periodontal status in older individuals. Special Care in Dentistry : Official Publication of the American Association of Hospital Dentists, the Academy of Dentistry for the Handicapped, and the American Society for Geriatric Dentistry, 38(6), 373-381. http://doi.org/10.1111/scd.12319

Chen, Q., Hu, C., Liu, Y., Song, R., Zhu, W., Zhao, H., ... Liu, Y. (2018). Pharmacokinetics, pharmacodynamics, safety, and tolerability of singledose denosumab in healthy Chinese volunteers: A randomized, single-blind, placebo-controlled study. PloS One, 13(6), e0197984. http://doi.org/10.1371/journal.pone.0197984 
Chiandussi, S., Biasotto, M., Dore, F., Cavalli, F., Cova, M. A., \& Di Lenarda, R. (2006). Clinical and diagnostic imaging of bisphosphonateassociated osteonecrosis of the jaws. Dento Maxillo Facial Radiology, 35(4), 236-243. http://doi.org/10.1259/dmfr/27458726

Cleeland, C. S., Body, J.-J., Stopeck, A., von Moos, R., Fallowfield, L., Mathias, S. D., ... Chung, K. (2013). Pain outcomes in patients with advanced breast cancer and bone metastases: results from a randomized, double-blind study of denosumab and zoledronic acid. Cancer, 119(4), 832-8. http://doi.org/10.1002/cncr.27789

Cummings, S. R., Black, D. M., Thompson, D. E., Applegate, W. B., BarrettConnor, E., Musliner, T. A., ... LaCroix, A. Z. (1998). Effect of alendronate on risk of fracture in women with low bone density but without vertebral fractures: results from the Fracture Intervention Trial. JAMA, 280(24), 2077-2082.

Cummings, S. R., Martin, J. S., McClung, M. R., Siris, E. S., Eastell, R., Reid, I. R., ... Christiansen, C. (2009). Denosumab for Prevention of Fractures in Postmenopausal Women with Osteoporosis. Retrieved from http://www.nejm.org/doi/full/10.1056/NEJMoa0809493

Daley-Yates, P. T., Dodwell, D. J., Pongchaidecha, M., Coleman, R. E., \& Howell, A. (1991). The clearance and bioavailability of pamidronate in patients with breast cancer and bone metastases. Calcified Tissue International, 49(6), 433-435.

Damm, D. D., \& Jones, D. M. (2013). Bisphosphonate-related osteonecrosis of the jaws: a potential alternative to drug holidays. General Dentistry, 61(5), 33-38.

DeSantis, C. E., Lin, C. C., Mariotto, A. B., Siegel, R. L., Stein, K. D., Kramer, J. L., ... Jemal, A. (2014). Cancer treatment and survivorship statistics, 2014. CA: A Cancer Journal for Clinicians, 64(4), 252-271. http://doi.org/10.3322/caac. 21235

Dimopoulos, M. A., Kastritis, E., Anagnostopoulos, A., Melakopoulos, I., Gika, D., Moulopoulos, L. A., ... Bamias, A. (2006). Osteonecrosis of the jaw in patients with multiple myeloma treated with bisphosphonates: evidence of increased risk after treatment with zoledronic acid. Haematologica, 91(7), 968-971.

Drake, M. T., Clarke, B. L., \& Khosla, S. (2008). Bisphosphonates: mechanism of action and role in clinical practice. Mayo Clinic Proceedings, 83(9), 1032-1045. http://doi.org/10.4065/83.9.1032

Durie, B. G. M., Katz, M., \& Crowley, J. (2005, July). Osteonecrosis of the jaw and bisphosphonates. The New England Journal of Medicine. United States. http://doi.org/10.1056/NEJM200507073530120 
Engelhardt, M., Terpos, E., Kleber, M., Gay, F., Wasch, R., Morgan, G., ... Palumbo, A. (2014). European Myeloma Network recommendations on the evaluation and treatment of newly diagnosed patients with multiple myeloma. Haematologica, 99(2), 232-242. http://doi.org/10.3324/haematol.2013.099358

Estilo, C. L., Van Poznak, C. H., Wiliams, T., Bohle, G. C., Lwin, P. T., Zhou, Q., ... Huryn, J. M. (2008). Osteonecrosis of the maxilla and mandible in patients with advanced cancer treated with bisphosphonate therapy. The Oncologist, 13(8), 911-920.

http://doi.org/10.1634/theoncologist.2008-0091

Farrugia, M. C., Summerlin, D.-J., Krowiak, E., Huntley, T., Freeman, S., Borrowdale, R., \& Tomich, C. (2006). Osteonecrosis of the mandible or maxilla associated with the use of new generation bisphosphonates. The Laryngoscope, 116(1), 115-120. http://doi.org/10.1097/01.mlg.0000187398.51857.3c

Favia, G., Tempesta, A., Limongelli, L., Crincoli, V., \& Maiorano, E. (2018). Medication-related osteonecrosis of the jaw: Surgical or non-surgical treatment? Oral Diseases, 24(1-2), 238-242. http://doi.org/10.1111/odi.12764

Ferlay, J., Soerjomataram, I., Dikshit, R., Eser, S., Mathers, C., Rebelo, M., ... Bray, F. (2015). Cancer incidence and mortality worldwide: sources, methods and major patterns in GLOBOCAN 2012. International Journal of Cancer, 136(5), E359-86. http://doi.org/10.1002/ijc.29210

Gertz, B. J., Holland, S. D., Kline, W. F., Matuszewski, B. K., Freeman, A., Quan, H., ... Porras, A. G. (1995). Studies of the oral bioavailability of alendronate. Clinical Pharmacology and Therapeutics, 58(3), 288-298. http://doi.org/10.1016/0009-9236(95)90245-7

Gilbert, S. M., Olsson, C. A., Benson, M. C., \& McKiernan, J. M. (2003). The role of intravenous zoledronic acid in the management of high-risk prostate cancer. Current Opinion in Urology, 13(2), 133-135. http://doi.org/10.1097/01.mou.0000058629.64616.cb

Hakobyan, K., \& Poghosyan, Y. (2017). Spontaneous bone formation after mandible segmental resection in "krokodil" drug-related jaw osteonecrosis patient: case report. Oral and Maxillofacial Surgery, 21(2), 267-270. http://doi.org/10.1007/s10006-017-0613-6

Hallmer, F., Korduner, M., Moystad, A., \& Bjornland, T. (2018). Treatment of diffuse sclerosing osteomyelitis of the jaw with denosumab shows remarkable results-A report of two cases. Clinical Case Reports, 6(12), 24342437. http://doi.org/10.1002/ccr3.1894 
Hoff, A. O., Toth, B. B., Altundag, K., Johnson, M. M., Warneke, C. L., Hu, M., ... Hortobagyi, G. N. (2008). Frequency and risk factors associated with osteonecrosis of the jaw in cancer patients treated with intravenous bisphosphonates. Journal of Bone and Mineral Research : The Official Journal of the American Society for Bone and Mineral Research, 23(6), 826-836. http://doi.org/10.1359/jbmr.080205

Hughes, D. E., Wright, K. R., Uy, H. L., Sasaki, A., Yoneda, T., Roodman, G. D., ... Boyce, B. F. (1995). Bisphosphonates promote apoptosis in murine osteoclasts in vitro and in vivo. Journal of Bone and Mineral Research : The Official Journal of the American Society for Bone and Mineral Research, 10(10), 1478-1487. http://doi.org/10.1002/jbmr.5650101008

Iranikhah, M., Deas, C., Murphy, P., \& Freeman, M. K. (2018). Effects of Denosumab After Treatment Discontinuation : A Review of the Literature. The Consultant Pharmacist : The Journal of the American Society of Consultant Pharmacists, 33(3), 142-151.

http://doi.org/10.4140/TCP.n.2018.142

Jacques, R. M., Boonen, S., Cosman, F., Reid, I. R., Bauer, D. C., Black, D. M., \& Eastell, R. (2012). Relationship of changes in total hip bone mineral density to vertebral and nonvertebral fracture risk in women with postmenopausal osteoporosis treated with once-yearly zoledronic acid $5 \mathrm{mg}$ : the HORIZON-Pivotal Fracture Trial (PFT). Journal of Bone and Mineral Research : The Official Journal of the American Society for Bone and Mineral Research, 27(8), 1627-1634. http://doi.org/10.1002/jbmr.1644

Janjan, N. A., Payne, R., Gillis, T., Podoloff, D., Libshitz, H. I., Lenzi, R., ... Yasko, A. (1998). Presenting symptoms in patients referred to a multidisciplinary clinic for bone metastases. Journal of Pain and Symptom Management, 16(3), 171-178.

Jarnbring, F., Kashani, A., Bjork, A., Hoffman, T., Krawiec, K., Ljungman, P., $\&$ Lund, B. (2015). Role of intravenous dosage regimens of bisphosphonates in relation to other aetiological factors in the development of osteonecrosis of the jaws in patients with myeloma. The British Journal of Oral \& Maxillofacial Surgery, 53(10), 1007-1011. http://doi.org/10.1016/j.bjoms.2015.10.006

Khamaisi, M., Regev, E., Yarom, N., Avni, B., Leitersdorf, E., Raz, I., \& Elad, S. (2007). Possible association between diabetes and bisphosphonaterelated jaw osteonecrosis. The Journal of Clinical Endocrinology and Metabolism, 92(3), 1172-1175. http://doi.org/10.1210/jc.2006-2036 
Khan, A., Morrison, A., Cheung, A., Hashem, W., \& Compston, J. (2016).

Osteonecrosis of the jaw (ONJ): diagnosis and management in 2015. Osteoporosis International : A Journal Established as Result of Cooperation between the European Foundation for Osteoporosis and the National Osteoporosis Foundation of the USA, 27(3), 853-859. http://doi.org/10.1007/s00198-015-3335-3

Kuhl, S., Walter, C., Acham, S., Pfeffer, R., \& Lambrecht, J. T. (2012). Bisphosphonate-related osteonecrosis of the jaws--a review. Oral Oncology, 48(10), 938-947. http://doi.org/10.1016/j.oraloncology.2012.03.028

Kyrgidis, A., Vahtsevanos, K., Koloutsos, G., Andreadis, C., Boukovinas, I., Teleioudis, Z., ... Triaridis, S. (2008). Bisphosphonate-related osteonecrosis of the jaws: a case-control study of risk factors in breast cancer patients. Journal of Clinical Oncology : Official Journal of the American Society of Clinical Oncology, 26(28), 4634-4638. http://doi.org/10.1200/JCO.2008.16.2768

Lane, N. E., \& Lukert, B. (1998). The science and therapy of glucocorticoidinduced bone loss. Endocrinology and Metabolism Clinics of North America, 27(2), 465-483.

Lasseter, K. C., Porras, A. G., Denker, A., Santhanagopal, A., \& Daifotis, A. (2005). Pharmacokinetic considerations in determining the terminal elimination half-lives of bisphosphonates. Clinical Drug Investigation, 25(2), 107-114. http://doi.org/10.2165/00044011-200525020-00003

Lazarovici, T. S., Yahalom, R., Taicher, S., Elad, S., Hardan, I., \& Yarom, N. (2009). Bisphosphonate-related osteonecrosis of the jaws: a single-center study of 101 patients. Journal of Oral and Maxillofacial Surgery : Official Journal of the American Association of Oral and Maxillofacial Surgeons, 67(4), 850-855. http://doi.org/10.1016/j.joms.2008.11.015

Lee, O. L., Horvath, N., Lee, C., Joshua, D., Ho, J., Szer, J., ... Zannettino, A. (2017). Bisphosphonate guidelines for treatment and prevention of myeloma bone disease. Internal Medicine Journal, 47(8), 938-951. http://doi.org/10.1111/imj.13502

Lin, J. H. (1996). Bisphosphonates: a review of their pharmacokinetic properties. Bone, 18(2), 75-85.

Lipton, A., Fizazi, K., Stopeck, A. T., Henry, D. H., Brown, J. E., Yardley, D. A., ... Jun, S. (2012). Superiority of denosumab to zoledronic acid for prevention of skeletal-related events: a combined analysis of 3 pivotal, randomised, phase 3 trials. European Journal of Cancer (Oxford, England : 1990), 48(16), 3082-3092. http://doi.org/10.1016/j.ejca.2012.08.002 
Lundqvist, A., Andersson, E., Ahlberg, I., Nilbert, M., \& Gerdtham, U. (2016). Socioeconomic inequalities in breast cancer incidence and mortality in Europe-a systematic review and meta-analysis. European Journal of Public Health, 26(5), 804-813. http://doi.org/10.1093/eurpub/ckw070

Madrid, C., Bouferrache, K., Abarca, M., Jaques, B., \& Broome, M. (2010). Bisphosphonate-related osteonecrosis of the jaws: how to manage cancer patients. Oral Oncology, 46(6), 468-470. http://doi.org/10.1016/j.oraloncology.2010.03.016

Magopoulos, C., Karakinaris, G., Telioudis, Z., Vahtsevanos, K., Dimitrakopoulos, I., Antoniadis, K., \& Delaroudis, S. (2007). Osteonecrosis of the jaws due to bisphosphonate use. A review of 60 cases and treatment proposals. American Journal of Otolaryngology, 28(3), 158-163. http://doi.org/10.1016/j.amjoto.2006.08.004

Marx, R. E. (2003). Pamidronate (Aredia) and zoledronate (Zometa) induced avascular necrosis of the jaws: a growing epidemic. Journal of Oral and Maxillofacial Surgery, 61(9), 1115-1117. http://doi.org/10.1016/S02782391(03)00720-1

Marx, R. E. (2008). Uncovering the cause of "phossy jaw" Circa 1858 to 1906: oral and maxillofacial surgery closed case files-case closed. Journal of Oral and Maxillofacial Surgery : Official Journal of the American Association of Oral and Maxillofacial Surgeons, 66(11), 2356-2363. http://doi.org/10.1016/j.joms.2007.11.006

Marx, R. E., Sawatari, Y., Fortin, M., \& Broumand, V. (2005). Bisphosphonate-induced exposed bone (osteonecrosis/osteopetrosis) of the jaws: risk factors, recognition, prevention, and treatment. Journal of Oral and Maxillofacial Surgery : Official Journal of the American Association of Oral and Maxillofacial Surgeons, 63(11), 1567-1575.

http://doi.org/10.1016/j.joms.2005.07.010

Mavrokokki, T., Cheng, A., Stein, B., \& Goss, A. (2007). Nature and frequency of bisphosphonate-associated osteonecrosis of the jaws in Australia. Journal of Oral and Maxillofacial Surgery : Official Journal of the American Association of Oral and Maxillofacial Surgeons, 65(3), 415-423. http://doi.org/10.1016/j.joms.2006.10.061

McClung, M. R., Wagman, R. B., Miller, P. D., Wang, A., \& Lewiecki, E. M. (2017). Observations following discontinuation of long-term denosumab therapy. Osteoporosis International : A Journal Established as Result of Cooperation between the European Foundation for Osteoporosis and the National Osteoporosis Foundation of the USA, 28(5), 1723-1732. http://doi.org/10.1007/s00198-017-3919-1 
Mhaskar, R., Kumar, A., Miladinovic, B., \& Djulbegovic, B. (2017). Bisphosphonates in multiple myeloma: an updated network meta-analysis. The Cochrane Database of Systematic Reviews, 12, CD003188. http://doi.org/10.1002/14651858.CD003188.pub4

Migliorati, C. A., Woo, S.-B., Hewson, I., Barasch, A., Elting, L. S., Spijkervet, F. K. L., \& Brennan, M. T. (2010). A systematic review of bisphosphonate osteonecrosis (BON) in cancer. Supportive Care in Cancer : Official Journal of the Multinational Association of Supportive Care in Cancer, 18(8), 1099-1106. http://doi.org/10.1007/s00520-010-0882-1

Miles, A. E. (1972). Phosphorus necrosis of the jaw: "phossy jaw". British Dental Journal, 133(5), 203-206.

Myers, M. L., \& McGlothlin, J. D. (1996). Matchmakers' “phossy jaw” eradicated. American Industrial Hygiene Association Journal, 57(4), 330-332.

Nguyen, V. H. (2017). Community osteoporosis screening services for the prevention of osteoporotic fractures in population health: a literature review. International Journal of Evidence-Based Healthcare, 15(2), 43-52. http://doi.org/10.1097/XEB.0000000000000104

Norderyd, O., Koch, G., Papias, A., Kohler, A. A., Helkimo, A. N., Brahm, C.-O., ... Frisk, F. (2015). Oral health of individuals aged 3-80 years in Jonkoping, Sweden during 40 years (1973-2013). II. Review of clinical and radiographic findings. Swedish Dental Journal, 39(2), 69-86.

O’Dell, K., \& Sinha, U. (2011). Osteoradionecrosis. Oral and Maxillofacial Surgery Clinics of North Aamerica, 23(3), 455-464. http://doi.org/10.1016/j.coms.2011.04.011

Ohga, N., Sato, J., Asaka, T., Morimoto, M., Yamazaki, Y., \& Kitagawa, Y. (2018). Successful conservative treatment of jaw osteonecrosis caused by denosumab in patients with multiple bone metastasis. Journal of Oral Science, 60(1), 159-162. http://doi.org/10.2334/josnusd.17-0027

Otto, S., Burian, E., Troeltzsch, M., Kaeppler, G., \& Ehrenfeld, M. (2018). Denosumab as a potential treatment alternative for patients suffering from diffuse sclerosing osteomyelitis of the mandible-A rapid communication. Journal of Cranio-Maxillo-Facial Surgery : Official Publication of the European Association for Cranio-Maxillo-Facial Surgery, 46(4), 534-537. http://doi.org/10.1016/j.jcms.2017.10.011

Otto, S., Pautke, C., Martin Jurado, O., Nehrbass, D., Stoddart, M. J., Ehrenfeld, M., \& Zeiter, S. (2017). Further development of the MRONJ minipig large animal model. Journal of Cranio-Maxillo-Facial Surgery : Official Publication of the European Association for Cranio-Maxillo-Facial Surgery, 45(9), 1503-1514. http://doi.org/10.1016/j.jcms.2017.07.002 
Otto, S., Pautke, C., Opelz, C., Westphal, I., Drosse, I., Schwager, J., ... Schieker, M. (2010). Osteonecrosis of the jaw: effect of bisphosphonate type, local concentration, and acidic milieu on the pathomechanism. Journal of Oral and Maxillofacial Surgery : Official Journal of the American Association of Oral and Maxillofacial Surgeons, 68(11), 2837-2845. http://doi.org/10.1016/j.joms.2010.07.017

Otto, S., Ristow, O., Pache, C., Troeltzsch, M., Fliefel, R., Ehrenfeld, M., \& Pautke, C. (2016). Fluorescence-guided surgery for the treatment of medication-related osteonecrosis of the jaw: A prospective cohort study. Journal of Cranio-Maxillo-Facial Surgery : Official Publication of the European Association for Cranio-Maxillo-Facial Surgery, 44(8), 1073-1080. http://doi.org/10.1016/j.jcms.2016.05.018

Otto, S., Schreyer, C., Hafner, S., Mast, G., Ehrenfeld, M., Stürzenbaum, S., \& Pautke, C. (2012). Bisphosphonate-related osteonecrosis of the jaws characteristics, risk factors, clinical features, localization and impact on oncological treatment. Journal of Cranio-Maxillo-Facial Surgery : Official Publication of the European Association for Cranio-Maxillo-Facial Surgery, 40(4), 303-9. http://doi.org/10.1016/j.jcms.2011.05.003

Panya, S., Fliefel, R., Probst, F., Troltzsch, M., Ehrenfeld, M., Schubert, S., \& Otto, S. (2017). Role of microbiological culture and polymerase chain reaction (PCR) of actinomyces in medication-related osteonecrosis of the jaw (MRONJ). Journal of Cranio-Maxillo-Facial Surgery : Official Publication of the European Association for Cranio-Maxillo-Facial Surgery, 45(3), 357-363. http://doi.org/10.1016/j.jcms.2017.01.006

Pautke, C., Bauer, F., Otto, S., Tischer, T., Steiner, T., Weitz, J., ... Kolk, A. (2011). Fluorescence-guided bone resection in bisphosphonate-related osteonecrosis of the jaws: first clinical results of a prospective pilot study. Journal of Oral and Maxillofacial Surgery : Official Journal of the American Association of Oral and Maxillofacial Surgeons, 69(1), 84-91. http://doi.org/10.1016/j.joms.2010.07.014

Pichardo, S. E. C., \& van Merkesteyn, J. P. R. (2016). Evaluation of a surgical treatment of denosumab-related osteonecrosis of the jaws. Oral Surgery, Oral Medicine, Oral Pathology and Oral Radiology, 122(3), 272-278. http://doi.org/10.1016/j.oooo.2016.03.008

Poghosyan, Y. M., Hakobyan, K. A., Poghosyan, A. Y., \& Avetisyan, E. K. (2014). Surgical treatment of jaw osteonecrosis in "Krokodil" drug addicted patients. Journal of Cranio-Maxillo-Facial Surgery : Official Publication of the European Association for Cranio-Maxillo-Facial Surgery, 42(8), 1639-1643. http://doi.org/10.1016/j.jcms.2014.05.005 
Pollock, R. A., Brown, T. W. J., \& Rubin, D. M. (2015). "Phossy Jaw" and "Bis-phossy Jaw" of the 19th and the 21st Centuries: The Diuturnity of John Walker and the Friction Match. Craniomaxillofacial Trauma \& Reconstruction, 8(3), 262-270. http://doi.org/10.1055/s-0035-1558452

Pozzi, S., Marcheselli, R., Sacchi, S., Baldini, L., Angrilli, F., Pennese, E., ... Pollastri, G. (2007). Bisphosphonate-associated osteonecrosis of the jaw: a review of 35 cases and an evaluation of its frequency in multiple myeloma patients. Leukemia \& Lymphoma, 48(1), 56-64. http://doi.org/10.1080/10428190600977690

Rasmusson, L., \& Abtahi, J. (2014). Bisphosphonate associated osteonecrosis of the jaw: an update on pathophysiology, risk factors, and treatment. International Journal of Dentistry, 2014, 471035. http://doi.org/10.1155/2014/471035

Ristow, O., Otto, S., Troeltzsch, M., Hohlweg-Majert, B., \& Pautke, C. (2015). Treatment perspectives for medication-related osteonecrosis of the jaw (MRONJ). Journal of Cranio-Maxillo-Facial Surgery : Official Publication of the European Association for Cranio-Maxillo-Facial Surgery, 43(2), 290-293. http://doi.org/10.1016/j.jcms.2014.11.014

Ruggiero, S., Gralow, J., Marx, R. E., Hoff, A. O., Schubert, M. M., Huryn, J. M., ... Valero, V. (2006). Practical guidelines for the prevention, diagnosis, and treatment of osteonecrosis of the jaw in patients with cancer. Journal of Oncology Practice, 2(1), 7-14. http://doi.org/10.1200/JOP.2006.2.1.7

Ruggiero, S. L., Dodson, T. B., Fantasia, J., Goodday, R., Aghaloo, T., Mehrotra, B., \& O’Ryan, F. (2014). American Association of Oral and Maxillofacial Surgeons position paper on medication-related osteonecrosis of the jaw--2014 update. Journal of Oral and Maxillofacial Surgery : Official Journal of the American Association of Oral and Maxillofacial Surgeons, 72(10), 1938-56. http://doi.org/10.1016/j.joms.2014.04.031

Ruggiero, S. L., Mehrotra, B., Rosenberg, T. J., \& Engroff, S. L. (2004). Osteonecrosis of the jaws associated with the use of bisphosphonates: a review of 63 cases. Journal of Oral and Maxillofacial Surgery : Official Journal of the American Association of Oral and Maxillofacial Surgeons, 62(5), 527534.

Russell, R. G. G., Watts, N. B., Ebetino, F. H., \& Rogers, M. J. (2008).

Mechanisms of action of bisphosphonates: similarities and differences and their potential influence on clinical efficacy. Osteoporosis International : A Journal Established as Result of Cooperation between the European Foundation for Osteoporosis and the National Osteoporosis Foundation of the USA, 19(6), 733-59. http://doi.org/10.1007/s00198-007-0540-8 
Russell, R. G. G., Xia, Z., Dunford, J. E., Oppermann, U., Kwaasi, A., Hulley, P. A., ... Ebetino, F. H. (2007). Bisphosphonates: an update on mechanisms of action and how these relate to clinical efficacy. Annals of the New York Academy of Sciences, 1117, 209-257. http://doi.org/10.1196/annals.1402.089

Saad, F., Brown, J. E., Van Poznak, C., Ibrahim, T., Stemmer, S. M., Stopeck, A. T., ... Dansey, R. (2012). Incidence, risk factors, and outcomes of osteonecrosis of the jaw: integrated analysis from three blinded activecontrolled phase III trials in cancer patients with bone metastases. Annals of Oncology : Official Journal of the European Society for Medical Oncology, 23(5), 1341-1347. http://doi.org/10.1093/annonc/mdr435

Saag, K. G., Koehnke, R., Caldwell, J. R., Brasington, R., Burmeister, L. F., Zimmerman, B., ... Furst, D. E. (1994). Low dose long-term corticosteroid therapy in rheumatoid arthritis: an analysis of serious adverse events. The American Journal of Medicine, 96(2), 115-123.

Saylor, P. J., \& Smith, M. R. (2010). Bone health and prostate cancer. Prostate Cancer and Prostatic Diseases, 13(1), 20-27. http://doi.org/10.1038/pcan.2009.50

Stockmann, P., Burger, M., von Wilmowsky, C., Ebker, T., Lutz, R., Bauersachs, A., ... Wehrhan, F. (2014). The outcome after surgical therapy of bisphosphonate-associated osteonecrosis of the jaw--results of a clinical case series with an average follow-up of 20 months. Clinical Oral Investigations, 18(4), 1299-1304. http://doi.org/10.1007/s00784-013-1092-2

Stopeck, A. T., Lipton, A., Body, J.-J., Steger, G. G., Tonkin, K., de Boer, R. H., ... Braun, A. (2010). Denosumab compared with zoledronic acid for the treatment of bone metastases in patients with advanced breast cancer: a randomized, double-blind study. Journal of Clinical Oncology : Official Journal of the American Society of Clinical Oncology, 28(35), 5132-5139. http://doi.org/10.1200/JCO.2010.29.7101

Tarakji, B., Saleh, L. A., Umair, A., Azzeghaiby, S. N., \& Hanouneh, S. (2015). Systemic review of dry socket: aetiology, treatment, and prevention. Journal of Clinical and Diagnostic Research : JCDR, 9(4), ZE10-3. http://doi.org/10.7860/JCDR/2015/12422.5840

Tarassoff, P., \& Csermak, K. (2003, October). Avascular necrosis of the jaws: risk factors in metastatic cancer patients. Journal of Oral and Maxillofacial Surgery : Official Journal of the American Association of Oral and Maxillofacial Surgeons. United States. 
Thumbigere-Math, V., Tu, L., Huckabay, S., Dudek, A. Z., Lunos, S., Basi, D. L., ... Gopalakrishnan, R. (2012). A retrospective study evaluating frequency and risk factors of osteonecrosis of the jaw in 576 cancer patients receiving intravenous bisphosphonates. American Journal of Clinical Oncology, 35(4), 386-392. http://doi.org/10.1097/COC.0b013e3182155fcb

Tortora GJ, D. B. (2011). Principles of anatomy \& physiology (13th ed.). New York : Wiley, cop. 2011.

Ulmner, M., Jarnbring, F., \& Torring, O. (2014). Osteonecrosis of the jaw in Sweden associated with the oral use of bisphosphonate. Journal of Oral and Maxillofacial Surgery : Official Journal of the American Association of Oral and Maxillofacial Surgeons, 72(1), 76-82. http://doi.org/10.1016/j.joms.2013.06.221

Vahtsevanos, K., Kyrgidis, A., Verrou, E., Katodritou, E., Triaridis, S., Andreadis, C. G., ... Antoniades, K. (2009). Longitudinal cohort study of risk factors in cancer patients of bisphosphonate-related osteonecrosis of the jaw. Journal of Clinical Oncology : Official Journal of the American Society of Clinical Oncology, 27(32), 5356-5362. http://doi.org/10.1200/JCO.2009.21.9584

Van den Wyngaert, T., Claeys, T., Huizing, M. T., Vermorken, J. B., \& Fossion, E. (2009). Initial experience with conservative treatment in cancer patients with osteonecrosis of the jaw $(\mathrm{ONJ})$ and predictors of outcome. Annals of Oncology : Official Journal of the European Society for Medical Oncology, 20(2), 331-336. http://doi.org/10.1093/annonc/mdn630

VanPutte CL, S. R. (2014). Seeley's anatomy \& physiology (10th ed.). New York, NY : McGraw-Hill.

Wang, Y., \& Qian, P.-Y. (2009). Conservative fragments in bacterial 16S rRNA genes and primer design for $16 \mathrm{~S}$ ribosomal DNA amplicons in metagenomic studies. PloS One, 4(10), e7401. http://doi.org/10.1371/journal.pone.0007401

Ward EF. (1928). Phosphorus necrosis in the manufacture of fireworks. J Ind Hyg Toxicol, 10, 314-330.

Wessel, J. H., Dodson, T. B., \& Zavras, A. I. (2008). Zoledronate, smoking, and obesity are strong risk factors for osteonecrosis of the jaw: a casecontrol study. Journal of Oral and Maxillofacial Surgery : Official Journal of the American Association of Oral and Maxillofacial Surgeons, 66(4), 625-631. http://doi.org/10.1016/j.joms.2007.11.032

Wilkinson, G. S., Kuo, Y.-F., Freeman, J. L., \& Goodwin, J. S. (2007). Intravenous bisphosphonate therapy and inflammatory conditions or surgery of the jaw: a population-based analysis. Journal of the National Cancer Institute, 99(13), 1016-1024. http://doi.org/10.1093/jnci/djm025 
Williamson, R. A. (2010). Surgical management of bisphosphonate induced osteonecrosis of the jaws. International Journal of Oral and Maxillofacial Surgery, 39(3), 251-255. http://doi.org/10.1016/j.ijom.2009.11.014

Yamamoto, D., Tsubota, Y., Utsunomiya, T., Sueoka, N., Ueda, A., Endo, K., ... Kon, M. (2017). Osteonecrosis of the jaw associated with everolimus: A case report. Molecular and Clinical Oncology, 6(2), 255-257. http://doi.org/10.3892/mco.2016.1100

Zarychanski, R., Elphee, E., Walton, P., \& Johnston, J. (2006). Osteonecrosis of the jaw associated with pamidronate therapy. American Journal of Hematology, 81(1), 73-75. http://doi.org/10.1002/ajh.20481

Zavras, A. I., \& Zhu, S. (2006). Bisphosphonates are associated with increased risk for jaw surgery in medical claims data: is it osteonecrosis? Journal of Oral and Maxillofacial Surgery : Official Journal of the American Association of Oral and Maxillofacial Surgeons, 64(6), 917-923. http://doi.org/10.1016/j.joms.2006.02.011

Zervas, K., Verrou, E., Teleioudis, Z., Vahtsevanos, K., Banti, A., Mihou, D., ... Terpos, E. (2006). Incidence, risk factors and management of osteonecrosis of the jaw in patients with multiple myeloma: a single-centre experience in 303 patients. British Journal of Haematology, 134(6), 620-623. http://doi.org/10.1111/j.1365-2141.2006.06230.x 
I 



\title{
Osteonecrosis of the jaw in patients treated with oral and intravenous bisphosphonates: experience in Sweden
}

\author{
Fredrik Hallmer, DDS, ${ }^{\mathrm{a}}$ Tore Bjørnland, DDS, Dr odont, ${ }^{\mathrm{b}}$ Anders Nicklasson, DDS, \\ Jonas P. Becktor, DDS, Med dr, ${ }^{\mathrm{d}}$ and Gunilla Andersson, DDS, Odont $\mathrm{dr}^{\mathrm{e}}$ \\ Malmö University, Malmö, Sweden; Skåne University Hospital, Lund, Sweden; University of Oslo, Oslo, Norway
}

Objective. To describe the prevalence, inciting factors, and treatment outcomes of bisphosphonate-related osteonecrosis of the jaw (BRONJ) during the 2003-2010 period in southern Sweden (population, approximately 1.2 million people).

Study Design. Patient records were searched for inflammatory conditions including unspecified inflammation, osteomyelitis, osteonecrosis due to drugs, and other osteonecrosis. Data on underlying disease, type of bisphosphonate (BP), inciting factor, location, stage, treatment, and treatment outcomes were collected.

Results. Of the 341 patients identified, 55 had been diagnosed with BRONJ. Those with a malignant disease were treated with intravenous BPs, and those with osteoporosis were treated with oral BPs. All but 5 were treated with antibiotics and 47 with local resection. Healing was recorded in $79 \%$ of patients with osteoporosis and in $26 \%$ of patients with malignant disease. Conclusions. Healing in patients with osteoporosis occurred more frequently than in patients with a malignant disease treated with intravenous BPs $(P=.00009)$. (Oral Surg Oral Med Oral Pathol Oral Radiol 2014;118:202-208)

The first articles on bisphosphonate-related osteonecrosis of the jaw (BRONJ) were published in 2003 and 2004, when oral and maxillofacial surgeons began to report cases of nonhealing of exposed, necrotic bone in the maxillofacial region in patients treated with bisphosphonates (BPs). ${ }^{1,2}$ At first, the condition was believed to be a new disease, but it proved to be the same disease that had existed more than 100 years ago in match factory workers and phosphate miners, in whom the disease was recognized as phossy jaw. ${ }^{3}$ Although it has been more than 10 years since the first publication in 2003, the pathogenesis of BRONJ is still poorly understood.

BPs are drugs that inhibit bone resorption, bone metabolism, and bone remodeling through inhibition of osteoclasts. ${ }^{4,5}$ BPs can be divided into 2 groups, nonnitrogen-containing and nitrogen-containing. Mainly nitrogen-containing BPs have been associated with the development of osteonecrosis of the jaws. The explanation is probably that the nitrogen-containing side

This study was supported by grants from the Faculty of Odontology, Malmö University, Malmö, Sweden.

${ }^{a}$ Senior resident, Department of Oral and Maxillofacial Surgery and Oral Medicine, Faculty of Odontology, Malmö University, Department of Oral and Maxillofacial Surgery, Skåne University Hospital. ${ }^{\mathrm{b}}$ Professor and Chairman, Department of Oral Surgery and Oral Medicine, Faculty of Odontology, University of Oslo. ${ }^{\mathrm{c}}$ General Dentist, Private Practice, Trelleborg, Sweden.

${ }^{\mathrm{d}}$ Associate Professor and Head, Department of Oral and Maxillofacial Surgery and Oral Medicine, Faculty of Odontology, Malmö University.

${ }^{\mathrm{e}}$ Associate Professor, Department of Oral and Maxillofacial Surgery and Oral Medicine, Faculty of Odontology, Malmö University.

Received for publication Jan 27, 2014; returned for revision Apr 30, 2014; accepted for publication May 7, 2014.

(c) 2014 Elsevier Inc. All rights reserved.

$2212-4403 / \$$ - see front matter

http://dx.doi.org/10.1016/j.oooo.2014.05.006 chains increase the potency and perhaps toxicity. ${ }^{6,7}$ Denosumab is another drug that also inhibits bone resorption and may cause osteonecrosis of the jaw as a side effect. Denosumab is an immunoglobulin G2 monoclonal antibody with affinity and specificity for RANKL (receptor activator of nuclear factor $\kappa \mathrm{B}$ ligand [TNFSF11]) that inhibits RANKL from activating its receptor, RANK (receptor activator of nuclear factor $\kappa \mathrm{B}$ [TNFRSF11 A]), on the surface of osteoclasts and their precursors. Prevention of the RANKL-RANK interaction inhibits osteoclast formation, function, and survival, thereby decreasing bone resorption. ${ }^{8,9}$

The intravenous nitrogen-containing BPs (zoledronate, pamidronate) and denosumab are mainly used in patients with metastatic bone disease (such as multiple myeloma, metastatic breast cancer, and metastatic prostate cancer) to decrease the risk of skeletal complications of the malignancy. ${ }^{8-11}$ In patients with osteoporosis, mainly orally administered BPs (e.g., alendronate) are used to preserve and strengthen existing bone by increasing its mineralization. Zoledronate can also be used as an annual intravenous infusion for the treatment of osteoporosis. ${ }^{12}$ The most commonly reported inciting factor for the initiation of BRONJ is tooth extraction. Other inciting factors include

\section{Statement of Clinical Relevance}

Bisphosphonate-related osteonecrosis has low prevalence in Sweden. Local resection of the necrotic parts of the jaw may give favorable results, and the treatment outcome is significantly better in patients with osteoporosis compared with patients with cancer. 
odontogenic infection, dental implant surgery, local trauma, or spontaneous occurrence. ${ }^{6,12}$

The preferred treatment of patients diagnosed with BRONJ has been the use of an antibacterial mouthrinse (e.g., chlorhexidine), symptomatic treatment with orally administered systemic antibiotics, and (in more severe cases) surgical debridement or resection for longer-term palliation of infection and pain. ${ }^{12}$ A 2011 publication reported promising results using a new treatment option based on fluorescence-guided bone resection of the necrotic lesion. ${ }^{13}$

The aim of the present study was to describe the prevalence, sites, inciting factors, and treatment outcomes of BRONJ in patients with cancer and patients with osteoporosis in southern Sweden (Skåne) for the period of 2003-2010. We tested the hypothesis that treatment outcome was better in patients with osteoporosis treated with oral BPs than in patients with a malignant disease treated with intravenous BPs.

\section{MATERIAL AND METHODS}

\section{Study design and sample}

In Sweden, the health care system has 21 administrative regions. Region Skane in the south is the third largest, with a population base of approximately 1.2 million persons. Four oral and maxillofacial surgery clinics at hospitals in Malmö, Lund, Helsingborg, and Kristianstad are responsible for the treatment of patients with BRONJ in the region. Patients diagnosed with maxillofacial pathology in the period 2003-2010 were identified in the Melior database at the 4 departments of oral and maxillofacial surgery. Patient records were searched for the ICD-10 (International Classification of Diseases 10th revision) World Health Organization inflammatory conditions of the jaw (K10.2), unspecified disease of jaws (K10.9), unspecified osteomyelitis (M86.9), osteonecrosis due to drugs (M87.1), and other osteonecroses (M87.8), and 341 patients were thus identified. Of those, 55 ( 37 women, 18 men) with the mean age of 72.2 years (range, 53-94 years) had been diagnosed with BRONJ and were included in the study. BRONJ was diagnosed as defined by the American Association of Oral and Maxillofacial Surgeons (AAOMS): "exposed bone in the maxillofacial region over a period of 8 weeks, current or previous treatment with bisphosphonates, and no history of radiation therapy to the jaws." 11

Site. The sites of BRONJ were categorized as proposed by Rocha et al. ${ }^{14}$ The jaws were divided into the right posterior maxilla (segment 1), anterior maxilla (segment 2), left posterior maxilla (segment 3), left posterior mandible (segment 4), anterior mandible (segment 5), and right posterior mandible (segment 6) using the distal surface of the canines as reference (Figure 1).
Staging. BRONJ was staged using the AAOMS 2009 recommendations ${ }^{12}$ : stage 0 , absence of bone exposure but presence of typical clinical, radiologic, or histologic signs of osteonecrosis of the jaw; stage 1, exposed necrotic bone without pain or signs of infection (asymptomatic); stage 2, exposed necrotic bone with pain, signs of infection, or both (symptomatic) (Figure 2); and stage 3, exposed necrotic bone with pain, signs of infection, or both plus one or more of the following: pathologic fracture, oral-cutaneous fistula, involvement of the maxillary sinus, or necrosis extending to the inferior border of the ramus of the mandible. ${ }^{12}$

Treatment. All patients were treated with chlorhexidine $10 \mathrm{~mL}(1 \mathrm{mg} / \mathrm{mL})$ mouthrinse twice a day during the treatment period. Antibiotic treatment was carried out with phenoxymethyl penicillin ( $1 \mathrm{~g}, 3$ times daily), metronidazole (400 mg, 3 times daily), or clindamycin (300 mg, 3 times daily) taken orally. Patients were treated with antibiotics when an infection was present. Local resection in stage 1 and 2 cases included treatment with superficial debridement, removal of sequestrum, or both. Stage 3 cases were treated with removal of sequestrum and resection of necrotic bone after elevation of a mucoperiosteal flap and primary closure.

Healing status was considered to be successful when there was complete mucosal coverage without any exposed bone and without any sign of infection. When final healing was obtained, the patients were followed up for 3 months at the department of oral and maxillofacial surgery. The patients were then referred back to their general dentists. The Regional Medical Ethical Committee, Lund, Sweden, (Dnr 2011/274) approved this study.

\section{Statistical methods}

SPSS for Windows (version 14.0; SPSS Inc, Chicago, IL, USA) was used for data management and statistical analysis. The Student $t$ test was used for continuous variables. Between-group comparisons before and after treatment were tested with the $\chi^{2}$ test. A significance level of $5 \%$ was used in all tests.

\section{RESULTS}

Between 2003 and 2010, the occurrence of BRONJ was 55 cases in a population of 1.2 million. The most common underlying disease was osteoporosis $(\mathrm{n}=24$; $44 \%$ ), followed by multiple myeloma ( $\mathrm{n}=15 ; 27 \%$ ), breast cancer $(\mathrm{n}=11 ; 20 \%)$, and prostate cancer $(\mathrm{n}=5 ; 9 \%)$. All patients with a malignant disease were treated with intravenous BPs $(n=31 ; 56 \%)$, and all patients with osteoporosis were treated with oral BPs. All patient data are presented in detail in Tables I and II.

The estimated number of patients on oral BPs during the period 2003-2010 in Region Skåne was 


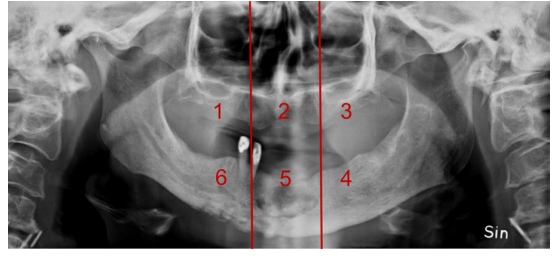

Fig. 1. Bisphosphonate-related osteonecrotic lesions in the anterior mandible (segment 5) and right posterior mandible (segment 6) using the distal surface of the canines as reference in a 53-year-old woman with osteoporosis treated with alendronate for 7 years. The sites of the necrosis were categorized as proposed by Rocha et al. ${ }^{14}$

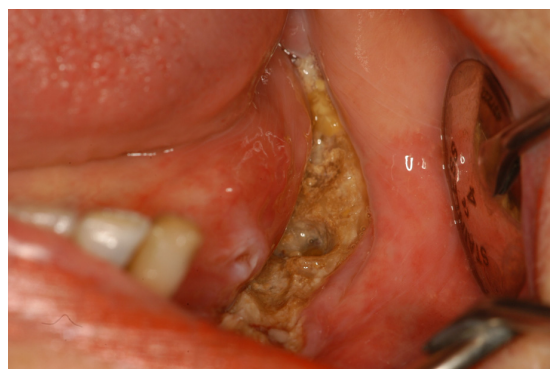

Fig. 2. Stage 2 bisphosphonate-related osteonecrotic lesion with exposed necrotic bone with pain and signs of infection (symptomatic) in a 68-year-old woman with myeloma treated with pamidronate for 6 years.

approximately 100000 according to the Swedish health system database (Socialstyrelsen). The prevalence of BRONJ in patients on oral BPs was estimated to be $0.024 \%$. The estimated number of patients on intravenous BPs during the same period in Region Skåne was approximately 1100 according to the same database. The prevalence of BRONJ in patients on intravenous BPs was estimated to be $2.8 \%$.

\section{Patients with osteoporosis treated with oral BPs}

Age and sex. Osteoporosis was present in 24 patients (mean age, $76.38 \pm 11.25$ years); 20 were women $(76.35 \pm 11.98$ years) and 4 were men $(76.50 \pm 7.94$ years) (see Table I).

Inciting factors. In patients with osteoporosis as the underlying disease $(n=24 ; 44 \%)$, necrotic lesions in the jaw were initiated by tooth extraction in 12 patients; 8 cases were spontaneous; 2 cases occurred after dental implant surgery; and in 2 cases the inciting factor for development of BRONJ was local trauma.
Site. In patients with osteoporosis, 17 cases of BRONJ were located in the mandible. Within the mandible, 8 lesions were localized in the left posterior mandible (segment 4), 5 in the right posterior mandible (segment 6), 3 in the anterior mandible (segment 5), and 1 in the anterior and right posterior mandible (segments 5 and 6). Of the 7 cases in the maxilla, 3 were in the left posterior maxilla (segment 3 ); 2 were in the anterior maxilla (segment 2); 1 was in the right posterior maxilla (segment 1); and 1 involved the whole maxilla (segments 1 to 3 ) (see Table I).

Staging. No cases were classified as stage $0 ; 5$ cases were stage 1,13 cases were stage 2 , and 6 cases were stage 3 (see Table I).

Treatment. Of the 24 patients with BRONJ, 22 were treated with antibiotics, and 20 were treated with a local resection of the necrotic lesion (see Table I). Healing occurred in 19 patients $(79.2 \%$ ) with osteoporosis, and all were treated with local resection of the necrotic lesion in combination with antibiotics, except 1 patient who received no antibiotics. In 5 patients, no healing was noticed; 1 of these was treated with local resection.

\section{Patients with cancer treated with intravenous BPs}

Age and sex. Malignant disease was identified in 31 patients with a mean age of $71.42 \pm 9.03$ years; 17 were women $(70.82 \pm 9.92$ years) and 14 were men (72.14 \pm 8.12 years) (see Table II).

Inciting factors. In patients with a malignant disease $(\mathrm{n}=31 ; 56 \%)$, the inciting factor for development of BRONJ was a tooth extraction in 24 cases; 4 cases appeared spontaneously; and 2 cases occurred after dental implant surgery. In 1 patient, the necrosis was initiated by local trauma (see Table II).

Site. In patients with BRONJ and a malignant disease, 26 cases were located in the mandible. Within the mandible, 14 lesions were localized in the right posterior mandible (segment 6), 8 in the left posterior mandible (segment 4), 3 in the anterior mandible (segment 5), and 1 throughout the whole mandible (segments 4 to 6 ). Of the 5 cases in the maxilla, 4 were in the right posterior maxilla (segment 1 ) and 1 involved the whole maxilla (segments 1 to 3) (see Table II).

Staging. No cases were classified as stage $0 ; 9$ cases were stage 1,18 cases were stage 2 , and 4 cases were stage 3 (see Table II).

Treatment. Of the 31 patients, 28 were treated with antibiotics. Local resection of the necrotic lesion was undertaken in 27 cases, and 24 of these received antibiotics as well. Three patients were treated with local resection alone. Healing was noticed in 8 patients $(25.8 \%)$ with a malignant disease, 5 whose underlying disease was breast cancer and 3 with multiple myeloma (see Table II). 
Table I. Characteristics of 24 patients with osteoporosis and BRONJ treated with oral BPs

\begin{tabular}{|c|c|c|c|c|c|c|c|c|c|c|c|}
\hline Gender & Age (y) & $B P$ & Trigger factor & Diabetes & Cortisone & Chemotherapy & $A B$ & Local resection & Site & Stage & Healing \\
\hline $\mathrm{M}$ & 85 & Alendronate & Tooth extraction & & $\mathrm{X}$ & & $\mathrm{X}$ & $\mathrm{X}$ & 4 & 2 & $\mathrm{X}$ \\
\hline $\mathrm{F}$ & 79 & Risedronate & Spontaneously & $\mathrm{X}$ & & & & $\mathrm{X}$ & 4 & 1 & $\mathrm{X}$ \\
\hline $\mathrm{F}$ & 76 & Alendronate & Spontaneously & & & & & & 5 & 2 & \\
\hline $\mathrm{F}$ & 67 & Alendronate & Spontaneously & & $\mathrm{X}$ & & $\mathrm{X}$ & & 6 & 1 & \\
\hline $\mathrm{F}$ & 65 & Risedronate & Implant & & & & $\mathrm{X}$ & & 2 & 2 & \\
\hline $\mathrm{F}$ & 94 & Alendronate & Spontaneously & & & & $\mathrm{X}$ & $\mathrm{X}$ & 4 & 3 & $\mathrm{X}$ \\
\hline $\mathrm{F}$ & 93 & Alendronate & Spontaneously & & & & $\mathrm{X}$ & & $1,2,3$ & 3 & \\
\hline $\mathrm{F}$ & 88 & Alendronate & Tooth extraction & & & & $\mathrm{X}$ & $\mathrm{X}$ & 4 & 2 & $\mathrm{X}$ \\
\hline $\mathrm{F}$ & 85 & Alendronate & Tooth extraction & & $\mathrm{X}$ & & $\mathrm{X}$ & $\mathrm{X}$ & 6 & 2 & $\mathrm{X}$ \\
\hline $\mathrm{F}$ & 88 & Alendronate & Spontaneously & & & & $\mathrm{X}$ & $\mathrm{X}$ & 3 & 2 & $\mathrm{X}$ \\
\hline $\mathrm{F}$ & 58 & Alendronate & Tooth extraction & & & & $\mathrm{X}$ & $\mathrm{X}$ & 3 & 1 & $\mathrm{X}$ \\
\hline $\mathrm{F}$ & 87 & Alendronate & Spontaneously & & & & $\mathrm{X}$ & $\mathrm{X}$ & 2 & 2 & $\mathrm{X}$ \\
\hline M & 76 & Alendronate & Tooth extraction & & $\mathrm{X}$ & & $\mathrm{X}$ & $\mathrm{X}$ & 6 & 3 & $\mathrm{X}$ \\
\hline $\mathrm{F}$ & 72 & Alendronate & Tooth extraction & & $\mathrm{X}$ & $\mathrm{X}$ & $\mathrm{X}$ & $\mathrm{X}$ & 1 & 2 & $\mathrm{X}$ \\
\hline M & 66 & Alendronate & Spontaneously & & & & $\mathrm{X}$ & $\mathrm{X}$ & 4 & 2 & $\mathrm{X}$ \\
\hline $\mathrm{F}$ & 80 & Alendronate & Trauma & & $\mathrm{X}$ & & $\mathrm{X}$ & $\mathrm{X}$ & 6 & 2 & $\mathrm{X}$ \\
\hline $\mathrm{F}$ & 80 & Alendronate & Trauma & $\mathrm{X}$ & $\mathrm{X}$ & & $\mathrm{X}$ & $\mathrm{X}$ & 5 & 1 & $\mathrm{X}$ \\
\hline M & 79 & Alendronate & Implant & $\mathrm{X}$ & $\mathrm{X}$ & $\mathrm{X}$ & $\mathrm{X}$ & $\mathrm{X}$ & 6 & 3 & $\mathrm{X}$ \\
\hline $\mathrm{F}$ & 88 & Alendronate & Tooth extraction & & & & $\mathrm{X}$ & $\mathrm{X}$ & 5 & 2 & $\mathrm{X}$ \\
\hline $\mathrm{F}$ & 69 & Alendronate & Tooth extraction & & $\mathrm{X}$ & & $\mathrm{X}$ & $\mathrm{X}$ & 4 & 2 & \\
\hline $\mathrm{F}$ & 53 & Alendronate & Tooth extraction & & & & $\mathrm{X}$ & $\mathrm{X}$ & 5,6 & 3 & $\mathrm{X}$ \\
\hline $\mathrm{F}$ & 77 & Alendronate & Tooth extraction & & & & $\mathrm{X}$ & $\mathrm{X}$ & 4 & 3 & $\mathrm{X}$ \\
\hline $\mathrm{F}$ & 68 & Alendronate & Tooth extraction & & & & $\mathrm{X}$ & $\mathrm{X}$ & 3 & 1 & $\mathrm{X}$ \\
\hline $\mathrm{F}$ & 60 & Alendronate & Tooth extraction & & $\mathrm{X}$ & $\mathrm{X}$ & $\mathrm{X}$ & $\mathrm{X}$ & 4 & 2 & $\mathrm{X}$ \\
\hline
\end{tabular}

$B R O N J$, bisphosphonate-related osteonecrosis of the jaw; $B P$, bisphosphonate; $A B$, antibiotic treatment.

\section{Patients with osteoporosis compared with those with cancer}

More women with osteoporosis were diagnosed with BRONJ than women with cancer $(P=.025)$. The patients with osteoporosis were older than the patients with a malignant disease $(P=.008)$. Healing in patients with osteoporosis treated with oral BPs occurred more frequently than in patients with a malignant disease treated with intravenous BPs $(P=.00009)$.

\section{DISCUSSION}

To the best of our knowledge, this is the first study from Scandinavia that reports the prevalence of BRONJ in both patients with cancer and those with osteoporosis. Our results confirm data from other studies indicating that the prevalence of BRONJ is much lower in patients on oral BPs than in patients treated with intravenous BPs. $^{12}$ The relatively low prevalence of BRONJ in patients on intravenous BPs in this study might be explained by the fact that most patients on BPs have a dental screening before starting BP treatment and thereby prevent later tooth extraction or dental infections triggering BRONJ. ${ }^{12}$ Because all inhabitants are covered by the health care system in Sweden and no private insurance is needed, economic reasons for not seeking health care can be ruled out. AAOMS stage I BRONJ is defined as exposed and necrotic bone in asymptomatic patients. These patients may therefore not seek health care and may therefore give a lower prevalence of BRONJ in our study. Patients with a symptomatic and painful condition in the jaws are more likely to seek health care and be treated at one of the departments of oral and maxillofacial surgery in the region and therefore be included in the study. Since the first publications on the topic of BRONJ were published in 2003 and 2004, ${ }^{1,2}$ some cases may have been incorrectly diagnosed in the early period of this study. Although the study is retrospective, probably most cases from the region are included, because all patient records with a diagnosis of inflammatory disease of the jaw, osteonecrosis due to drugs, and other osteonecrosis were screened in accordance with the recommendations of Bergdahl et al. ${ }^{15}$

No patients with osteonecrosis of the jaw due to denosumab treatment were identified in our study. This drug was not available in Sweden during the study period 2003-2010. Most cases of BRONJ (78\%) were localized in the mandible, and in the majority of cases (65\%), the inciting factor for the development of BRONJ was tooth extraction. These results are in accordance with those of other studies. ${ }^{6,16,17}$

The most important finding in this study was the difference in healing of the necrotic lesion between patients treated with oral BPs for osteoporosis and patients treated with intravenous BPs for a malignant disease. A significantly better treatment outcome, with complete healing of the mucosa and no pain, was identified in the osteoporosis group $(79.2 \%)$ treated with oral BPs than in patients with cancer treated with 


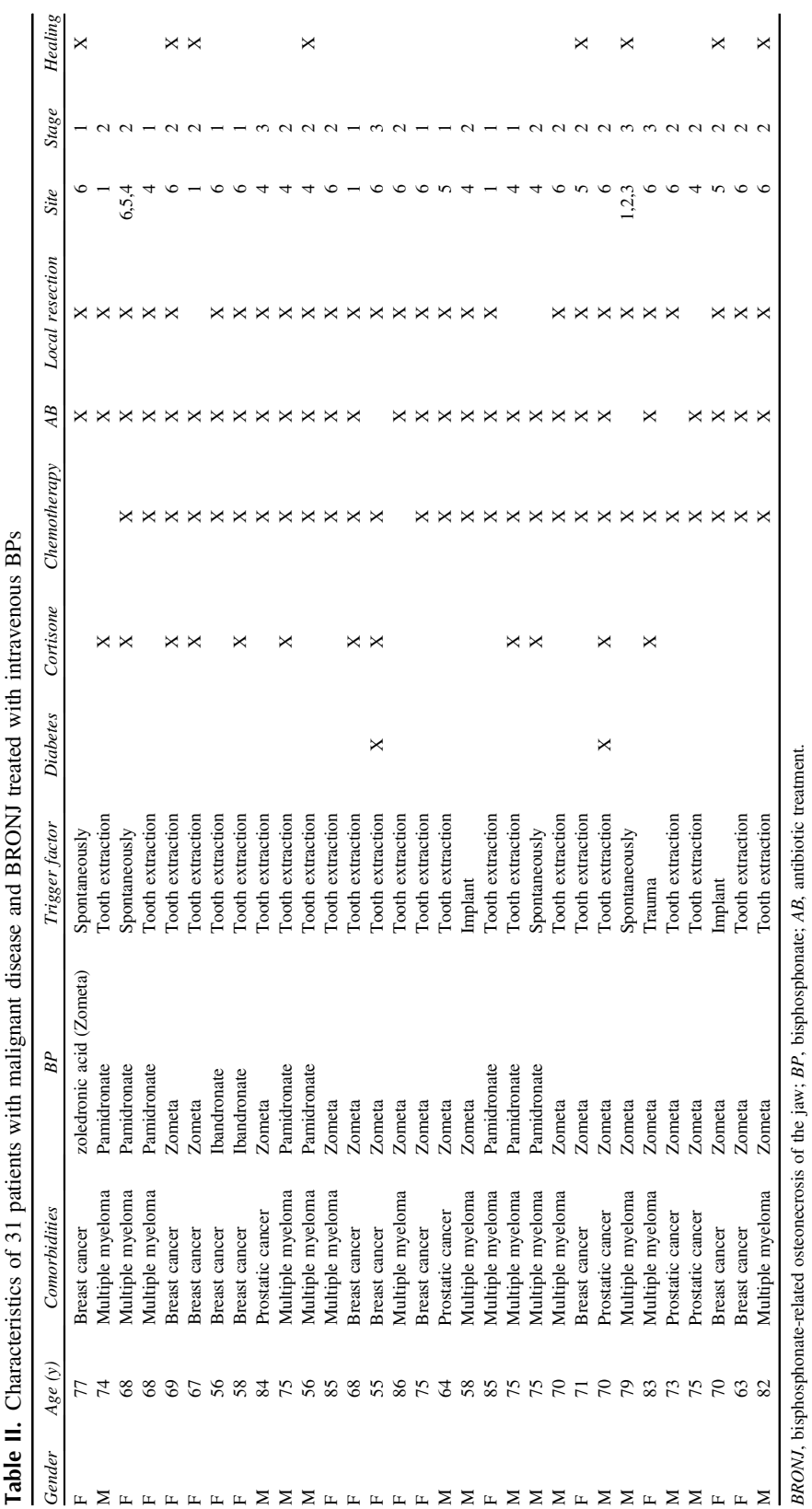


intravenous BPs $(25.8 \%)$. All successful cases were treated with a combination of surgical therapy and systemic antibiotics, except for 1 case treated with antibiotics alone and 1 case treated with local resection alone. Recurrence of BRONJ was not recorded in any patients after final healing and referral back to their general dentists.

A decade after the first reports of BRONJ, there are still controversies about whether conservative treatment with antibiotics alone or in combination with surgical therapy results in healing. According to the latest position paper by the AAOMS, conservative treatment, including superficial debridement and systemic antibiotics, is recommended in stage 1 and 2 lesions, whereas surgical therapy with removal of the bone lesion is only recommended in stage 3 cases. ${ }^{12}$ In our study, surgical treatment of BRONJ in patients with osteoporosis led to healing in most cases regardless of stage. The most likely explanation for the successful treatment recorded in patients with osteoporosis is that they were treated with oral BPs. One hypothesis is that BRONJ is a result of BP-induced suppression of the remodeling of the bone in the jaws. In an animal study by Allen and Burr, ${ }^{18}$ female beagle dogs were given daily treatment with alendronate for 3 years, equivalent to the dose for osteoporosis. That study found significant reduction in the intracortical bone turnover rate in the mandible compared with age-matched animals. Within the mandible, the suppression of bone turnover was greatest in the alveolar process. In patients with cancer, intravenous BPs, such as zoledronate, pamidronate, and ibandronate, have higher binding affinity and potency, probably resulting in greater remodeling suppression compared with oral BPs, such as alendronate, used in the treatment of osteoporosis. ${ }^{4}$ The differences in potency between oral and intravenous BPs probably explain the differences in treatment outcome between patients with osteoporosis and those with cancer.

After a television program in Australia about the association between osteonecrosis of the jaw and BP use was broadcast, there was a reduction in the number of prescriptions filled for BPs. It was estimated that this resulted in 70 hip fractures, 60 other fractures, and 14 deaths that might otherwise have been prevented. ${ }^{19}$

Although BRONJ is a serious complication of BP treatment, the positive effects of the medication predominate. According to the results in our study, it seems that surgical therapy can be carried out successfully in the majority of cases of BRONJ in patients with osteoporosis using oral BPs. This is in contrast to patients on intravenous BPs. A low success rate in treatment of BRONJ in patients with cancer on intravenous BPs in this study demands new treatment strategies. A new technique with fluorescence-guided bone resection in stage 2 and 3 BRONJ lesions in patients with intravenous BP treatment for metastatic bone disease has shown promising results, with mucosal closure without signs of wound dehiscence in $85 \%$ (17 of 20) of cases at the site of the previous osteonecrosis. ${ }^{13}$

The risk factors for BRONJ are still unknown, but some studies suggest that comorbidities (such as diabetes) and comedications (such as steroids) increase the risk for necrosis of the jaw. ${ }^{2,6}$ Information on medication and comorbidities was inconsistently reported in the patient records in the present retrospective study, so risk assessment was not possible. Smoking is thought also to play a crucial role in the risk of development of BRONJ. ${ }^{20}$ Data on these habits were absent in most patient records in our study. In the same health region in southern Sweden, a prospective study was started in 2012 in which all patients diagnosed with BRONJ are carefully monitored. Possible risk factors are recorded, and new treatment strategies may be suggested.

\section{CONCLUSION}

The prevalence of BRONJ seems to be low in Skåne. The treatment outcome of BRONJ is significantly better in patients with osteoporosis treated with oral BPs compared with patients with cancer treated with intravenous BPs. The most common location for BRONJ is the mandible, and tooth extraction is the most common inciting factor.

The authors thank Per-Erik Isberg for invaluable help with the statistical analysis.

\section{REFERENCES}

1. Marx RE. Pamidronate (Aredia) and zoledronate (Zometa) induced avascular necrosis of the jaws: a growing epidemic. J Oral Maxillofac Surg. 2003;61:1115-1117.

2. Ruggiero SL, Mehrotra B, Rosenberg TJ, Engroff SL. Osteonecrosis of the jaws associated with the use of bisphosphonates: a review of 63 cases. J Oral Maxillofac Surg. 2004;62:527-534.

3. Hellstein J, Marek C, Pharm BS. Bisphosphonate osteochemonecrosis (bis-phossy jaw): is this phossy jaw of the 21st century? J Oral Maxillofac Surg. 2005;63:682-689.

4. Allen M, Burr D. The pathogenesis of bisphosphonate-related osteonecrosis of the jaw: so many hypotheses, so few data. J Oral Maxillofac Surg. 2009;67:61-70.

5. Allen MR, Burr DB. Bisphosphonate effects on bone turnover, microdamage, and mechanical properties: what we think we know and what we know that we don't know. Bone. 2011;49:56-65.

6. Otto S, Schreyer C, Hafner S, et al. Bisphosphonate-related osteonecrosis of the jaws-characteristics, risk factors, clinical features, localization and impact on oncological treatment. J Craniomaxillofac Surg. 2012;40:303-309.

7. Otto S, Pautke C, Opelz C, et al. Osteonecrosis of the jaw: effect of bisphosphonate type, local concentration, and acidic milieu on the pathomechanism. J Oral Maxillofac Surg. 2010;68:2837-2845.

8. Cummings SR, San Martin J, McClung MR, et al. Denosumab for prevention of fractures in postmenopausal women with osteoporosis. N Engl J Med. 2009;361:756-765. 
9. Stopeck AT, Lipton A, Body JJ, et al. Denosumab compared with zoledronic acid for the treatment of bone metastases in patients with advanced breast cancer: a randomized double-blind study. J Clin Oncol. 2010;28:5132-5139.

10. Terpos E, Sezer O, Croucher PI, et al. The use of bisphosphonates in multiple myeloma: recommendations of an expert panel on behalf of the European Myeloma Network. European Myeloma Network. Ann Oncol. 2009;20:1303-1317.

11. Saylor PJ, Smith MR. Bone health and prostate cancer. Prostate Cancer Prostatic Dis. 2010;13:20-27.

12. Ruggiero SL, Dodson TB, Assael LA, Landesberg R, Marx RE, Mehrotra B. American Association of Oral and Maxillofacial Surgeons position paper on bisphosphonate-related osteonecrosis of the jaws-2009 update. J Oral Maxillofac Surg. 2009:67:2-12.

13. Pautke C, Bauer F, Otto S, et al. Fluorescence-guided bone resection in bisphosphonate-related osteonecrosis of the jaws: first clinical results of a prospective pilot study. J Oral Maxillofac Surg. 2011;69:84-91.

14. Rocha GC, Jaguar GC, Moreira CR, Neves EG, Fonseca FP, Pedreira EN. Radiographic evaluation of maxillofacial region in oncology patients treated with bisphosphonates. Oral Surg Oral Med Oral Pathol Oral Radiol. 2012;114:19-25.

15. Bergdahl J, Jarnbring F, Ehrenstein V, et al. Evaluation of an algorithm ascertaining cases of osteonecrosis of the jaw in the Swedish National Patient Register. Clin Epidemiol. 2013;5:1-7.
16. Ulmner M, Jarnbring F, Törring O. Osteonecrosis of the jaw in Sweden associated with the oral use of bisphosphonate. J Oral Maxillofac Surg. 2014;72:76-82.

17. Kos M, Kuebler JF, Luczak K, Engelke W. Bisphosphonaterelated osteonecrosis of the jaws: a review of 34 cases and evaluation of risk. J Craniomaxillofac Surg. 2010;38:255-259.

18. Allen MR, Burr DB. Mandible matrix necrosis in beagle dogs after 3 years of daily oral bisphosphonate treatment. J Oral Maxillofac Surg. 2008;66:987-994.

19. Sambrook PN, Chen JS, Simpson JM, March LM. Impact of adverse news media on prescriptions for osteoporosis: effect on fractures and mortality. Med J Aust. 2010;193:154-156.

20. Wessel JH, Dodson TB, Zavras AI. Zoledronate, smoking, and obesity are strong risk factors for osteonecrosis of the jaw: a casecontrol study. J Oral Maxillofac Surg. 2008;66:625-631.

\section{Reprint requests:}

\section{Fredrik Hallmer}

Department of Oral and Maxillofacial Surgery and Oral Medicine Faculty of Odontology

Malmö University

20506 Malmö-SE

Sweden

fredrik.hallmer@mah.se 

II 



\section{Bacterial diversity in medication-related osteonecrosis of the (D) jaw}

Fredrik Hallmer, DDS, ${ }^{\mathrm{a}, \mathrm{b}}$ Tore Bjørnland, DDS, Dr odont, ${ }^{\mathrm{c}}$ Gunilla Andersson, DDS, Odont dr, ${ }^{\mathrm{d}}$ Jonas P. Becktor, DDS, Med dr, ${ }^{\mathrm{e}}$ Anne K. Kristoffersen, Senior Engineer, ${ }^{\mathrm{f}}$ and Morten Enersen, DDS, $\mathrm{PhD}^{\mathrm{g}}$

Objective. The aim was to study the association between microflora and medication-related osteonecrosis of the jaw (MRONJ) by using culture-independent molecular techniques to detect bacteria in necrotic bone lesions.

Study Design. Included were 18 consecutive patients with MRONJ, 10 with osteoporosis and 8 cancer patients. Bone biopsies were retrieved from the center of the necrotic bone and from visually healthy bone, and $16 S r R N A$ gene fragments from bacterial DNA were amplified with polymerase chain reaction.

Results. The study revealed a diversity of bacteria represented by $16 \mathrm{~S} r R N A$ sequences in all the necrotic bone samples and in $60 \%$ of the visually healthy bone. Eight dominating taxa groups were identified at the genus level: Porphyromonas,

Lactobacillus, Tannerella, Prevotella, Actinomyces, Treponema, Streptococcus, and Fusobacterium.

Conclusions. The necrotic bone lesions contained mainly anaerobic bacteria, representative of periodontal microflora,

suggesting that a periodontal infection in combination with antiresorptive treatment could initiate osteonecrosis. (Oral Surg

Oral Med Oral Pathol Oral Radiol 2017;123:436-444)

Medication-related osteonecrosis of the jaw (MRONJ) is a serious side effect associated with both bisphosphonate (BP) and denosumab treatment. It is defined by the American Association of Oral and Maxillofacial Surgeons as exposed necrotic bone or bone that can be probed through an intraoral or extraoral fistula in the maxillofacial region after current or previous treatment with antiresorptive or antiangiogenic agents. It must have persisted for longer than 8 weeks, with no history of radiation therapy to or obvious metastatic disease of the jaw. ${ }^{1}$

Data from a recent study carried out in southern Sweden showed that the prevalence of MRONJ in patients on oral BPs was $0.024 \%$, and in patients on intravenous treatment it was $2.8 \%{ }^{2}$

The antiresorptive drugs $\mathrm{BP}$ and denosumab are frequently used in high doses to treat skeletal complications induced by metastatic cancer ${ }^{3}$ and in low doses

This study was supported by grants from the Faculty of Odontology, Malmö University, Sweden.

${ }^{a}$ Consultant, Department of Oral and Maxillofacial Surgery, Skåne University Hospital, Lund, Sweden.

${ }^{b}$ Department of Oral and Maxillofacial Surgery, Malmö University, Faculty of Odontology, Malmö, Sweden.

cProfessor and Chairman, Department of Oral Surgery and Oral Medicine, Faculty of Dentistry, University of Oslo, Oslo, Norway.

${ }^{\mathrm{d}}$ Associate Professor, Department of Oral and Maxillofacial Surgery, Malmö University, Faculty of Odontology, Malmö, Sweden.

eAssociate Professor and Head, Department of Oral and Maxillofacial Surgery Malmö University, Faculty of Odontology, Malmö, Sweden. ${ }^{\mathrm{f}}$ Senior Engineer, Department of Oral Biology, Faculty of Dentistry, University of Oslo, Oslo, Norway.

${ }^{\mathrm{g}}$ Associate Professor, Department of Oral Biology, Faculty of Dentistry, University of Oslo, Oslo, Norway.

Received for publication Jun 20, 2016; returned for revision Oct 17, 2016; accepted for publication Nov 25, 2016.

(c) 2016 Elsevier Inc. All rights reserved.

2212-4403/\$ - see front matter

http://dx.doi.org/10.1016/j.oooo.2016.11.011 to treat osteoporosis. ${ }^{4,5}$ BPs inhibit bone resorption, turnover, and renewal through inhibition of osteoclasts. ${ }^{6,7}$ Denosumab, which also inhibits bone resorption, is a monoclonal antibody against the ligand of receptor activator of nuclear factor- $\kappa \mathrm{B}$ (RANKL). Denosumab inhibits RANKL from activating its receptor, RANK, on the surface of osteoclasts and their precursors. Prevention of RANKL-RANK interaction by denosumab inhibits osteoclast differentiation, function, and survival, thereby decreasing bone resorption. ${ }^{5}$

Osteoradionecrosis of the jaw is a complication of radiation therapy for treatment of malignancy in the maxillofacial region. The clinical appearance of MRONJ and osteoradionecrosis is similar, but the pathogenesis is supposedly different. Osteoradionecrosis is caused by local cell death in the bone due to radiation, and it has been proposed that the disease is triggered by a superficial secondary infection. ${ }^{8}$ Aas et al. ${ }^{9}$ demonstrated how marrow spaces of the mandible are infiltrated by a wide variety of bacterial species in patients with osteoradionecrosis. In conclusion, they stressed the need to be aware of these complex bacterial communities in future clinical therapy for these patients.

Although it is more than 10 years since a publication first described the pathogenesis of MRONJ, ${ }^{10}$ the disease is still poorly understood. Many hypotheses

\section{Statement of Clinical Relevance}

Whether infection is a primary or secondary event in the pathophysiology of medication-related osteonecrosis of the jaw (MRONJ) is controversial. This study reveals that the necrotic bone contains mainly periodontal microflora, suggesting that a periodontal infection could initiate osteonecrosis. 
Table I. Characteristics of 18 patients with medication-related osteonecrosis of the jaw treated with oral or intravenous bisphosphonate and/or subcutaneously administered denosumab

\begin{tabular}{lcclllc}
\hline Patient no. & Gender & Age & Due disease & Antiresorptive treatment & Trigger factor & Stage \\
\hline 1 & F & 86 & Osteoporosis & Alendronate & Tooth extraction & 2 \\
2 & F & 68 & Osteoporosis & Alendronate & Tooth extraction & 2 \\
3 & F & 70 & Osteoporosis & Alendronate & Denture trauma & 2 \\
4 & F & 72 & Osteoporosis & Alendronate & Tooth extraction & 2 \\
5 & F & 91 & Osteoporosis & Alendronate & Tooth extraction & 2 \\
6 & F & 68 & Osteoporosis & Alendronate & Tooth extraction & 2 \\
7 & F & 86 & Osteoporosis & Prolia + risedronate & Tooth extraction & 2 \\
8 & F & 70 & Osteoporosis & Alendronate & Tooth extraction & 2 \\
9 & F & 78 & Osteoporosis & Aclasta + alendronate & Tooth extraction & 2 \\
10 & F & 75 & Osteoporosis & Alendronate & Denture trauma & 2 \\
11 & F & 76 & Breast cancer & Xgeva + Zometa & Local infection & 2 \\
12 & F & 82 & Breast cancer & Xgeva & Tooth extraction & 1 \\
13 & F & 66 & Breast cancer & Xgeva & Local infection & 2 \\
14 & F & 41 & Breast cancer & Xgeva & Local infection & 2 \\
15 & M & 66 & Myeloma & Pamidronate & Tooth extraction & 2 \\
16 & M & 68 & Prostate cancer & Xgeva & Local infection & 2 \\
17 & M & 65 & Prostate cancer & Xgeva & Local infection & 2 \\
18 & M & 66 & Prostate cancer & Xgeva & Tooth extraction & 2 \\
\hline
\end{tabular}

have been proposed, and one of the most supported is that the bone necrosis is a result of BP-induced remodeling and suppression of bone in the jaw. It has also been debated whether the infection is a primary or secondary event in the pathophysiology. ${ }^{6}$

There is scarce literature studying the association between oral microflora and MRONJ. A study with limited sample size indicated that the bone associated with MRONJ was heavily colonized by specific oral bacteria. ${ }^{11}$ In osteoradionecrosis, ${ }^{9}$ the oral microflora seems to be a risk factor in development of the lesion. The aim of the present study was to investigate the association between the oral microbiota and BP- or denosumab-induced osteonecrosis of the jaw by using $16 S$ rRNA pyrosequencing technique.

\section{MATERIALS AND METHODS \\ Patients}

Twenty-two consecutive patients with MRONJ referred to the Departments of Oral and Maxillofacial Surgery, Skåne University Hospital, Sweden, between June 2013 and February 2015 were recruited for the study. All patients were living in an area of southern Sweden with a population base of 1.3 million. The following data were recorded before treatment in case report form: gender, age, due disease, BP and/or denosumab therapy and dosage, other medical treatment, and inciting factors, site, and staging of MRONJ.

Eighteen patients were included in the study, and the detailed data are presented in Table I.

Four patients were excluded due to current antibiotic treatment or antibiotic treatment within 3 months prior to the study. Ethical approval was given by the Ethical Board in Lund, Sweden (Dnr 2012/760). The study was conducted in compliance with the Helsinki Declaration, and each patient in the project signed a detailed informed consent form.

\section{Location and staging of the osteonecrosis}

The location of the necrosis was defined, according to Rocha et al., ${ }^{12}$ as follows: where the jaw bones divided into right posterior maxilla (segment 1), anterior maxilla (segment 2), left posterior maxilla (segment 3), left posterior mandible (segment 4), anterior mandible (segment 5), and right posterior mandible (segment 6), using the distal surface of the canines as reference. $^{12}$

The disease was staged 0-4 according to the 2014 recommendations of the American Association of Oral and Maxillofacial Surgeons. ${ }^{1}$ Stage 0 was defined as no clinical evidence of necrotic bone but nonspecific clinical findings, radiographic changes, and symptoms; stage 1 as exposed necrotic bone or fistulas that probe to bone without pain or signs of infection (asymptomatic); stage 2 as exposed necrotic bone or fistulas that probe to bone with pain and/or signs of infection (symptomatic); and stage 3 as exposed necrotic bone or fistulas that probe to bone with pain and/or signs of infection and one or more of the following: pathological fracture, orocutaneous fistula, involvement of the maxillary sinus, or necrosis extending to the inferior border of the ramus of the mandible. ${ }^{1}$

\section{Bone sample collection}

The bone samples were retrieved by the same surgeon at the Department of Oral and Maxillofacial Surgery, Skåne University Hospital, and analyzed at the 


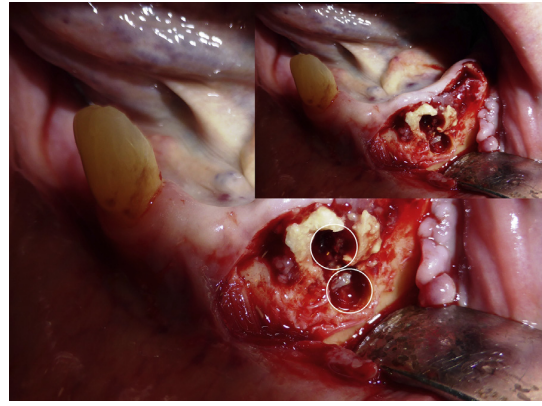

Fig. 1. Two separate bone biopsies were collected from each patient in relation to the surgical treatment of the necrosis. The superior sample was retrieved from the center of the necrotic bone lesion and the inferior sample was then retrieved from a region of visually healthy bone adjacent to the necrotic bone.

Department of Oral Biology, Faculty of Dentistry, University of Oslo, Norway.

Two separate bone biopsies were collected from each patient in relation to the surgical treatment of the necrosis. The biopsies were collected with 2 separate 3-mm sterile trepan burrs. After removing the superficial layers exposed to the oral milieu with a round burr under irrigation with saline, the first sample was retrieved from the center of the necrotic bone lesion. The second sample was then retrieved from a region of visually healthy bone adjacent to the necrotic bone (Figure 1). Special care was taken not to contaminate the biopsy areas before, during, or after sampling. Each biopsy was immediately placed in a cryotube with DNA/RNA stabilizing solution (RNA Later) and frozen for further storage at $-20^{\circ} \mathrm{C}$.

In 2 healthy patients, bone biopsies were collected in relation to planned surgical extraction of impacted third molars without any signs of local odontogenic infection. The biopsies were collected as described above.

\section{Bacterial analysis}

DNA extraction and polymerase chain reaction. DNA extractions of clinical samples were performed using the MasterPure DNA isolation kit from Epicentre (MCD85201, Epicentre Biotechnologies, WI). $16 \mathrm{~S}$ $r R N A$ gene fragments from bacterial DNA were amplified with polymerase chain reaction (PCR) using universal eubacterial primers, forward primer $334 \mathrm{f} \mathrm{(5-}$ CCAGACTCCTACGGGAGGCAGC- $3^{\prime}$ ), and reverse primer 939 r (5'CTTGTGCGGGCCCCCGTCAATTC$\left.3^{\prime}\right),{ }^{13,14}$ targeting the V3-V5 hypervariable region. PCR reactions were performed with 32 cycles in $20 \mu 1$ mixture of OneTaq supermix (New England Biolabs,
Ipswich, MA, USA) in an Applied Biosystems (Foster City, CA, USA) PCR cycler. A second PCR with index fusion adaptorprimer A with $16 \mathrm{~S} r R N A 334 \mathrm{f}$ sequence and adaptorprimer B with $16 S$ rRNA $939 \mathrm{r}$ sequence was performed with 26 cycles. Then the amplicons were purified using Agencourt Ampure Beads (Agencourt Bioscience, Beckman Coulter, Brea, CA, USA) followed by DNA quantitation and quality examination using the 2100 Bioanalyzer and the High Sensitivity DNA Assay kit (Agilent Technologies, Santa Clara, CA, USA). The final amplicon preparation products were used in emulsion PCR with the Roche GS Lib-L kit (Roche Diagnostics, Mannheim, Germany) with a molecules-per-bead ratio of 0.7. The emulsion PCR, library bead purification, and sequencing on the 454 GS Junior Roche system were performed according to the manufacturer.

Pyrosequencing data processing and taxonomic classification. A data analysis workflow based on the Quantitative Insights Into Microbial Ecology (QIIME) pipeline was implemented. ${ }^{15,16}$ Pyrosequencing data standard flowgram format file was demultiplexed with the command split_library.py, with restriction in read length removal of reads that were smaller than 300 bases and larger than 600 bases. Then the command denoise_wrapper.py was used to remove homopolymers and qualify the correct signaling bases in the sequence, thus increasing the accuracy of the whole QIIME pipeline.

Chimera filtering was performed afterward using the UCHIME algorithm by either the reference-based or de novo method. ${ }^{17}$ Reads that were classified as chimeric by both methods were removed.

Picking otu was selected with the open reference otus.py with $16 S r R N A$ reference database from Silva database (SSU Ref NR 119) and from the Human Oral Microbiome Database (HOMD) (16 $S$ rRNA Ref Seq Version 13.2 FASTA file in QIIME format). The command core_diversity_analyses.py was used to evaluate the diversity of the microbial community within a sample $(\alpha$-diversity) and between samples ( $\beta$-diversity).

The microbiome profiles from QIIME analysis were also used in Megan 5.2.3 to visualize and evaluate the microbial community diversity at the genus level. Species diversity in each sample was determined by blasting individual sample fast sequence directly in HOMD $16 S$ rRNA.

\section{RESULTS}

\section{Underlying disease}

The most common underlying disease was osteoporosis $(\mathrm{n}=10,56 \%)$, followed by breast cancer $(\mathrm{n}=4,22 \%)$, prostate cancer $(\mathrm{n}=3,17 \%)$, and multiple myeloma $(\mathrm{n}=1,6 \%)$. Altogether, 18 patients with MRONJ (14 female, 4 male), with a mean age of 71.9 years 
Table II. Diversity index in necrotic bone samples ( $\mathrm{n}=18$ samples $)$

\begin{tabular}{lccc}
\hline & Chaol & Shannon & Phylogenetic distance \\
\hline Average & 175.4 & 3.32 & 11.41 \\
Maximum & 326.95 & 6.9 & 18.33 \\
Minimum & 37.6 & 1.86 & 3.56 \\
\hline
\end{tabular}

(range, 41-91 years), were included in the study (Table I).

\section{Antiresorptive treatment}

The most common antiresorptive treatments were oral BPs for 8 patients, followed by subcutaneously administered denosumab for 6 patients, a combination of oral and intravenous BPs or denosumab for 3 patients, and intravenous BPs for 1 patient (Table I).

\section{Site}

In 15 cases of MRONJ, the lesion was located in the mandible. Six lesions were localized in the right posterior mandible (segment 6), five in the left posterior mandible (segment 4), 2 in the anterior mandible (segment 5), and 2 in the anterior and left posterior mandible (segments 5 and 4). Three cases were localized in the maxilla, 2 in the left posterior (segment 3 ) and 1 each in the anterior and right posterior maxilla (segments 1 and 2; Table I).

\section{Stage}

One patient was classified as stage 1 and 17 patients were classified as stage 2 (Table I).

\section{Trigger factors}

The necrotic lesions were initiated by tooth extraction in 11 patients, local infection in 5 patients, and trauma due to denture wear in 2 patients (Table I).

\section{Pyrosequencing data}

After a quality check including denoising and chimera check (UCHIME) analysis, 86,225 reads were evaluated. In necrotic bone samples from 18 patients, all were strongly positive for $16 S \mathrm{rRNA}$ PCR. Visually healthy bone samples from 7 patients (nos. 2, 4, 5, 10, 17, 12, and 13) were negative for $16 S r R N A$ PCR. In 11 patients, the visually healthy bone was also detected as positive, where 6 PCR products were strong and 5 weak. There was a mean of 3245 reads per necrotic bone sample; the lowest number was 242 and the highest 9632 .

For the visually healthy bone samples, the mean was 2528 reads, with the lowest number 231 and the highest 5662 .
Table III. Diversity index in visual healthy bone samples ( $\mathrm{n}=11$ samples)

\begin{tabular}{lccc}
\hline & Chaol & Shannon & Phylogenetic distance \\
\hline Average & 101.4 & 2.56 & 7.5 \\
Maximum & 260.7 & 5.70 & 17.8 \\
Minimum & 16.75 & 1.16 & 2.9 \\
\hline
\end{tabular}

\section{Rarefaction}

From 86,225 reads, 82,513 (95.7\%) were assigned, and rarefaction analysis showed that after 500 reads, nearly all operational taxonomic units were observed, and after 1000 reads, saturation was seen. There was no significantly higher diversity in the sample with a very high number of reads.

The alpha diversity was measured by Chao1, Shannon, and phylogenetic distance (PD) (Tables II and III).

The average diversity index (Chao1, Shannon, PD) for the necrotic bone samples $(n=18)$ was higher than for the visually healthy bone samples $(n=11)$, indicating greater diversity in the necrotic bone samples.

\section{Phyla observed in all samples}

Seven taxa (operational taxonomic units) were detected at the phylum level in all bone samples (82,513 reads). The most abundant bacterial phylum in both necrotic and visual healthy bone samples was Bacteroidetes (36,671 reads, $44.0 \%)$, followed by Firmicutes $(29,340$ reads, $35.5 \%$ ), Synergistetes (7411 reads, $8.9 \%$ ), Actinobacteria (4334 reads, 5.0\%), Spirochaetes (2402 reads, 2.9\%), Fusobacteria (2048 reads, 2.4\%), and Proteobacteria (227 reads, $0.3 \%$ ).

\section{Abundance of the bacterial groups at the genus level}

At the genus level, 37 taxa groups were detected, 26 taxa with more than 10 reads, and 8 with fewer than 4 reads. Nine OTUs were identified in 1 sample, and 5 were identified in fewer than 3 samples.

Eight dominating taxa groups were identified at the genus level in both necrotic and visual healthy bone samples: Porphyromonas, Lactobacillus, Tannerella, Prevotella, Actinomyces, Treponema, Streptococcus, and Fusobacterium. In some patients, the periopathogenic bacteria dominated, and in others, Lactobacillus or Prevotella dominated. It was of interest to compare bacterial diversity between different antiresorptive treatments, although it is a small study. Patients with osteoporosis are on the left side of the diagram and those with cancer on the right side (Figure 2).

When comparing necrotic samples from patients with osteoporosis treated with BPs, a higher level of 


\section{Osteoporosis patients}

(1-10)

\section{Cancer patients}

(11-14 breast c., 15 myeloma, $16-18$ prostata c.)

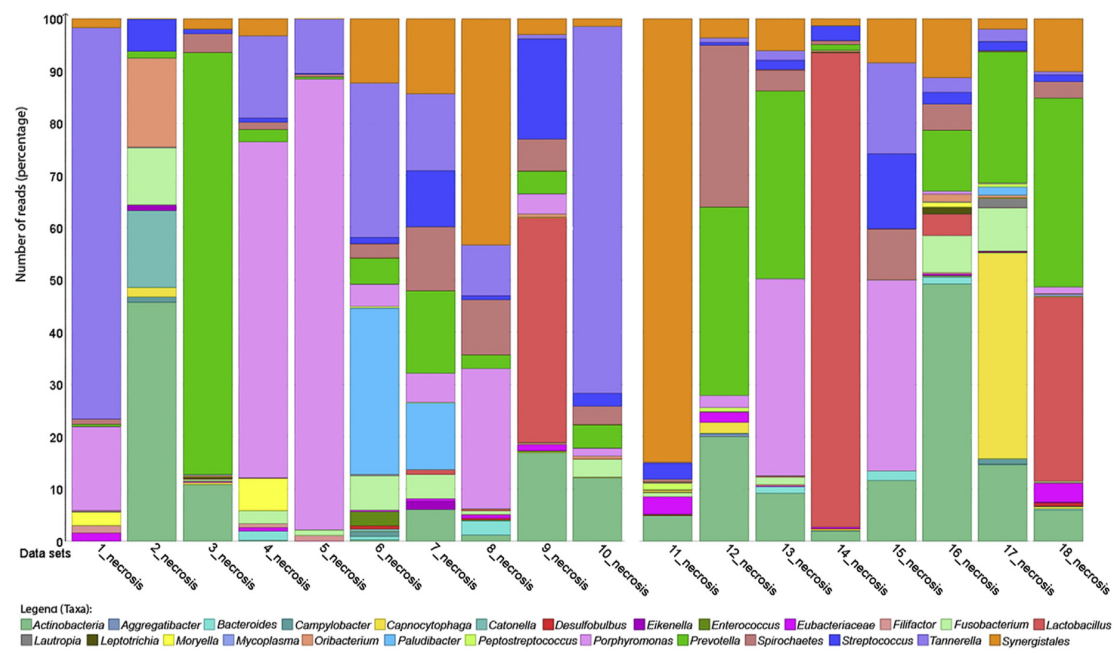

Fig. 2. Taxonomic profiles at the genus level of all necrotic bone samples.

periodontal bacteria was detected in this group than in the group treated with denosumab (Xgeva).

Comparing the taxonomic profiles of the necrotic and visually healthy bone samples in each patient, the pair of samples mirrored each other in 5 patients. When using a cut-off limit of 500 reads per sample, a clear picture of the similarity in each pair was seen, as shown in Figure 3. The microflora inside the necrotic lesions have an oral origin. Detection of the same microflora in the peripheral zone of the lesion (visually healthy bone) indicates the flow of microorganisms through the bone texture (Figure 3).

Analyses of the bone samples from the 2 healthy controls were negative for $16 \mathrm{~S} r R N A$ by PCR.

\section{Diversity in species}

When searching for specific species in each genus group, we found high diversity in nearly all dominating genera, showing high diversity in samples with few reads as well as those with more than 1000 reads. Samples with more than 3000 reads just had more reads of each of the species found in samples with fewer reads. The species list in each genus group is identified as $99-100 \%$ in $500-550$ bases (Table III). Streptococcus oralis and Streptococcus mitis have $100 \%$ identity in this area of $16 S$ rRNA, the fragment nt350-nt900.
The greatest diversity was observed in the genus groups Actinomyces, Eubacterium, Fusobacterium, Lactobacillus, Prevotella, Streptococcus, and Treponema, as illustrated in Table IV.

\section{DISCUSSION}

This study reveals a diversity of bacteria represented by $16 S r R N A$ sequences in all the necrotic bone samples and in the peripheral zones of $60 \%$ of the lesions. Meticulous care was taken not to contaminate biopsies from visually healthy bone in the MRONJ patients. Since the bacterial profiles of the visually healthy bone samples mirrored the necrotic bone samples from the same patients (Figure 3), it is probably not contamination from handling of the biopsies. Despite that, it is not possible to rule out contamination. Another plausible explanation is that the necrotic lesions were more extended in the jaw bone than could be judged by clinical and radiological findings. However, it was not possible to take bone biopsies from another part of the jaw, since the risk of inducing a new site of MRONJ was calculated to be too high. The results of the biopsies from the 2 healthy controls indicate that bone penetration is not likely to occur in healthy bone. 


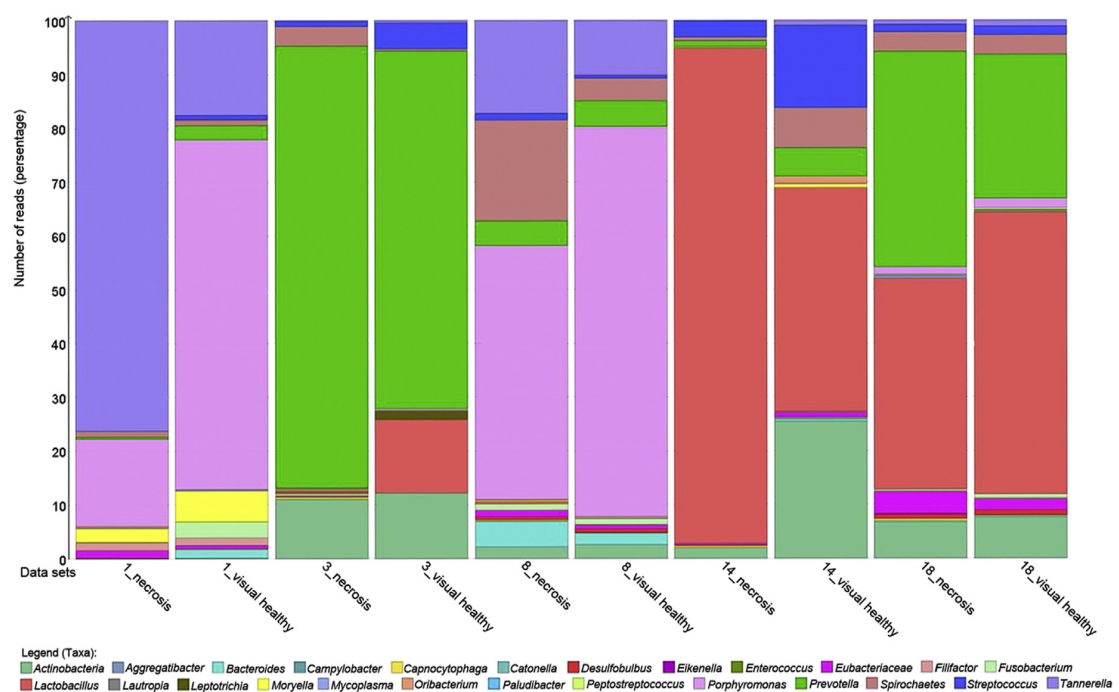

Fig. 3. Taxonomic profile in necrotic versus visual healthy bone samples that mirror each other appears clearly when sample reads are $>500$.

Table IV. Overview of most prevalent bacteria at species level

\begin{tabular}{|c|c|c|c|c|c|c|c|}
\hline Actinomyces & Eubacterium & Fusobacterium & Lactobacillus & Porphyromonas & Prevotella & Streptococcus & Treponema \\
\hline cardiffensis & infirmum & naviforme & acidophilus & cndodontalis & baroniae & anginosus & denticola \\
\hline gerencseriae & brachy & $\begin{array}{c}\text { nucleatum ss } \\
\text { nucleatum }\end{array}$ & catenaformis & gingivalis & buccae & constellatus & lecithinolyticum \\
\hline israelii & minutum & $\begin{array}{l}\text { nucleatum ss } \\
\text { polymorphum }\end{array}$ & crispatus & & denticola & gordonii & maltophilum \\
\hline massiliensis & nodatum & $\begin{array}{c}\text { nucleatum ss } \\
\text { vincentii }\end{array}$ & gasseri & & intermedia & intermedius & parvum \\
\hline meyeri & yurii & $\begin{array}{l}\text { nucleatum ss. } \\
\text { animalis }\end{array}$ & johnsonii & & Maculosa & oligofermentans & socranskii \\
\hline \multirow[t]{8}{*}{ oris } & \multirow[t]{8}{*}{ saburreum } & & oris & & marshii & oralis/mitis & $\begin{array}{l}\text { socranskii ss } \\
\text { buccale }\end{array}$ \\
\hline & & & panis & & melaninogenica & parasanguinis I & $\begin{array}{r}\text { socranskii ss } \\
\text { socranskii }\end{array}$ \\
\hline & & & pentosus & & multiformis & parasanguinis II & vincentii \\
\hline & & & rhamnosus & & multisaccharivorax & peroris & \\
\hline & & & vaginalis & & nigrescens & salivarius & \\
\hline & & & & & oralis & sanguinis & \\
\hline & & & & & oris & sinensis & \\
\hline & & & & & $\begin{array}{l}\text { pleuritidis } \\
\text { shahii }\end{array}$ & & \\
\hline
\end{tabular}

No other bone in the body is as frequently exposed to infection as the jaw bone, where odontogenic infection sites can be present before BP or denosumab treatment starts. In this study, no control samples were taken of jaw bone before treatment with BP or monoclonal antibody in order to confirm an earlier infectious process because of ethical considerations. There are no available reports of periodontitis before beginning antiresorptive treatment to support a transfer of periopathogens.

Our results indicate a transfer of periopathogenic bacteria to the jaw bone before or during treatment. 
Whether the treatment itself induces changes in the bone structure and makes it available to oral microflora is an open question. However, our findings indicate that the diversity of microbiota may be involved in MRONJ lesions, as primary or secondary infectious agents.

There are different hypotheses concerning the pathophysiology of MRONJ. Many studies have reported the most common initiating factor for its development to be dentoalveolar trauma, with tooth extraction accounting for most cases. ${ }^{2,18,19}$ Development of MRONJ is also reported to occur spontaneously. However, minor trauma resulting in lesions of the oral mucosa could also lead to MRONJ, which might be the cause in those cases reported as spontaneously occurring. ${ }^{20}$

Another more likely hypothesis is that oral infection might play a leading part in the pathogenesis of MRONJ. After tooth extraction, oral bacteria gain access to the bone and can easily colonize the extraction socket. ${ }^{1,21,22}$ A study by Thumbigere-Math et al. ${ }^{23}$ revealed that patients with MRONJ had more teeth with clinical attachment loss and more missing teeth compared with controls. These results indicate that periodontal infection could be a possible risk factor in the development of MRONJ lesions. ${ }^{23}$ Periodontal disease is a polymicrobial chronic infection, ${ }^{22,24,25}$ and the periodontal microbiota are diverse and always dominated by anaerobic and facultative species as opportunistic pathogens. ${ }^{26}$ The red and orange complex bacteria described by Socransky et al. are a collection of potent anaerobic bacteria contributing to progression of chronic periodontitis. ${ }^{27}$ Porphyromonas gingivalis, Tannerella forsythia, and Treponema denticola, considered the red complex bacteria, represent an indicator of progression of periodontal destruction together with the members of the orange complex, although the periodontal microbiota are more diverse. $^{27}$ The results of the present study show that all samples harbored periodontal pathogens, including those from the 2 edentulous patients (Table I), indicating that these bacterial species might precede or be part of the development of MRONJ. Although there is general acceptance that there is a change in the microbiota from dentate to edentulism, it is well documented that periodontal pathogens can also be detected in patients with full dentures. ${ }^{28,29}$

Other studies also indicate periopathogenic-related infection; Hansen et al. ${ }^{30}$ detected Actinomyces israelii and Sedghizadesh et al. ${ }^{31}$ observed Fusobacterium, Actinomyces species, and Treponema by using electron microscopy.

The multifactorial process of bone homeostasis in these patients may be disrupted by N-BPs. However, bacterial migration may be an important part of progressive osteonecrosis by inducing inflammation in the border between necrotic and healthy bone.
In the present study, Porphyromonas gingivalis, Treponema denticola and Tannerella forsythia were observed in the necrotic bone samples and in the visually healthy peripheral zone. Of these 3 species, only Treponema denticola is motile and able to respond chemotactically to environmental stimuli. ${ }^{32}$ Treponema species play a role in the etiology of several human chronic diseases, including syphilis and yaws (T. pallidum), periodontal disease including chronic periodontitis, and acute necrotizing ulcerative gingivitis ( $T$. denticola, T. lecithinolyticum, T. socranskii, and others). We observed several Treponema species in the necrotic bone samples, including those 3 mentioned by Holt and Ebersole ${ }^{33}$ and Mysak. ${ }^{34}$

Destructive periodontitis is associated with a Th1-Th17 immune response and activation of RANKLinduced osteoclasts. Polymicrobial intraoral inoculation of Porphyromonas gingivalis, Treponema denticola, and Tannerella forsythia has been shown to cause high levels of bone resorption. ${ }^{3,36}$ In addition, Porphyromonas gingivalis $\mathrm{K} 1$ and $\mathrm{K} 2$ serotypes induce a strong Th1-Th17 response. These serotypes induce higher osteoclast activation by increased Th17-associated RANKL production and an antigen-specific memory T lymphocyte response. ${ }^{37}$ The patients treated with BPs had more Porphyromonas gingivalis in their necrotic samples than the patients treated with monoclonal antibodies against RANKL, indicating an active role of $\mathrm{BP}$ in inducing environmental conditions for periopathogenic bacteria. Pushalkar et al. ${ }^{38}$ also found Fusobacterium nucleatum, Prevotell denticola, and Bacteroidetes in MRONJ patients, although they also found high titers of Streptococcus spp. In addition, they also analyzed antimicrobial genes and found specific genes such as leukocyte secretory protease inhibitor, proteinase 3, and several interleukins upregulated, whereas several other genes specifically downregulated. This indicates a bacterial trigger for the necrosis.

One hypothesis has been that MRONJ is caused by an acidic milieu. At neutral $\mathrm{pH}, \mathrm{BPs}$ bind to bone and are known to be released from bone in an acidic milieu. ${ }^{39}$ In this study, we found $16 S$ rRNA sequences of bacterial species commonly found in periodontal infections. These anaerobic bacteria are known to digest protein compounds and peptides in cell tissue and thereby elaborate various compounds such as $\mathrm{H}_{2} \mathrm{~S}, \mathrm{NH}_{3}$, and amines that elicit an inflammatory response responsible for loss of periodontal tissue, pocket formation, and loosening and loss of teeth. These bacteria are known to produce a basophilic milieu. ${ }^{40-42}$ Therefore, there might be factors other than acidic milieu that contribute to the development of MRONJ, since our results indicate that polymicrobial interaction is part of its progression. 
Furthermore, the results of the present study might suggest that the same prophylactic dental-decision protocol for patients intended for radiation of the jaw due to head and neck cancer ${ }^{43}$ could be considered for patients scheduled for BP or denosumab treatment. Teeth with severe periodontal disease should be removed before antiresorptive treatment. This might reduce the number of patients who develop MRONJ. Further studies are needed to confirm the hypothesis.

\section{CONCLUSION}

The necrotic bone lesions contained mainly anaerobic bacteria, representative of periodontal microflora, suggesting that a periodontal infection in combination with antiresorptive treatment could initiate osteonecrosis. The choice of antibiotic treatment when indicated seems to be a drug sensitive to anaerobic bacteria.

\section{REFERENCES}

1. Ruggiero SL, Dodson TB, Fantasia J, et al. American Association of Oral and Maxillofacial Surgeons position paper on medicationrelated osteonecrosis of the jaw: 2014 update. J Oral Maxillofac Surg. 2014:72:1938-1956.

2. Hallmer F, Bjørnland T, Nicklasson A, Becktor JP, Andersson G. Osteonecrosis of the jaw in patients treated with oral and intravenous bisphosphonates: experience in Sweden. Oral Surg Oral Med Oral Pathol Oral Radiol. 2014;118:202-208.

3. Cleeland CS, Body JJ, Stopeck A, et al. Pain outcomes in patients with advanced breast cancer and bone metastases: results from a randomized, double-blind study of denosumab and zoledronic acid. Cancer. 2013;119:832-838.

4. Sambrook P, Cooper C. Osteoporosis. Lancet (London). 2006;367:2010-2018.

5. Cummings SR, Martin JS, McClung MR, et al. Denosumab for prevention of fractures in postmenopausal women with osteoporosis. N Engl J Med. 2009;361:756-765. Available at: http://www. nejm.org/doi/full/10.1056/NEJMoa0809493. Accessed May 10, 2016.

6. Allen MR, Burr DB. The pathogenesis of bisphosphonate-related osteonecrosis of the jaw: so many hypotheses, so few data. J Oral Maxillofac Surg. 2009;67(Suppl 5):61-70.

7. Allen MR, Burr DB. Bisphosphonate effects on bone turnover, microdamage, and mechanical properties: what we think we know and what we know that we don't know. Bone. 2011:49:56-65.

8. Marx RE. Osteoradionecrosis: a new concept of its pathophysiology. J Oral Maxillofac Surg. 1983;41:283-288.

9. Aas JA, Reime L, Pedersen K, et al. Osteoradionecrosis contains a wide variety of cultivable and non-cultivable bacteria. J Oral Microbiol. 2010;2:5072.

10. Marx RE. Pamidronate (Aredia) and zoledronate (Zometa) induced avascular necrosis of the jaws: a growing epidemic. J Oral Maxillofac Surg. 2003;61:1115-1117.

11. Wei X, Pushalkar S, Estilo C, et al. Molecular profiling of oral microbiota in jawbone samples of bisphosphonate-related osteonecrosis of the jaw. Oral Dis. 2012;18:602-612.

12. Rocha GC, Jaguar GC, Moreira CR, Neves EG, Fonseca FP, Pedreira EN. Radiographic evaluation of maxillofacial region in oncology patients treated with bisphosphonates. Oral Surg Oral Med Oral Pathol Oral Radiol. 2012;114(Suppl 5):S19-S25.
13. Baker GC, Smith JJ, Cowan DA. Review and re-analysis of domain-specific 16 S primers. J Microbiol Methods. 2003;55: 541-555.

14. Wang Y, Qian P-Y. Conservative fragments in bacterial $16 \mathrm{~S}$ rRNA genes and primer design for $16 \mathrm{~S}$ ribosomal DNA amplicons in metagenomic studies. PLoS One. 2009;4:e7401.

15. Kuczynski J, Stombaugh J, Walters WA, González A, Caporaso JG, Knight R. Using QIIME to analyze $16 \mathrm{~S}$ rRNA gene sequences from microbial communities. Curr Protoc Microbiol. 2012; Chapter 1:Unit 1,E.5.

16. Gaspar JM, Thomas WK. Assessing the consequences of denoising marker-based metagenomic data. PLoS One. 2013;8: e60458.

17. Edgar RC, Haas BJ, Clemente JC, Quince C, Knight R. UCHIME improves sensitivity and speed of chimera detection. Bioinformatics. 2011;27:2194-2200.

18. Schiodt M, Reibel J, Oturai P, Kofod T. Comparison of nonexposed and exposed bisphosphonate-induced osteonecrosis of the jaws: a retrospective analysis from the Copenhagen cohort and a proposal for an updated classification system. Oral Surg Oral Med Oral Pathol Oral Radiol. 2014;117:204-213.

19. Otto S, Schreyer C, Hafner S, et al. Bisphosphonate-related osteonecrosis of the jaws: characteristics, risk factors, clinical features, localization and impact on oncological treatment. J Craniomaxillofac Surg. 2012:40:303-309.

20. Yazdi PM, Schiodt M. Dentoalveolar trauma and minor trauma as precipitating factors for medication-related osteonecrosis of the jaw (ONJ): a retrospective study of 149 consecutive patients from the Copenhagen ONJ Cohort. Oral Surg Oral Med Oral Pathol Oral Radiol. 2015;119:416-422.

21. Stockmann P, Wehrhan F, Schwarz-Furlan S, et al. Increased human defensine levels hint at an inflammatory etiology of bisphosphonate-associated osteonecrosis of the jaw: an immunohistological study. J Transl Med. 2011:9:135.

22. Loesche WJ, Grossman NS. Periodontal disease as a specific, albeit chronic, infection: diagnosis and treatment. Clin Microbiol Rev, 2001:14:727-752:table of contents.

23. Thumbigere-Math V, Michalowicz BS, Hodges JS, et al. Periodontal disease as a risk factor for bisphosphonate-related osteonecrosis of the jaw. J Periodontol. 2014;85:226-233.

24. Peters BM, Jabra-Rizk MA, O'May GA, Costerton JW, Shirtliff ME. Polymicrobial interactions: impact on pathogenesis and human disease. Clin Microbiol Rev. 2012;25:193-213.

25. Hajishengallis G, Lamont RJ, Graves DT. The enduring importance of animal models in understanding periodontal disease. Virulence. 2015;6:229-235.

26. Haffajee AD, Japlit M, Bogren A, Kent RL, Goodson JM, Socransky SS. Differences in the subgingival microbiota of Swedish and USA subjects who were periodontally healthy or exhibited minimal periodontal disease. J Clin Periodontol. 2005;32:33-39.

27. Socransky SS, Haffajee AD, Cugini MA, Smith C, Kent RL. Microbial complexes in subgingival plaque. J Clin Periodontol. 1998;25:134-144.

28. Sachdeo A, Haffajee AD, Socransky SS. Biofilms in the edentulous oral cavity. J Prosthodont. 2008;17:348-356.

29. O'Donnell LE, Robertson D, Nile CJ, et al. The oral microbiome of denture wearers is influenced by levels of natural dentition. PLoS One. 2015;10:e137717.

30. Hansen T, Kunkel M, Springer E, et al. Actinomycosis of the jaws: histopathological study of 45 patients shows significant involvement in bisphosphonate-associated osteonecrosis and infected osteoradionecrosis. Virchows Arch. 2007;451:1009-1017.

31. Sedghizadeh PP, Kumar SKS, Gorur A, Schaudinn C, Shuler CF, Costerton JW. Identification of microbial biofilms in 
osteonecrosis of the jaws secondary to bisphosphonate therapy. J Oral Maxillofac Surg. 2008:66:767-775.

32. Dashper SG, Seers CA, Tan KH, Reynolds EC. Virulence factors of the oral spirochete Treponema denticola. J Dent Res. 2011;90: 691-703.

33. Holt SC, Ebersole JL. Porphyromonas gingivalis, Treponema denticola, and Tannerella forsythia: the "red complex," a prototype polybacterial pathogenic consortium in periodontitis. Periodontol 2000. 2005;38:72-122.

34. Mysak J, Podzimek S, Sommerova P, et al. Porphyromonas gingivalis: major periodontopathic pathogen overview. J Immunol Res. 2014;2014:476068

35. Kesavalu L, Bakthavatchalu V, Rahman MM, et al. Omega-3 fatty acid regulates inflammatory cytokine/mediator messenger RNA expression in Porphyromonas gingivalis-induced experimental periodontal disease. Oral Microbiol Immunol. 2007;22:232-239.

36. Kesavalu L, Sathishkumar S, Bakthavatchalu V, et al. Rat model of polymicrobial infection, immunity, and alveolar bone resorption in periodontal disease. Infect Immun. 2007:75:1704-1712.

37. Vernal R, Díaz-Zúñiga J, Melgar-Rodríguez S, et al. Activation of RANKL-induced osteoclasts and memory $\mathrm{T}$ lymphocytes by Porphyromonas gingivalis is serotype dependant. J Clin Periodontol. 2014:41:451-459.

38. Pushalkar S, Li X, Kurago Z, et al. Oral microbiota and host innate immune response in bisphosphonate-related osteonecrosis of the jaw. Int J Oral Sci. 2014:6:219-226.
39. Russell RGG, Watts NB, Ebetino FH, Rogers MJ. Mechanisms of action of bisphosphonates: similarities and differences and their potential influence on clinical efficacy. Osteoporos Int. 2008;19: 733-759.

40. Cimasoni G. Crevicular fluid updated. Monogr Oral Sci. 1983;12: III-VII:1-152. Available at: http://europepmc.org/abstract/med/ 6348520. Accessed May 10, 2016.

41. Bickel M, Cimasoni G. The $\mathrm{pH}$ of human crevicular fluid measured by a new microanalytical technique. J Periodontal Res. 1985;20:35-40.

42. Byrne N, Strous M, Crépeau V, et al. Presence and activity of anaerobic ammonium-oxidizing bacteria at deep-sea hydrothermal vents. ISME J. 2009;3:117-123.

43. Bruins HH, Jolly DE, Koole R. Preradiation dental extraction decisions in patients with head and neck cancer. Oral Surg Oral Med Oral Pathol Oral Radiol Endod. 1999;88:406-412.

Reprint requests:

Fredrik Hallmer

Department of Oral and Maxillofacial Surgery

Faculty of Odontology

Malmö University

20506 Malmö-SE

Sweden

Fredrik.hallmer@mah.se 

III 



\title{
Prevalence, initiating factor, and treatment outcome of medication-related osteonecrosis of the jaw-a 4-year prospective study
}

\author{
Fredrik Hallmer, DDS, ${ }^{a}$ Gunilla Andersson, DDS, Odont. Dr., ${ }^{\mathrm{b}}$ Bengt Götrick, DDS, Odont. Dr., ${ }^{\mathrm{c}}$ \\ Gunnar Warfvinge, DDS, Odont. Dr., ${ }^{\mathrm{d}}$ Jonas Anderud, DDS, Odont. Dr., ${ }^{\mathrm{e}}$ and Tore Bjørnland, DDS, Odont. Dr. ${ }^{\mathrm{f}}$
}

\begin{abstract}
Objectives. Medication-related osteonecrosis of the jaw (MRONJ) has a wide range of prevalence, and a standard therapy has not yet been established. The aim of this study was to analyze the prevalence and initiating factors of MRONJ and the outcomes of surgical therapy.

Study Design. In a prospective cohort study, all patients diagnosed with MRONJ in the Region of Skåne, in Sweden, were included. Predictor variables (comorbidity, site, stage, gender) and initiating factors (tooth extraction, periodontitis) were recorded. Surgical treatment was sequestrectomy or block resection, and the outcome variable was healing after 2 months. To estimate the prevalence, data on the use of bisphosphonate and denosumab were used.

Results. Fifty-five patients with MRONJ were identified. The prevalence of MRONJ was $0.043 \%$ among patients treated with oral bisphosphonates, $1.03 \%$ among those on intravenous bisphosphonates and $3.64 \%$ in those on high-dose denosumab. Periodontal disease preceded development of MRONJ in 41 patients. Fifty patients were treated surgically and followed up for at least 2 months. Remission or healing occurred in $80 \%$ of patients treated with sequestrectomy and in $92.5 \%$ of patients treated with block resection.

Conclusions. The prevalence of MRONJ in Sweden is low. Periodontitis is the most common initiating factor. The outcome of treatment of MRONJ is healing in most patients treated surgically. (Oral Surg Oral Med Oral Pathol Oral Radiol 2018;126:477-485)
\end{abstract}

The antiresorptive drugs bisphosphonates (BPs) and denosumab are widely, efficiently, and safely used in osteoporosis to preserve and strengthen existing bone by increasing its mineralization, to treat hypercalcemia of malignancy, and to treat bone metastasis of solid malignant tumors. ${ }^{1-5}$ Intravenous BPs and denosumab are mainly used in patients with metastatic bone disease, such as metastatic breast cancer and metastatic prostate cancer, or in patients with multiple myeloma. ${ }^{2-5}$ In patients with osteoporosis, oral BPs are mostly used. In some patients who do not tolerate oral BPs, zoledronic acid can be used as an annual infusion or denosumab as subcutaneous injection twice a year for the treatment of osteoporosis. ${ }^{2,6}$ BPs inhibit bone

${ }^{a}$ Consultant, Department of Oral and Maxillofacial Surgery, Malmö University, Faculty of Odontology, Malmö, Sweden; Skåne University Hospital, Kristianstad, Helsingborg, Malmö, Lund, Sweden.

${ }^{\mathrm{b}}$ Associate Professor, Department of Oral and Maxillofacial Surgery, Malmö University, Faculty of Odontology, Malmö, Sweden.

${ }^{c}$ Associate Professor and Head, Department of Oral Diagnostics, Malmö University, Faculty of Odontology, Malmö, Sweden.

${ }^{\mathrm{d}}$ Professor and Head, Department of Oral Pathology, Malmö University, Faculty of Odontology, Malmö, Sweden.

${ }^{\mathrm{e}}$ Consultant, Department of Oral and Maxillofacial Surgery, Maxillofacial Unit, Hallands Hospital, Halmstad, Sweden.

${ }^{\mathrm{f}}$ Professor and Chairman, Department of Oral Surgery and Oral Medicine, Faculty of Dentistry, University of Oslo, Oslo, Norway.

Received for publication Dec 27, 2017; returned for revision Jul 1, 2018; accepted for publication Aug 22, 2018.

(c) 2018 Elsevier Inc. All rights reserved.

$2212-4403 / \$$-see front matter

http://doi.org/10.1016/j.00oo.2018.08.015 resorption and bone turnover and offer renewal through inhibition of the osteoclast activity. ${ }^{7,8}$

Denosumab is an immunoglobulin G2 monoclonal antibody with affinity and specificity for RANK ligand (RANKL), which inhibits RANKL from activating its receptor, RANK, on the surface of osteoclasts and their precursors. Prevention of the RANKL-RANK interaction inhibits osteoclast formation, function, and survival, thereby decreasing bone resorption. ${ }^{2}$

Medication-related osteonecrosis of the jaw (MRONJ) is reported as a serious side effect associated with both BPs and denosumab. The first report on MRONJ came in 2003, and after this, numerous cases of nonhealing exposed, necrotic bone in the maxillofacial region have been reported in patients treated with BPs or denosumab. ${ }^{9-11}$

Data from a retrospective study carried out in the same region as that of the present study reported a prevalence of MRONJ to be $0.024 \%$ in patients on oral BPs and $2.8 \%$ in patients on intravenous treatment. ${ }^{11}$ A wide range of prevalence rates of MRONJ

\section{Statement of Clinical Relevance}

Prevalence of medication-related osteonecrosis of the jaw is higher in patients treated with denosumab compared with those treated with bisphosphonate. A periodontal infection initiates the osteonecrosis in most cases. Medication-related osteonecrosis of the jaw can be successfully treated surgically in all stages. 
$(0 \%-27.5 \%)$ has been reported in studies from different parts of the world. ${ }^{12,13}$

The pathogenesis of MRONJ is still being debated, but recent data suggest that odontogenic infections, such as periodontitis, might play a crucial role and contribute to the development of disease. A recent study showed that necrotic bone lesions contained mainly anaerobic bacteria, representative of periodontal microflora, suggesting that periodontal infection in combination with antiresorptive treatment could initiate osteonecrosis. $^{14}$

The treatment of choice for MRONJ is still controversial, and the American Association of Oral and Maxillofacial Surgeons (AAOMS) recommends antibacterial mouth rinses, symptomatic treatment with antibiotics in the early stages, and, in more severe cases, superficial debridement for long-term palliation of infection and pain. ${ }^{10}$ More recent reports have suggested a more radical treatment strategy with surgical removal of the necrotic bone and primary closure, in combination with antibiotic treatment. ${ }^{15-18}$

The aim of the present study was to estimate the prevalence of MRONJ in the Region of Skane and to evaluate the treatment outcome after sequestrectomy versus block resection.

The study aimed to investigate the following:

- The prevalence of MRONJ in the Region of Skane is higher in the prospective study compared with a retrospective study from the same region.

- Block resection is a good treatment method for MRONJ.

- Comorbidity is the most important prognostic variable in the regarding healing after surgery.

- The most common initiating factor for the development of MRONJ is tooth extraction.

The specific aims of the present study were to analyze the prevalence and the initiating factors for MRONJ and the outcome of surgical therapy in the course of 4 years.

\section{MATERIAL AND METHODS Study design}

To address the research purpose, the investigators designed and implemented a prospective cohort study that included 2 study populations. In Sweden, the health care system has 21 administrative regions. The Region of Skane in the south is the third largest, with a population base of approximately 1.3 million people. Four oral and maxillofacial surgery clinics in Skåne (Malmö, Lund, Helsingborg, and Kristianstad) are responsible for the treatment of patients with MRONJ. One maxillofacial surgeon (F.H.), who worked at all of the 4 Oral and Maxillofacial Surgery departments during the entire study period, was responsible for the diagnosis, recruitment, and treatment of all patients with MRONJ in Skane. The first study population was composed of all patients presenting for evaluation and management of MRONJ between January 1, 2012, and December 31, 2015.

\section{Variables}

Before treatment, gender, age, comorbidity, BP and/or denosumab therapy, dosage, and duration of therapy until necrosis occurred were recorded in the form of a case report. Initiating factors, site, and staging of MRONJ were registered. Intraoral radiographs taken before tooth extraction by the general dentists referring the patient to hospital were retrieved to analyze the diagnosis initiating MRONJ. A horizontal visual analogue scale (VAS) from 0 to $10(0=$ "no pain"; $10=$ "pain cannot be worse") was used before and after treatment to record pain intensity.

From 1973, Swedish citizens are being covered by a public health care system, and no private insurance is needed; economic reasons for not seeking health care can, therefore, be ruled out. Referral of patients with suspected MRONJ by general dentists to specialists is a common and easy procedure. In the Region of Skane, there are no private clinics for oral and maxillofacial surgery. It is, thus, likely that most patients with MRONJ in Skane were included during the study period.

To be included in the study sample, patients had to be referred to one of the oral and maxillofacial surgery clinics in Skane. The outcome variable was healing after 2 months after treatment.

\section{Prevalence}

The population in the Region of Skane is approximately 1.3 million (2012: 1,263,088; 2015: 1,301,316) (www.skatteverket.se). Data on the use of BPs and denosumab in the Region of Skane during the period 2012-2015 were obtained from statistics on prescriptions, and statistics on drugs delivered to the health care sector in the region (www.socialstyrelsen.se) served as the second study population.

MRONJ was diagnosed on the basis of the definition by the AAOMS: "exposed bone in the maxillofacial region over a period of 8 weeks, current or previous treatment with bisphosphonates or denosumab, and no prior history of radiation therapy to the jaws." ${ }^{, 10}$

\section{Site}

The location of the necrosis was defined according to the description by Rocha et al. ${ }^{19}$ : The jaw was divided into the right posterior maxilla (segment 1), anterior maxilla (segment 2), left posterior maxilla (segment 3), left posterior mandible (segment 4), 
anterior mandible (segment 5), and right posterior mandible (segment 6), with the distal surface of the canines serving as the reference.

\section{Staging}

The staging of the disease included stages 0 to 3 , according to the recommendations of the AAOMS (2014). ${ }^{10}$ Stage 0 was defined as no clinical evidence of necrotic bone but nonspecific clinical findings, radiographic changes, and symptoms; stage 1 was defined as exposed necrotic bone or fistulas that could be probed to bone without pain or signs of infection (asymptomatic); stage 2 was defined as exposed necrotic bone or fistulas that could be probed to bone with pain or signs of infection (symptomatic); and stage 3 was defined as exposed necrotic bone or fistulas that could be probed to bone with pain or signs of infection and one or more of the following: pathologic fracture, oral-cutaneous fistula, and involvement of the maxillary sinus or necrosis extending to the inferior border of the ramus of the mandible.

\section{Histologic analysis}

Surgical bone specimens were analyzed by an oral pathologist (G.W.) to confirm MRONJ and to rule out concurrent metastatic disease of the jaws. ${ }^{20}$

\section{Medical treatment}

All patients were treated with antibiotics for 10 days, starting 2 days before the surgical treatment. The antibiotic treatment was carried out with phenoxymethylpenicillin or clindamycin per os in case of allergy to phenoxymethylpenicillin.

Following consultation with the patient's oncologist, each patient continued BPs or denosumab medication during the period of surgical treatment unless a break was recommended by the oncologist. For patients undergoing cancer treatment, antiresorptive treatment was an important part of the disease management and necessary for prolonging survival.

Patients were classified into 2 groups according to the type of surgical treatment:

\section{Surgical treatment}

Sequestrectomy

Patients who did not have progressive bone disease but had ongoing bone destruction with a well-defined sequestrum were treated with a local mucosal flap, removal of the sequestrum, debridement of the necrotic bone, and closure in one layer with Vicryl 3-0 sutures.

\section{Block resection}

In patients with progressive bone disease with ongoing bone destruction, observed on radiographs, or ongoing pain and infection, surgical removal of the necrotic bone and primary closure was performed.

Surgical marginal block resection (Figure 1) included thorough surgical debridement with saucerization of bone until the vital bleeding bone margins were reached (Figure 2). Primary closure was done with Vicryl 3-0 sutures in layers, leaving no dead space.

\section{Healing}

The term "healed" was used to describe no bone exposure and no infection in the jaw affected by MRONJ. "Remission" was defined as improvement resulting in a reduced area of exposed bone, healthy surrounding mucosa, downgraded stage, and no symptoms $(\mathrm{VAS}=0)$. Patients were examined after 1 week and then at monthly intervals until 3 months postoperatively. They were then followed-up every 3 months and asked to contact the clinic if they felt that they had any problems between these appointments. One year after the surgical treatment, panoramic radiography was performed, and if it did not provide sufficient view of the surgical area, cone beam computed tomography was performed.

Ethical approval for the study was given by the Ethical Review Board in Lund, Sweden (Dnr 2012/760). The study was conducted in compliance with the tenets of the Helsinki Declaration, and each patient included in the study signed a detailed informed consent form.

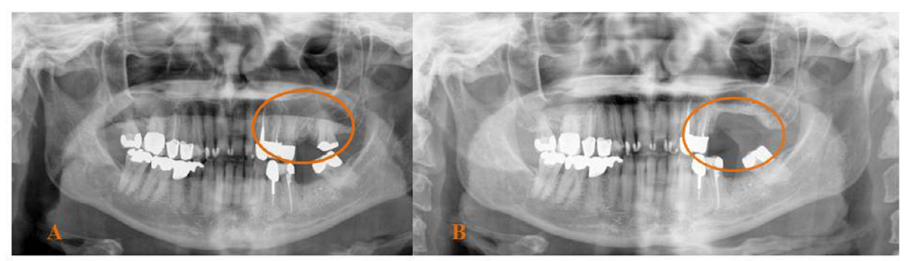

Fig. 1. Medication-related osteonecrosis of the jaw (MRONJ) caused by denosumab in the left posterior maxilla (segment 3) in a 63-year-old woman with breast cancer treated with block resection; panoramic radiograph before (A) and after treatment (B). 


$\begin{array}{lll}480 \text { Hallmer et al. } & \text { December } 2018\end{array}$

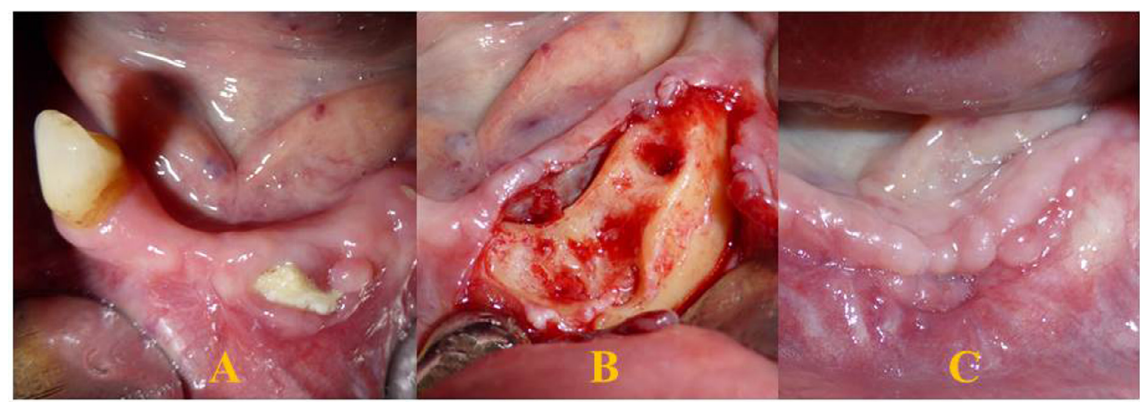

Fig. 2. A, Stage 2 Medication-related osteonecrosis of the jaw (MRONJ) located in the anterior mandible in a 66-year-old woman with breast cancer, treated with denosumab for 13 months. B, Block resection of the MRONJ lesion until the vital bleeding bone margins were reached and smoothing of sharp edges. C, Healing at follow-up 10 months postoperatively.

\section{Statistical methods}

SPSS for Windows, version 14 (SPSS, Chicago, IL) was used for data management and statistical analysis. Data were analyzed by using Fisher's exact test. A significance level of $5 \%$ was used in all tests.

\section{RESULTS}

Fifty-five patients with MRONJ were recruited. Fortythree were women (mean age 73.1 years) and 12 were men (mean age 63.6 years). The most common comorbidity was osteoporosis $56 \%(\mathrm{n}=31)$, followed by breast cancer $20 \%(\mathrm{n}=11)$, prostate cancer $11 \%$ $(n=6)$, multiple myeloma 9\% $(n=5)$, lung carcinoma $2 \%(\mathrm{n}=1)$, and giant cell carcinoma $2 \%(\mathrm{n}=1)$. Fifty patients were included in the study and followed up for 2 to 46 months (mean $=15.9$ months). Five patients were excluded either because the patients died or progression of their diseases made it impossible for them to attend a follow-up visit after 2 months (Figure 3).

There were no significant differences $(P=.176)$ in healing in relation to the comorbidities (Table I).

\section{Prevalence}

The estimated number of patients on oral BPs (for treatment of osteoporosis), alendronic acid, and risedronic acid, during the period 2012-2015 was around 50,000 in the Region of Skane. The prevalence of MRONJ among patients on oral BPs was estimated to be $0.043 \%$.

We estimated that around 700 patients were on intravenous BPs (for treatment of metastatic diseases), zoledronic acid, and pamidronic acid, during the period 2012-2015 in the Region of Skane. The prevalence of MRONJ among patients on intravenous BPs was estimated to be $1.03 \%$.

The estimated number of patients on high-dose denosumab for treatment of metastatic diseases during the period 2012-2015 in the Region of Skane was approximately 1700 . The prevalence of MRONJ among patients on denosumab was estimated to be $3.64 \%$.

\section{Oral BPs}

Twenty-five patients were treated with oral BPs. Twenty-one patients had monthly alendronic acid, 70 $\mathrm{mg} ; 3$ patients received ibandronic acid, $50 \mathrm{mg} /$ day; and 1 patient was on risedronic acid, $35 \mathrm{mg} /$ week.

The mean duration of treatment with oral BPs before development of MRONJ was 70.5 months (range 25-180 months). The mean accumulated dose was $4503 \mathrm{mg}$ for alendronic acid, 156,000 mg for ibandronic acid, and $3395 \mathrm{mg}$ for risedronic acid before development of MRONJ.

\section{Intravenous BPs}

Seven patients were treated with intravenous BPs-4 patients with zoledronic acid, $4 \mathrm{mg} / \mathrm{month}$; and 3 patients with pamidronic acid, $90 \mathrm{mg} / \mathrm{month}$.

The mean duration of treatment with zoledronic acid before development of MRONJ was 30 months (range 10-65 months), and the mean accumulated dose was $150 \mathrm{mg}$. The mean duration of treatment with

Table I. Healing in relation to comorbidities-osteoporosis and cancer

\begin{tabular}{|c|c|c|c|c|c|}
\hline & & & $\begin{array}{l}\text { Outcome } \\
\text { Healed }\end{array}$ & $\begin{array}{l}\text { Failed or } \\
\text { remission }\end{array}$ & Total \\
\hline \multirow[t]{2}{*}{ Comorbidity } & Osteoporosis & $\begin{array}{l}\text { Count } \\
\%\end{array}$ & $\begin{array}{c}23 \\
79.3 \%\end{array}$ & $\begin{array}{l}6 \\
20.7 \%\end{array}$ & $\begin{array}{l}29 \\
100.0 \%\end{array}$ \\
\hline & Cancer & $\begin{array}{l}\text { Count } \\
\%\end{array}$ & $\begin{array}{c}13 \\
61.9 \%\end{array}$ & $\begin{array}{l}8 \\
38.1 \%\end{array}$ & $\begin{array}{l}21 \\
100.0 \%\end{array}$ \\
\hline Total & & $\begin{array}{l}\text { Count } \\
\%\end{array}$ & $\begin{array}{c}36 \\
72.0 \%\end{array}$ & $\begin{array}{l}14 \\
28.0 \%\end{array}$ & $\begin{array}{l}50 \\
100.0 \%\end{array}$ \\
\hline
\end{tabular}


pamidronic acid before development of MRONJ was 18 months (range 5-24 months), and the mean accumulated dose was $1620 \mathrm{mg}$.

\section{Denosumab}

Eleven patients were treated with subcutaneously administered denosumab, $120 \mathrm{mg}$ once a month. The mean duration of treatment before development of MRONJ was 15.8 months (range 6-41 months). One patient was treated with subcutaneously administered denosumab, $60 \mathrm{mg}$ twice a year. The mean duration of treatment before development of MRONJ was 17 months. The mean accumulated dose of denosumab given before development of MRONJ was $1740 \mathrm{mg}$.

\section{Combination of oral BPs, intravenous BPs, and/or denosumab}

Eleven patients were treated with a combination of oral and/or intravenous BPs and/or denosumab.

Five patients were treated with monthly oral BPs-4 with alendronic acid, $70 \mathrm{mg}$; and 1 with risedronic acid, $35 \mathrm{mg}$, and subsequently switched to subcutaneously administered denosumab, $60 \mathrm{mg}$ twice a year. The mean duration of treatment with oral BPs in combination with denosumab before development of MRONJ was 84 months (range 40-106 months).

Three patients were treated with monthly oral BPs2 with alendronic acid, $70 \mathrm{mg}$; and 1 with risedronic acid, $35 \mathrm{mg}$, and then switched to an annual infusion with zoledronic acid, $5 \mathrm{mg}$. The mean duration of antiresorptive treatment was 83 months (range 48-89 months) before development of MRONJ.

Two patients were treated with intravenous BPs-zoledronic acid, $4 \mathrm{mg} / \mathrm{month}$, and then switched to subcutaneously administered denosumab, $120 \mathrm{mg} / \mathrm{month}$. The mean duration of antiresorptive treatment was 61 months (range 56-66 months) before development of MRONJ.

One patient was treated with intravenous BPs-zoledronic acid, $4 \mathrm{mg} / \mathrm{month}$, and then switched to orally administered ibandronic acid, $50 \mathrm{mg} /$ day. The total duration of antiresorptive treatment before development of MRONJ was 89 months.

\section{Site}

Most lesions were located in the mandible $75 \%$ $(n=41)$, with 32 occurring in the posterior part (segment 4 or 6), 5 in the anterior part, and 4 in more than one segment of the mandible.

Fourteen $(25 \%)$ lesions were located in the maxilla-11 in the posterior part, 2 in the anterior part, and 1 involving more than one segment of the maxilla.

There were no significant differences $(P=.156)$ in healing in relation to the site of the necrosis (Table II).
Table II. Healing in relation to the site of necrosis

\begin{tabular}{|c|c|c|c|c|c|}
\hline & & & $\begin{array}{l}\text { Outcome } \\
\text { Healed }\end{array}$ & $\begin{array}{l}\text { Failed or } \\
\text { remission }\end{array}$ & Total \\
\hline \multirow[t]{12}{*}{ Site } & 1 or 3 & Count & 8 & 2 & 10 \\
\hline & & $\%$ & $80 \%$ & $20 \%$ & $100 \%$ \\
\hline & 2 & Count & 2 & 0 & 2 \\
\hline & & $\%$ & $100 \%$ & $0.0 \%$ & $100 \%$ \\
\hline & Whole & Count & 0 & 1 & 1 \\
\hline & & $\%$ & $0 \%$ & $100 \%$ & $100 \%$ \\
\hline & 4 or 6 & Count & 22 & 6 & 28 \\
\hline & & $\%$ & $78.6 \%$ & $21.4 \%$ & $100 \%$ \\
\hline & 5 & Count & 2 & 3 & 5 \\
\hline & & $\%$ & $40 \%$ & $60.0 \%$ & $100 \%$ \\
\hline & Whole & Count & 2 & 2 & 4 \\
\hline & & $\%$ & $50 \%$ & $50.0 \%$ & $100 \%$ \\
\hline \multirow[t]{2}{*}{ Total } & & Count & 36 & 14 & 50 \\
\hline & & $\%$ & $72 \%$ & $28 \%$ & $100 \%$ \\
\hline
\end{tabular}

\section{Stage}

Ten patients were at stage 1 disease, 36 patients at stage 2 , and 9 patients at stage 3 .

There were no significant differences $(P=.067)$ in healing in relation to the stage of the necrosis (Table III).

\section{Initiating factor}

The most common initiating factors for the development of MRONJ were tooth extraction in 39 patients, marginal periodontitis in 10 , apical periodontitis in 2 , and denture trauma in 1 ; in 3 patients, MRONJ occurred spontaneously. There was no significant difference $(P=.394)$ in healing in relation to the initiating factors (Table IV).

In 32 of 39 cases, the initiating factor was tooth extraction; it was possible to obtain pre-extraction intraoral radiographs from the general dental practitioner. These were analyzed by a specialist in oral and maxillofacial radiology. Twenty-nine $(91 \%)$ of the 32 tooth extractions were of teeth with severe marginal periodontitis (15 patients), apical periodontitis (3

Table III. Healing in relation to stage of necrosis

\begin{tabular}{lllcll}
\hline & & & $\begin{array}{c}\text { Outcome } \\
\text { Healed }\end{array}$ & Failed or remission & Total \\
\hline Stage & 1 & Count & 7 & 1 & 8 \\
& & $\%$ & $87.5 \%$ & $12.5 \%$ & $100 \%$ \\
& 2 & Count & 26 & 8 & 34 \\
& & $\%$ & $76.5 \%$ & $23.5 \%$ & $100 \%$ \\
& 3 & Count & 3 & 5 & 8 \\
& & $\%$ & $37.5 \%$ & $62.5 \%$ & $100 \%$ \\
Total & & Count & 36 & 14 & 50 \\
& & $\%$ & $72 \%$ & $28 \%$ & $100 \%$ \\
\hline
\end{tabular}


Table IV. Healing in relation to initiating factor

\begin{tabular}{cccccl}
\hline & & & $\begin{array}{l}\text { Outcome } \\
\text { Healed }\end{array}$ & $\begin{array}{l}\text { Failed or } \\
\text { remission }\end{array}$ & Total \\
\hline $\begin{array}{c}\text { Initiating } \\
\text { factor }\end{array}$ & Extraction & Count & 26 & 9 & 35 \\
& & $\%$ & $74.3 \%$ & $25.7 \%$ & $100 \%$ \\
& Spontaneous & Count & 2 & 0 & 2 \\
& & $\%$ & $100 \%$ & $0.0 \%$ & $100 \%$ \\
& Infection & Count & 6 & 5 & 11 \\
& & $\%$ & $54.5 \%$ & $45.5 \%$ & $100 \%$ \\
& Trauma & Count & 2 & 0 & 2 \\
& & $\%$ & $100 \%$ & $21.4 \%$ & $100 \%$ \\
& & Count & 36 & 14 & 50 \\
& & $\%$ & $72 \%$ & $28 \%$ & $100 \%$ \\
\hline
\end{tabular}

patients), or both on the same tooth (11 patients). In addition to MRONJ being caused by marginal periodontitis in 10 patients and by apical periodontitis alone in 2, local periodontal destruction, including marginal bone loss adjacent to root surfaces, preceded development of MRONJ in a total of 41 patients.

\section{Histologic analysis}

The histologic analysis of resected bone confirmed the diagnosis MRONJ without any sign of metastasis or tumors in all cases. All specimens showed necrotic fragments of bone, with extensive resorption of the trabecular surfaces. Most often, marrow spaces were filled with bacteria along with granulation tissue. In addition, slender cords of squamous epithelium sometimes covered the bone surfaces. Occasionally, there were signs of previous bone apposition (Figure 4). The resection samples showed no signs of metastatic disease of the jaw.

\section{Surgical treatment}

Sequestrectomy

Ten patients were treated with sequestrectomy. In 5 cases $(50 \%)$, the lesions healed (Table V). Three patients went into remission ( 2 with stage 2 and 1 with stage 3 disease). The overall improvement rate was $80 \%$ ) (8 of 10 patients).

Mean follow-up time was 13.3 months (range 5-29 months). After healing, no adverse events were recorded.

\section{Block resection}

Forty patients were treated with block resection. In 31 patients, $(77.5 \%)$, the lesions healed (see Table V). Six patients went into remission (4 with stage 2 and 2 with stage 3$)$. The overall improvement rate was $92.5 \%$ ( 37 of 40 patients).

Mean follow-up time was 16.7 months (range 2-46 months). After healing, no adverse events were recorded.

There were no differences $(P=.118)$ in healing in patients treated surgically with block resection or sequestrectomy (see Table V).

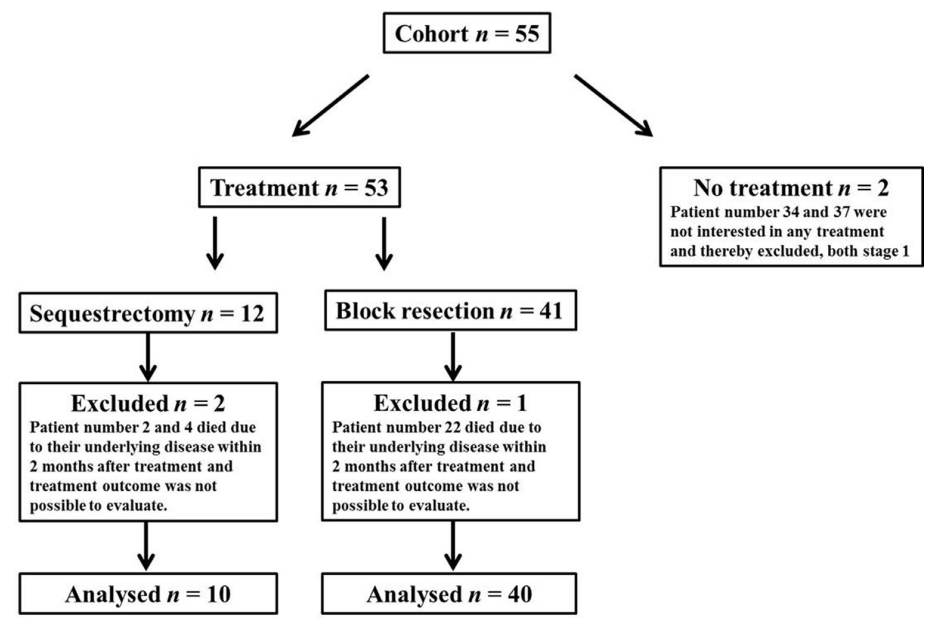

Fig. 3. Flow chart describing the inclusion and treatment process of the patients. 


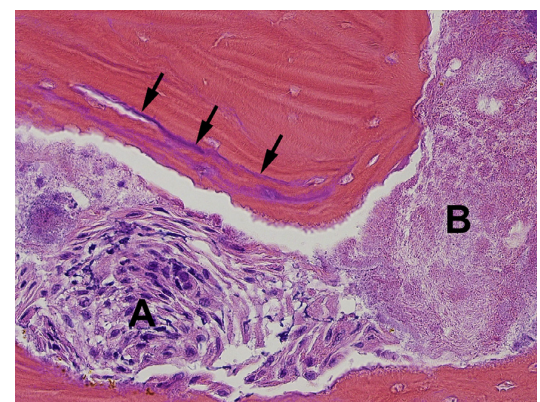

Fig. 4. Bone specimen from a 76-year-old woman treated with alendronate for 70 months for osteoporosis. Section shows necrotic bone with signs of recent bone apposition (arrows) and resorption. Fragments of squamous epithelium (A) and bacteria (B) have replaced the original bone marrow (hematoxylin \& eosin stain; original magnification $\times 40$ ).

There were no differences $(P=.094)$ in the healing rate between men and women (Table VI).

\section{Pain intensity}

Mean VAS scores for 10 patients treated with sequestrectomy before and after treatment were 3.9 and 1.0, respectively. Mean VAS scores for 40 patients treated with block resection before and after treatment were 3.8 and 0.2 , respectively. Mean VAS scores for 6 patients in remission before and after treatment were 3.7 and 0.0 , respectively.

\section{DISCUSSION}

It is probable that most cases of MRONJ in Skane in the period 2012-2015 were included in this study. Those few not included might be patients not seeking health care because their lesions were asymptomatic; we, therefore, estimate that around $90 \%$ have been included. In a retrospective study ${ }^{11}$ that included patients from the same health care region (Skåne), the same number of

Table V. Healing in relation to surgical treatment with block resection versus sequestrectomy

\begin{tabular}{cccccc}
\hline & & & $\begin{array}{c}\text { Outcome } \\
\text { Healed }\end{array}$ & $\begin{array}{c}\text { Failed or } \\
\text { remission }\end{array}$ & Total \\
\hline $\begin{array}{c}\text { Surgical } \\
\text { treat }\end{array}$ & Sequestrectomy & Count & 5 & 5 & 10 \\
& & $\%$ & $50 \%$ & $50 \%$ & $100 \%$ \\
& Block resection & Count & 31 & 9 & 40 \\
Total & & $\%$ & $77.5 \%$ & $22.5 \%$ & $100 \%$ \\
& & Count & 36 & 14 & 50 \\
& & $\%$ & $72 \%$ & $28 \%$ & $100 \%$ \\
\hline
\end{tabular}

patients $(\mathrm{n}=55)$ with MRONJ were identified, but with an inclusion period of 8 years compared with the 4 years in the present prospective study. This further supports the hypothesis that dropouts are few.

To our knowledge, this is the first study to report that the condition of extracted teeth may be a causative factor in MRONJ. The finding that periodontal disease preceded tooth extraction and probably initiated the development of MRONJ in most cases in the study highlights the need for a dental examination before commencing antiresorptive treatment because this step may help reduce and prevent MRONJ. This finding further supports the data from our previous study indicating that necrotic bone contains mainly anaerobic bacteria, representative of periodontal microflora, suggesting that periodontal infection, in combination with antiresorptive treatment, initiates osteonecrosis. ${ }^{14}$

Our results confirm the findings of a previous retrospective study from the same region showing the prevalence of MRONJ to be much lower in patients on oral BPs for the treatment of osteoporosis compared with patients receiving intravenous BPs for the treatment of metastatic disease. ${ }^{11}$ This Swedish study reported a relatively low prevalence of MRONJ in comparison with studies from other countries showing higher prevalence. ${ }^{12}$ This might be explained by the decrease in the number of individuals with marginal bone loss and periodontitis since the general dental insurance was introduced in Sweden in 1973. ${ }^{21}$

A standard therapy for MRONJ has not yet been established, and surgery has previously been reported to be capable of exacerbating bone exposure. ${ }^{22-24}$ Treatment recommendations by the AAOMS indicate that conservative therapies could be applied to stage 1 and stage $2 \mathrm{MRONJ}$ and that a surgical procedure may be unnecessary. ${ }^{10}$ This is in contrast to the results in the present study, where healing after block resection of MRONJ occurred in 3 of 4 patients, compared with sequestrectomy, where only healing occurred in only $50 \%$ of the patients. On the basis of our results, we recommend that block resection should be the treatment of choice. In a previous study, ${ }^{11}$ only in $26 \%$ of the

Table VI. Healing in relation to gender

\begin{tabular}{llllll}
\hline & & $\begin{array}{l}\text { Outcome } \\
\text { Healed }\end{array}$ & $\begin{array}{l}\text { Failed or } \\
\text { remission }\end{array}$ & Total \\
\hline Gender & Male & Count & 4 & 5 & 9 \\
& & $\%$ & $44.4 \%$ & $55.6 \%$ & $100 \%$ \\
& Female & Count & 32 & 9 & 41 \\
& & $\%$ & $78.0 \%$ & $22.0 \%$ & $100 \%$ \\
Total & & Count & 36 & 14 & 50 \\
& & $\%$ & $72 \%$ & $28 \%$ & $100 \%$ \\
\hline
\end{tabular}


patients with metastatic disease healing occurred after treatment with sequestrectomy.

In most reports, healing of MRONJ is defined as no signs of exposed necrotic bone after treatment and complete mucosal coverage. In the present study, $72 \%$ of the lesions healed completely. However, for patients with MRONJ, especially those with metastatic disease, palliation is probably sufficient as a treatment goal. In our study, another 6 patients (11\%) went into remission without subjective symptoms, but with some remaining exposed bone, after block resection in combination with oral antibiotics. These patients were not willing to undergo additional surgery, and this suggests that they had been successfully treated, with their disease stage now being downgraded to stage 1 from stage 2 or 3 before treatment.

Our success rate among patients treated with block surgery is in accordance with those of other studies. ${ }^{15,17,25}$ A recent study showed that periodontal pathogenic bacteria are present in visually healthy bone adjacent to necrotic bone. ${ }^{14}$ Better healing with block resection than with sequestrectomy may be explained by the fact that all infected bone was removed.

Even more radical surgical approaches with coverage of sinus communication after surgical removal of necrotic bone, along with the buccal fat pad, ${ }^{26}$ or, in the mandible, coverage with a myofascial flap ${ }^{27}$ might have resulted in the higher success rate when combined with block resection. However, in the present study none of the patients with unhealed lesions after surgery was interested in a second surgical intervention. In stage 3 , immediate reconstruction with vascularized graft was considered an option. However, the operation was not possible because of the patient's disease.

On the basis of the results from a previous study, an antibiotic specific for oral microflora ${ }^{14}$ (phenoxymethylpenicillin) was used per os for 10 days. The same success rate was obtained when an intravenous broadspectrum antibiotic, such as sitafloxacin, was used. ${ }^{28}$ Phenoxymethylpenicillin, an antibiotic that is specific for oral microflora, lowers the risk of developing resistant strains and is, therefore, highly recommended.

In patients medicated with oral BPs, the median treatment time was 70.5 months before being diagnosed with MRONJ, similar to the data reported by Fung et al. ${ }^{29}$ In our study, we also found a tendency, not statistically verified, for MRONJ to appear earlier in patients treated with high-dose denosumab (15.8 months) compared with zoledronic acid (30 months). Further studies are needed to confirm these results.

Although MRONJ is a serious adverse effect of treatment with BPs and denosumab, the benefits of the medications' effects on the disease and on quality of life outweigh the harms. Instead of stopping antiresorptive treatment, a drug holiday before tooth extraction, if possible, may help reduce the number of patients developing MRONJ, ${ }^{10}$ especially among patients on denosumab, which has a much shorter half-life compared with BPs.

We consider the risk of bias in our present prospective study to be relatively low because dropouts were few as a result of the benefits of the Swedish health care system. The patients were also consecutively recruited and treated by the same surgeon. A limitation of the study is that a control group could not be included because of ethical considerations.

\section{CONCLUSIONS}

The prevalence of MRONJ in Sweden is low. Periodontitis is the most common initiating factor. The treatment outcome of MRONJ demonstrates healing in most patients treated surgically. Our data suggest that treatment with BPs and denosumab can be continued because of the relatively low risk of MRONJ.

\section{ACKNOWLEDGMENT}

The authors wish to thank Per-Erik Isberg for the invaluable help with statistical analysis and Dr. Henrik Ellfors for analysis of the retrieved radiographs.

\section{REFERENCES}

1. Major P, Lortholary A, Hon J, et al. Zoledronic acid is superior to pamidronate in the treatment of hypercalcemia of malignancy: a pooled analysis of two randomized, controlled clinical trials. $J$ Clin Oncol. 2001;19:558-567.

2. Cummings SR, Martin JS, McClung MR, et al. Denosumab for prevention of fractures in postmenopausal women with osteoporosis December 2009. Available at: http://www.nejm.org/doi/ full/10.1056/NEJMoa0809493; Accessed May 10, 016.

3. Stopeck AT, Lipton A, Body J-J, et al. Denosumab compared with zoledronic acid for the treatment of bone metastases in patients with advanced breast cancer: a randomized, doubleblind study. J Clin Oncol. 2010;28:5132-5139.

4. Terpos E, Sezer O, Croucher PI, et al. The use of bisphosphonates in multiple myeloma: recommendations of an expert panel on behalf of the European Myeloma Network. Ann Oncol Off J Eur Soc Med Oncol. 2009;20:1303-1317.

5. Saylor PJ, Smith MR. Bone health and prostate cancer. Prostate Cancer Prostatic Dis. 2010;13:20-27.

6. Jacques RM, Boonen S, Cosman F, et al. Relationship of changes in total hip bone mineral density to vertebral and nonvertebral fracture risk in women with postmenopausal osteoporosis treated with once-yearly zoledronic acid $5 \mathrm{mg}$ : the HORIZON-Pivotal Fracture Trial (PFT). J Bone Miner Res. 2012;27:1627-1634.

7. Allen MR, Burr DB. The pathogenesis of bisphosphonate-related osteonecrosis of the jaw: so many hypotheses, so few data. J Oral Maxillofac Surg. 2009;67:61-70.

8. Allen MR, Burr DB. Bisphosphonate effects on bone turnover, microdamage, and mechanical properties: what we think we know and what we know that we don't know. Bone. 2011;49:56-65.

9. Marx RE. Pamidronate (Aredia) and zoledronate (Zometa) induced avascular necrosis of the jaws: a growing epidemic. $J$ Oral Maxillofac Surg. 2003;61:1115-1117. 
10. Ruggiero SL, Dodson TB, Fantasia J, et al. American Association of Oral and Maxillofacial Surgeons position paper on medication-related osteonecrosis of the jaw-2014 update. J Oral Maxillofac Surg. 2014;72:1938-1956.

11. Hallmer F, Bjørnland T, Nicklasson A, Becktor JP, Andersson G. Osteonecrosis of the jaw in patients treated with oral and intravenous bisphosphonates: experience in Sweden. Oral Surg Oral Med Oral Pathol Oral Radiol. 2014;118:202-208.

12. Kuhl S, Walter C, Acham S, Pfeffer R, Lambrecht JT. Bisphosphonate-related osteonecrosis of the jaws-a review. Oral Oncol. 2012:48:938-947.

13. Goodwin JS, Zhou J, Kuo Y-F, Baillargeon J. Risk of jaw osteonecrosis after intravenous bisphosphonates in cancer patients and patients without cancer. Mayo Clin Proc. 2017:92:106-113.

14. Hallmer F, Bjornland T, Andersson G, Becktor JP, Kristoffersen AK, Enersen M. Bacterial diversity in medication-related osteonecrosis of the jaw. Oral Surg Oral Med Oral Pathol Oral Radiol. 2017;123:436-444.

15. Williamson RA. Surgical management of bisphosphonate induced osteonecrosis of the jaws. Int J Oral Maxillofac Surg. 2010;39:251-255

16. Bedogni A, Saia G, Bettini G, et al. Long-term outcomes of surgical resection of the jaws in cancer patients with bisphosphonate-related osteonecrosis. Oral Oncol. 2011;47:420-424.

17. Stockmann P, Burger M, von Wilmowsky C, et al. The outcome after surgical therapy of bisphosphonate-associated osteonecrosis of the jaw-results of a clinical case series with an average follow-up of 20 months. Clin Oral Investig. 2014;18:1299-1304.

18. Pichardo SEC, van Merkesteyn JPR. Evaluation of a surgical treatment of denosumab-related osteonecrosis of the jaws. Oral Surg Oral Med Oral Pathol Oral Radiol. 2016;122:272-278.

19. Rocha GCMA, Jaguar GC, Moreira CR, Neves EG, Fonseca FP, Pedreira EN. Radiographic evaluation of maxillofacial region in oncology patients treated with bisphosphonates. Oral Surg Oral Med Oral Pathol Oral Radiol. 2012;114:S19-S25.

20. Bedogni A, Saia G, Ragazzo M, et al. Bisphosphonate-associated osteonecrosis can hide jaw metastases. Bone. 2007;41: 942-945.

21. Norderyd O, Koch G, Papias A, et al. Oral health of individuals aged 3-80 years in Jonkoping, Sweden during 40 years (1973-
2013). II. Review of clinical and radiographic findings. Swed Dent J. 2015:39:69-86.

22. American Association of Oral and Maxillofacial Surgeons position paper on bisphosphonate-related osteonecrosis of the jaws. $J$ Oral Maxillofac Surg. 2007;65:369-376.

23. Ruggiero S, Gralow J, Marx RE, et al. Practical guidelines for the prevention, diagnosis, and treatment of osteonecrosis of the jaw in patients with cancer. $J$ Oncol Pract. 2006;2:7-14.

24. Van den Wyngaert T, Claeys T, Huizing MT, Vermorken JB, Fossion E. Initial experience with conservative treatment in cancer patients with osteonecrosis of the jaw (ONJ) and predictors of outcome. Ann Oncol Off J Eur Soc Med Oncol. 2009;20:331-336.

25. Otto S, Ristow O, Pache C, et al. Fluorescence-guided surgery for the treatment of medication-related osteonecrosis of the jaw: a prospective cohort study. $J$ Craniomaxillofac Surg. 2016;44:1073-1080.

26. Melville JC, Tursun R, Shum JW, Young S, Hanna IA, Marx RE, A technique for the treatment of oral-antral fistulas resulting from medication-related osteonecrosis of the maxilla: the combined buccal fat pad flap and radical sinusotomy. Oral Surg Oral Med Oral Pathol Oral Radiol. 2016;122:287-291.

27. Lemound J, Eckardt A, Kokemuller H, et al. Bisphosphonateassociated osteonecrosis of the mandible: reliable soft tissue reconstruction using a local myofascial flap. Clin Oral Investig. 2012;16:1143-1152.

28. Ikeda T, Kuraguchi J, Kogashiwa Y, Yokoi H, Satomi T, Kohno N. Successful treatment of bisphosphonate-related osteonecrosis of the jaw (BRONJ) patients with sitafloxacin: new strategies for the treatment of BRONJ. Bone. 2015;73:217-222.

29. Fung P, Bedogni G, Bedogni A, et al. Time to onset of bisphosphonate-related osteonecrosis of the jaws: a multicentre retrospective cohort study. Oral Dis. 2017;23:477-483.

Reprint requests:

Fredrik Hallmer, Department of Oral and Maxillofacial Surgery, Faculty of Odontology, Malmö University, 20506 Malmö-SE, Sweden.

Fredrik.hallmer@mah.se 



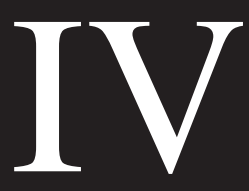





\section{Incidence of and risk factors for medication-related osteonecrosis in women}

with breast cancer with bone metastasis: a cohort study

Fredrik Hallmer ${ }^{1,2}$, Olöf Bjarnadottir ${ }^{3,4}$, Per Malmström ${ }^{3,4}$, Bengt Götrick ${ }^{5}$,Gunilla Andersson ${ }^{1}$

${ }^{1}$ Department of Oral and Maxillofacial Surgery, Malmö University, Faculty of Odontology,

Malmö, Sweden. ${ }^{2}$ Department of Oral and Maxillofacial Surgery, Skåne University Hospital, Lund, Sweden. ${ }^{3}$ Division of Oncology and Pathology, Department of Clinical Sciences, Lund University, Lund, Sweden. ${ }^{4}$ Department of Haematology, Oncology and Radiation Physics, Skåne University Hospital, Lund, Sweden. ${ }^{5}$ Department of Oral Diagnostics, Malmö University, Faculty of Odontology, Malmö, Sweden.

Corresponding author

Fredrik Hallmer

Department of Oral and Maxillofacial Surgery

Faculty of Odontology, Malmö University

20506 Malmö-SE

Sweden

Fredrik.hallmer@mah.se

Tel. 0046707148211 


\begin{abstract}
Objectives: Incidence of medication-related osteonecrosis of the jaw (MRONJ) is widely reported and risk factors have not yet been determined. The aim of this study was to prospectively determine the incidence and define risk factors for MRONJ in patients with metastatic breast cancer treated with zoledronic acid and/or denosumab.
\end{abstract}

Study design: In a prospective cohort study performed in Region Skåne, Sweden from 1st of January 2012 until 31st of December 2015, all breast cancer patients diagnosed with radiographic evidence of one or several bone metastases and treated with zoledronic acid or denosumab were included. Systemic risk factors (age, zoledronic acid or denosumab use, treatment time, chemotherapy or corticosteroid use, diabetes and smoking habits) were recorded. All patients diagnosed with MRONJ between 1st of January 2012 and 31st of May 2018 were included in the study.

Results: Out of 242 patients, sixteen, (6.6\%), developed MRONJ during the 77 months of study. The incidence of MRONJ in patients treated with zoledronic acid was $4.1 \%$, and for patients with denosumab $13.6 \%$. The risk of developing MRONJ in patients on denosumab was significantly higher compared to treatment with zoledronic acid (OR 3.7; 95\% CI 1.3-10.6). Corticosteroid use was associated with a significantly decreased risk of MRONJ (OR $0.3 ; 95 \% \mathrm{Cl} 0.1-0.8$ ) and diabetes was associated with a significantly increased risk of MRONJ (OR 4.5; 95\% Cl 1.1-18.1). Chemotherapy and smoking were not associated with a significantly increased risk of MRONJ. 
Conclusion: The incidence of MRONJ is $6.6 \%$ and more than three times higher in denosumabtreated breast cancer patients compared to patients treated with zoledronic acid. Corticosteroid use decreased the risk of developing MRONJ.

Key words: Breast cancer; Medication-related osteonecrosis of the jaw; Bisphosphonate; Denosumab; Incidence; Risk factors 


\section{Introduction}

Breast cancer is the most common cancer form in women worldwide and the second most common cause of cancer death $(1,2)$. In Sweden the 5-year survival rate for breast cancer is $90 \%$ but surviving breast cancer patients remain at risk for late recurrence several years after the primary diagnosis (3). To reduce the risk of local and distant recurrences endocrine treatment and/or chemotherapy are administered. Bone is the most common and often the first location for metastases (4). Antiresorptive medication, i.e. intravenous (i.v) bisphosphonate and/or subcutanous (s.c.) denosumab are frequently used to reduce skeletal-related events (SREs) associated with bone metastases and to treat cancer-related conditions in metastatic settings like hypercalcemia $(5,6)$.

For postmenopausal women with early breast cancer several studies have shown that treatment with bisphosphonate i.v. reduces tumour progression, decreases recurrence in bone and visceral sites as well as breast cancer mortality $(7,8)$. Thus, bisphosphonate treatment was recently recommended as adjuvant treatment for post-menopausal breast cancer patients (9). Also, the inhibitor of receptor activator of nuclear factor $K B$ ligand (RANKL), denosumab, has been shown to reduce the clinical fracture risk in patients with breast cancer (10). In another randomised study patients treated with denosumab had a better quality of life and fewer SREs (11).

Medication-related osteonecrosis of the jaw (MRONJ), earlier known as bisphosphonate-related osteonecrosis of the jaw (BRONJ), was first described in 2000, when avascular necrosis of the jaw was detected in patients treated with the i.v. bisphosphonates pamidronate or zoledronic acid $(12,13)$. The American Association of Oral and Maxillofacial Surgeons has defined MRONJ as 
a condition where patients treated with antiresorptive and/or antiangiogenic agents develop exposed bone or bone that can be probed through an intraoral or extraoral fistula in the maxillofacial region (14). It should have persisted for more than eight weeks, and there should neither be a history of metastatic disease in the jaw nor of radiation therapy of the region (14). The pathophysiology of MRONJ is still debated. Inflammation and infection, decresed angiogenesis and inhibition of osteoclastic bone resorption and remodeling have been suggested as causes $(14,15)$. Described risk factors for developing MRONJ are duration of antiresorptive treatment, dentoalveolar surgery, tooth exctraction and periodontitis $(14,16-18)$. The estimated prevalence of MRONJ varies widely $(14,19)$. In southern Sweden (Skåne) the prevalance of MRONJ with intravenous bisphophonate was estimated to be $2.8 \%$ (20). Previous

incidence studies of MRONJ have mainly been retrospective. As the indications for antiresorptive treatment has expanded and as denosumab treatment has been introduced, it has become increasingly important to estimate the incidence and define risk factors.

The aim of this study was to prospectively determine the incidence and define risk factors for MRONJ in patients with metastatic breast cancer treated with zoledronic acid and/or denosumab.

\section{Materials and methods}

Women above 17 years of age from Region Skåne with histologically or cytologically confirmed breast cancer and radiographic evidence of one or several bone metastases were eligible for study entry. 
The catchment area was Region Skåne with a population of 1.3 million and four Departments of Oncology responsible for the treatment of breast cancer and four Oral and Maxillofacial Surgery clinics responsible for the treatment of patients with MRONJ.

Patients receiving zoledronic acid or denosumab during the study period were identified in the treatment registries and the medical records at the four participating hospitals.

Exclusion criteria were prior exposure to oral or i.v. bisphosphonates and/or denosumab for treatment of advanced cancer, prior treatment with oral bisphosphonates or denosumab for other bone loss conditions (e.g. osteoporosis), a history of evidence of MRONJ or osteomyelitis of the jaw as well as radiation therapy to the head and neck region.

To ensure a certain exposure to the antiresorptive medication, we included patients who received at least 3 infusions of zoledronic acid or 3 injections of denosumab. Patients were enrolled from January $1^{\text {st }} 2012$ and to December $31^{\text {st }} 2015$ and followed until May $31^{\text {st }} 2018$. Treatment consisted of four mg of zoledronic acid administered i.v. during 15 minutes every 4 to 6 weeks or $120 \mathrm{mg}$ denosumab (Xgeva ${ }^{\circledR}$, Amgen Inc., Thousand Oaks, California, USA) s.c. every 4 weeks.

Data collected from patient medical records included age, bisphosphonate or denosumab use, treatment time, chemotherapy or corticosteroid use, diabetes and smoking habits.

The cohort included 263 patients. Of these 21 patients were excluded, 15 with only one infusion with zoledronic acid, three with only one treatment with denosumab and 3 treated with oral bisphosphonates due to osteoporosis prior to the study. Thus the studied cohort consisted of $242(92.0 \%)$ patients. Mean age of the study group was 64.0 years (range 31-90). 
All patients diagnosed with MRONJ between $1^{\text {st }}$ of January 2012 and $31^{\text {st }}$ of May 2018 were analysed in the study.

All participants of the clinical study part signed an informed consent form. The study was conducted in compliance with the Helsinki Declaration. Ethical approval was given by the Ethical Review Board in Lund, Sweden (Dnr 2011/274) and (Dnr 2018/344).

\section{Statistical analysis}

The relation between MRONJ and different background variables (treatment time, corticosteroid treatment, chemotherapy, diabetes mellitus and smoking) were investigated by odds-ratios (OR) with $95 \%$ confidence intervals. The OR was tested by chi-square tests using a significance level of $5 \%$.

The relation between Time to MRONJ and different background variables (corticosteroid treatment, chemotherapy, diabetes mellitus and smoking) were investigated by the log-rank test. The data were also analysed using the Kaplan-Meier method.

All calculations were done in SPSS version 25 (IBM Corp. Released 2017. IBM SPSS Statistics for Windows, Version 25.0. Armonk, NY: IBM Corp.).

\section{Incidence}

Sixteen of the 242 patients (6.6\%) developed MRONJ during the study period. Mean age was 64.6 years (range 41.0-84.0). The incidence of MRONJ in patients treated with zoledronic acid was $4.1 \%$, and for patients with denosumab $13.6 \%$. For patients initially treated with zoledronic acid which subsequently switched to denosumab the incidence was $8.3 \%$ (Table I). The risk of 
developing MRONJ in patients on denosumab was significantly higher compared with zoledronic acid (OR 3.7; 95\% Cl 1.3-10.6, $\mathrm{p}=0.011)$.

\section{Risk factors}

Mean treatment time for all patients was 27.5 months. For patients developing MRONJ the mean treatment time was 35.3 months (range 8-70) and in patients not developing MRONJ 27.0 months (range 2-77). The mean treatment time for zoledronic acid was $26.1 \pm 17.0$ months, 25.4 \pm 16.7 months for patients not developing MRONJ and $40.9 \pm 18.8$ months with MRONJ. The mean treatment time for denosumab was $30.8 \pm 17.5$ months, $31.3 \pm 17.5$ months for patients without development of MRONJ and 27.8 \pm 18.5 months with MRONJ.

Corticosteroid treatment was administered to 163 of the 242 patients. Of these 163 , six were diagnosed with MRONJ compared to ten of the 79 not receiving corticosteroids. Corticosteroid use was associated with a significantly decreased risk of MRONJ (OR $0.3 ; 95 \% \mathrm{Cl} 0.1-0.8$, $p=0.008$ ). The mean treatment time of antiresorptive treatment was $25.1 \pm 17.0$ months with

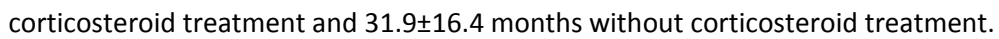

Chemotherapy was administered to 145 of the 242 patients. Of the 145 chemotherapy treated patients, 12 were diagnosed with MRONJ compared to four of the 97 not receiving chemotherapy. Chemotherapy was not associated with a significantly increased risk of MRONJ 
(OR 2.1; 95\% $\mathrm{Cl}$ 0.7-6.7, $\mathrm{p}=0.2$ ). The mean treatment time of antiresorptive treatment was $26.1 \pm 16.9$ months with chemotherapy and $29.6 \pm 17.6$ months without chemotherapy.

In the cohort, 14 of the 242 patients had diabetes mellitus. Three diabetes mellitus patients had MRONJ out of a total of 16 patients with MRONJ. Diabetes was associated with a significantly increased risk of MRONJ (OR 4.5; 95\% Cl 1.1-18.1, $\mathrm{p}=0.02$ ). The mean treatment time of antiresorptive treatment was $20.5 \pm 17.7$ months with diabetes and $28.0 \pm 17.2$ months without.

Twenty-seven of the 242 patients were regular smokers, four out of 16 in the group with MRONJ. Smoking was not associated with a statistically increased risk of MRONJ (OR $2.9 ; 95 \% \mathrm{Cl}$ 0.9-9.9, $\mathrm{p}=0.07)$. The mean treatment time of antiresorptive treatment was $30.7 \pm 18.8$ months in smokers and 27.1 \pm 17.1 months in non-smokers.

\section{Discussion}

In this prospective cohort study, the incidence of MRONJ in breast cancer patients treated with antiresorptive medication was investigated. In addition, factors that can influence the risk of MRONJ were identified. For zoledronic acid the incidence of MRONJ was $4.1 \%$ and for denosumab $13.6 \%$. The identification of factors that can influence the risk of developing MRONJ was also at major finding in a recent study. In addition, factors that can influence the risk of MRONJ were identified. Corticosteroid use was associated with decreased risk of MRONJ and diabetes mellitus showed increased risk.

In Region Skåne, all patients with disseminated breast cancer is treated at one of the four 
Oncology departments and recorded in the data base in this study. As there are no private Oncology clinics in the region it is estimated that very few patients with antiresorptive treatment were missed or overlooked. The awareness of MRONJ is also high and patients with symptoms in the teeth or jaws during antiresorptive treatment are regularly referred to the Departments of Oral and Maxillofacial Surgery. Most patients received treatment when MRONJ developed. Therefore it is unlikely that cases of MRONJ were overlooked or missed. The few cases not detected might involve patients who do not seek health care due to asymptomatic MRONJ lesions. A shortcoming of the study was that the number of patients and events was not sufficient for multivariable analyses of risk factors.

For zoledronic acid, the incidence of MRONJ (4.1\%) is in accordance with the study by Bamias et al who reported an incidence of $2.9 \%$ of MRONJ in breast cancer patients treated with BPs (16), while the incidence for MRONJ in the total material is high (6.6\%). The explanation for this is a more than three times as high a risk for MRONJ after denosumab compared with zoledronic acid. Patients on denosumab developed MRONJ already after 28 months while in patients on zoledronic acid the mean time was 41 months. Plausible explanations for the higher incidence and earlier onset of MRONJ in patients treated with denosumab (13.6\%) might be different mechanisms of the medication and effect on the patient. Stopeck et al. demonstrated that SRES were delayed longer and reduction in bone turnover was increased with denosumab compared to zoledronic acid (5). In a study comparing denosumab and zoledronic acid in several cancer types, both bone turnover markers were significantly lower and hypocalcemia was more common in the denosumab group, which can suggest stronger bone affinity (21). 
Although MRONJ is a serious complication to antiresorptive treatment, the benefits of the medication with reduction of SRE and a better quality of life quality predominate.

Furthermore, if MRONJ develops, most patients can be treated surgically with sequestrectomy, block or segmental resection with complete healing in the majority of cases (22-26). The advantage of surgical treatment of MRONJ in patients on denosumab is if a drug-holiday can be applied. This is possible since the half-life in bone is 3-6 months and normal osteoclast function can be expected after approximately 12 months in these patients $(27,28)$ while BPs has a halflife in bone of 10-12 years (29).

The significantly decreased risk of MRONJ in patients with corticosteroid treatment is in contrast to findings in other studies were corticosteroid intake have been reported as a systemic risk factor for MRONJ $(14,19)$. Corticosteroids have several roles to play in the treatment of breast cancer patients, including as an antiemetic agent and to treat pain and inflammation (30). Our findings might be explained by a positive anti-inflammatory effect of corticosteroids reducing periodontitis which in most cases is a strong local risk factor for triggering MRONJ $(22,31)$. In addition, MRONJ often starts as an osteomyelitis with periosteal bone formation as seen in stage 0 lesions, probably caused by the inflammatory response to an oral infection such as marginal or apical periodontitis, and might thus be prevented by corticosteroid treatment. The risk for MRONJ in patients on chemotherapy was not significant, probably because the study groups were too small. The highest significantly increased risk of MRONJ was recorded in patients with diabetes in accordance with findings by Jarnbring et al (32). One explanation for this is that periodontist is more common in patients with diabetes (33), however the medical 
risks (microangiopati) with diabetes probably predominate in the development of MRONJ in these group of patients.

In a study by Kyrgidis A et al (34), smoking was reported as a risk factor for MRONJ in cancer patients, however not statistically significant. The authors concluded that smoking does not seem to be an independent risk factor. Thumbigere-Math et al showed in a retrospective study that smoking significantly increased the risk of developing MRONJ in cancer patients (35). In our study, there was no significant increase in risk. This might be explained by a small number of smoking patients in study IV. However, in our study, there was no significant increase in risk (OR 2.94; $95 \%$ and $\mathrm{Cl} 0.88-9.88$ ). This might be explained by a small number of smoking patients in the cohort.

To summarise, this prospective cohort study has provided assessment of MRONJ incidence and risk factors in patients with disseminated breast cancer on zoledronic acid and/or denosumab. The main strength of this study is that the vast majority of breast cancer patients and those who developed MRONJ in Region Skåne during a 4-year period participated in the study. A new striking finding not previously reported is the more than three times higher risk of MRONJ in patients treated with denosumab compared with zoledronic acid and that corticosteroids decreased the risk of developing MRONJ. The incidence of MRONJ reported in this study does not outweigh the benefits of the antiresorptive treatment especially since the MRONJ-lesions can be successfully treated. 


\section{References}

1. Ferlay J, Soerjomataram I, Dikshit R, Eser S, Mathers C, Rebelo M, et al. Cancer incidence and mortality worldwide: sources, methods and major patterns in GLOBOCAN 2012. Int J cancer. United States; 2015 Mar;136(5):E359-86.

2. DeSantis CE, Lin CC, Mariotto AB, Siegel RL, Stein KD, Kramer JL, et al. Cancer treatment and survivorship statistics, 2014. CA Cancer J Clin. United States; 2014;64(4):252-71.

3. Brewster AM, Hortobagyi GN, Broglio KR, Kau S-W, Santa-Maria CA, Arun B, et al. Residual risk of breast cancer recurrence 5 years after adjuvant therapy. J Natl Cancer Inst. United States; 2008 Aug;100(16):1179-83.

4. Coleman RE, Rubens RD. The clinical course of bone metastases from breast cancer. Br J Cancer. England; 1987 Jan;55(1):61-6.

5. Stopeck AT, Lipton A, Body J-J, Steger GG, Tonkin K, de Boer RH, et al. Denosumab compared with zoledronic acid for the treatment of bone metastases in patients with advanced breast cancer: a randomized, double-blind study. J Clin Oncol. United States; 2010 Dec;28(35):5132-9.

6. Hortobagyi GN, Theriault RL, Porter L, Blayney D, Lipton A, Sinoff C, et al. Efficacy of pamidronate in reducing skeletal complications in patients with breast cancer and lytic bone metastases. Protocol 19 Aredia Breast Cancer Study Group. N Engl J Med. United States; 1996 Dec;335(24):1785-91.

7. Gnant M, Mlineritsch B, Schippinger W, Luschin-Ebengreuth G, Postlberger S, Menzel C, et al. Endocrine therapy plus zoledronic acid in premenopausal breast cancer. N Engl J Med. United States; 2009 Feb;360(7):679-91.

8. Adjuvant bisphosphonate treatment in early breast cancer: meta-analyses of individual patient data from randomised trials. Lancet (London, England). England; 2015 Oct;386(10001):1353-61.

9. Curigliano G, Burstein HJ, P Winer E, Gnant M, Dubsky P, Loibl S, et al. De-escalating and escalating treatments for early-stage breast cancer: the St. Gallen International Expert Consensus Conference on the Primary Therapy of Early Breast Cancer 2017. Ann Oncol Off J Eur Soc Med Oncol. England; 2017 Aug;28(8):1700-12.

10. Gnant M, Pfeiler G, Dubsky PC, Hubalek M, Greil R, Jakesz R, et al. Adjuvant denosumab in breast cancer (ABCSG-18): a multicentre, randomised, double-blind, placebo-controlled trial. Lancet (London, England). England; 2015 Aug;386(9992):433-43.

11. Martin M, Bell R, Bourgeois H, Brufsky A, Diel I, Eniu A, et al. Bone-related complications and quality of life in advanced breast cancer: results from a randomized phase III trial of denosumab versus zoledronic acid. Clin Cancer Res. United States; 2012 Sep;18(17):4841-9.

12. Marx RE. Pamidronate (Aredia) and zoledronate (Zometa) induced avascular necrosis of the jaws: a growing epidemic. J Oral Maxillofac Surg [Internet]. Elsevier; 2003 Sep 1 [cited 2016 Apr 4];61(9):1115-7. Available from: http://www.joms.org/article/S0278239103007201/fulltext

13. Ruggiero SL, Mehrotra B, Rosenberg TJ, Engroff SL. Osteonecrosis of the jaws associated with the use of bisphosphonates: a review of 63 cases. J Oral Maxillofac Surg. United States; 2004 
May;62(5):527-34.

14. Ruggiero SL, Dodson TB, Fantasia J, Goodday R, Aghaloo T, Mehrotra B, et al. American Association of Oral and Maxillofacial Surgeons position paper on medication-related osteonecrosis of the jaw--2014 update. J Oral Maxillofac Surg [Internet]. 2014 Oct [cited 2016 May 4];72(10):1938-56. Available from: http://www.sciencedirect.com/science/article/pii/S0278239114004637

15. Hallmer F, Bjornland T, Andersson G, Becktor JP, Kristoffersen AK, Enersen M. Bacterial diversity in medication-related osteonecrosis of the jaw. Oral Surg Oral Med Oral Pathol Oral Radiol. United States; 2017 Apr;123(4):436-44.

16. Bamias A, Kastritis E, Bamia C, Moulopoulos LA, Melakopoulos I, Bozas G, et al. Osteonecrosis of the jaw in cancer after treatment with bisphosphonates: incidence and risk factors. J Clin Oncol. United States; 2005 Dec;23(34):8580-7.

17. Allen MR, Burr DB. The pathogenesis of bisphosphonate-related osteonecrosis of the jaw: so many hypotheses, so few data. J Oral Maxillofac Surg [Internet]. 2009 May [cited 2016 Apr 4];67(5 Suppl):61-70. Available from: http://www.sciencedirect.com/science/article/pii/S0278239109001128

18. Otto S, Schreyer C, Hafner S, Mast G, Ehrenfeld M, Stürzenbaum S, et al. Bisphosphonate-related osteonecrosis of the jaws - characteristics, risk factors, clinical features, localization and impact on oncological treatment. J Craniomaxillofac Surg [Internet]. 2012 Jun [cited 2016 May 10];40(4):303-9. Available from: http://www.sciencedirect.com/science/article/pii/S1010518211001156

19. Saad F, Brown JE, Van Poznak C, Ibrahim T, Stemmer SM, Stopeck AT, et al. Incidence, risk factors, and outcomes of osteonecrosis of the jaw: integrated analysis from three blinded activecontrolled phase III trials in cancer patients with bone metastases. Ann Oncol Off J Eur Soc Med Oncol. England; 2012 May;23(5):1341-7.

20. Hallmer F, Bjørnland T, Nicklasson A, Becktor JP, Andersson G. Osteonecrosis of the jaw in patients treated with oral and intravenous bisphosphonates: experience in Sweden. Oral Surg Oral Med Oral Pathol Oral Radiol [Internet]. 2014 Aug [cited 2016 May 10];118(2):202-8. Available from: http://www.sciencedirect.com/science/article/pii/S221244031400474X

21. Lipton A, Fizazi K, Stopeck AT, Henry DH, Brown JE, Yardley DA, et al. Superiority of denosumab to zoledronic acid for prevention of skeletal-related events: a combined analysis of 3 pivotal, randomised, phase 3 trials. Eur J Cancer. England; 2012 Nov;48(16):3082-92.

22. Hallmer F, Andersson G, Gotrick B, Warfvinge G, Anderud J, Bjornland T. Prevalence, initiating factor, and treatment outcome of medication-related osteonecrosis of the jaw-a 4-year prospective study. Oral Surg Oral Med Oral Pathol Oral Radiol. United States; 2018 Aug;

23. Otto S, Ristow O, Pache C, Troeltzsch M, Fliefel R, Ehrenfeld M, et al. Fluorescence-guided surgery for the treatment of medication-related osteonecrosis of the jaw: A prospective cohort study. J Craniomaxillofac Surg. Scotland; 2016 Aug;44(8):1073-80.

24. Williamson RA. Surgical management of bisphosphonate induced osteonecrosis of the jaws. Int J Oral Maxillofac Surg. Denmark; 2010 Mar;39(3):251-5.

25. Pichardo SEC, van Merkesteyn JPR. Evaluation of a surgical treatment of denosumab-related osteonecrosis of the jaws. Oral Surg Oral Med Oral Pathol Oral Radiol. United States; 2016 Sep;122(3):272-8. 
26. Bedogni A, Saia G, Bettini G, Tronchet A, Totola A, Bedogni G, et al. Long-term outcomes of surgical resection of the jaws in cancer patients with bisphosphonate-related osteonecrosis. Oral Oncol. England; 2011 May;47(5):420-4.

27. McClung MR, Wagman RB, Miller PD, Wang A, Lewiecki EM. Observations following discontinuation of long-term denosumab therapy. Osteoporos Int. England; 2017 May;28(5):1723-32.

28. Iranikhah M, Deas C, Murphy P, Freeman MK. Effects of Denosumab After Treatment Discontinuation : A Review of the Literature. Consult Pharm. United States; 2018 Mar;33(3):14251.

29. Lasseter KC, Porras AG, Denker A, Santhanagopal A, Daifotis A. Pharmacokinetic considerations in determining the terminal elimination half-lives of bisphosphonates. Clin Drug Investig. New Zealand; 2005;25(2):107-14.

30. Hesketh PJ, Kris MG, Basch E, Bohlke K, Barbour SY, Clark-Snow RA, et al. Antiemetics: American Society of Clinical Oncology Clinical Practice Guideline Update. J Clin Oncol. United States; 2017 Oct;35(28):3240-61.

31. Chatzopoulos GS, Cisneros A, Sanchez M, Wolff LF. Systemic medical conditions and periodontal status in older individuals. Spec Care Dentist. United States; 2018 Nov;38(6):373-81.

32. Jarnbring F, Kashani A, Bjork A, Hoffman T, Krawiec K, Ljungman P, et al. Role of intravenous dosage regimens of bisphosphonates in relation to other aetiological factors in the development of osteonecrosis of the jaws in patients with myeloma. Br J Oral Maxillofac Surg. Scotland; 2015 Dec;53(10):1007-11.

33. Nascimento GG, Leite FRM, Vestergaard P, Scheutz F, Lopez R. Does diabetes increase the risk of periodontitis? A systematic review and meta-regression analysis of longitudinal prospective studies. Acta Diabetol. Germany; 2018 Jul;55(7):653-67.

34. Kyrgidis A, Vahtsevanos K, Koloutsos G, Andreadis C, Boukovinas I, Teleioudis Z, et al. Bisphosphonate-related osteonecrosis of the jaws: a case-control study of risk factors in breast cancer patients. J Clin Oncol. United States; 2008 Oct;26(28):4634-8.

35. Thumbigere-Math V, Tu L, Huckabay S, Dudek AZ, Lunos S, Basi DL, et al. A retrospective study evaluating frequency and risk factors of osteonecrosis of the jaw in 576 cancer patients receiving intravenous bisphosphonates. Am J Clin Oncol. United States; 2012 Aug;35(4):386-92. 


\begin{tabular}{lcccc}
\hline Table I & & & & \\
\hline $\begin{array}{l}\text { Antiresorptive } \\
\text { treatment }\end{array}$ & Control & MRONJ & Total & Incidence \\
Zoledronic acid & 164 & 7 & 171 & $4,1 \%$ \\
Denosumab & 51 & 8 & 59 & $13,6 \%$ \\
Z+D & 11 & 1 & 12 & $8,3 \%$ \\
\hline Total & 226 & 16 & 242 & $6,6 \%$ \\
\hline
\end{tabular}

Table I. Incidence of MRONJ in women with disseminated breast cancer according to anitresorptive treatment. The risk of developing MRONJ in patients on denosumab was significantly higher compared with treatment of zoledronic acid or zoledronic acid who switched to denosumab $(p=0.039)$ and denosumab compared to treatment with zoledronic acid alone $(p=0.011)$. 


\begin{tabular}{|c|c|c|c|c|c|c|c|}
\hline Table II & & & & & & & \\
\hline Corticosteroids & No MRONJ & MRONJ & Total & (\%) & OR & $95 \% \mathrm{Cl}$ & $p$ \\
\hline No treatment & 69 & 10 & 79 & $12,7 \%$ & & & \\
\hline Treatment & 157 & 6 & 163 & $3,7 \%$ & 0.3 & $0.1-0.8$ & 0.008 \\
\hline \multicolumn{8}{|l|}{ Chemotherapy } \\
\hline No treatment & 93 & 4 & 97 & $4,1 \%$ & & & \\
\hline Treatment & 133 & 12 & 145 & $8,3 \%$ & 2.1 & $0.7-6.7$ & 0.2 \\
\hline \multicolumn{8}{|l|}{ Diabetes } \\
\hline No & 215 & 13 & 228 & $5,7 \%$ & & & \\
\hline Yes & 11 & 3 & 14 & $21,4 \%$ & 4.5 & $1.1-18.1$ & 0.02 \\
\hline \multicolumn{8}{|l|}{ Smoking } \\
\hline No & 203 & 12 & 215 & $5,6 \%$ & & & \\
\hline Yes & 23 & 4 & 27 & $14,8 \%$ & 2.9 & $0.9-9.9$ & 0.07 \\
\hline
\end{tabular}

Table II. Risk factors of MRONJ in women with disseminated breast cancer according to corticosteroid treatment, chemotherapy, diabetes or smoking. Corticosteroid use was associated with a significant decreased risk of MRONJ and diabetes was associated with a significantly increased risk of MRONJ. Chemotherapy or smoking was not associated with a significant increased risk of MRONJ. 


ISBN 978-9I-7I04-983-4 (print)

ISBN 978-9 I-7 I 04-984-I (pdf)

MALMÖ UNIVERSITY 20506 MALMÖ, SWEDEN WWW.MAU.SE 